Atmos. Chem. Phys., 18, 10089-10122, 2018

https://doi.org/10.5194/acp-18-10089-2018

(C) Author(s) 2018. This work is distributed under

the Creative Commons Attribution 4.0 License.

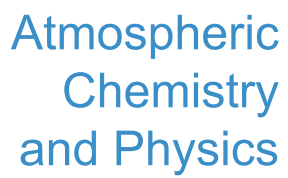

(c) (P)

\title{
Mineralogy and physicochemical features of Saharan dust wet deposited in the Iberian Peninsula during an extreme red rain event
}

\author{
Carlos Rodriguez-Navarro, Fulvio di Lorenzo, and Kerstin Elert \\ Dept. Mineralogy and Petrology, University of Granada, Fuentenueva s/n, 18002 Granada, Spain \\ Correspondence: Carlos Rodriguez-Navarro (carlosrn@ugr.es)
}

Received: 26 February 2018 - Discussion started: 1 March 2018

Revised: 8 June 2018 - Accepted: 15 June 2018 - Published: 16 July 2018

\begin{abstract}
The mineralogy and physicochemical features of Saharan dust particles help to identify source areas and determine their biogeochemical, radiative, and health effects, but their characterization is challenging. Using a multianalytical approach, here we characterized with unprecedented level of detail the mineralogy and physicochemical properties of Saharan dust particles massively wet deposited $\left(\sim 18 \mathrm{~g} \mathrm{~m}^{-2}\right)$ following an extreme "red rain" event triggered by a northern African cyclone that affected the southern Iberian Peninsula during 21-23 February 2017. Abundant palygorskite and illite, and relatively high carbonate contents, well-known northern and north-western Saharan dust indicators, along with low chlorite content and significant amounts of smectites and kaolinite, whose abundance increases southwards in the western Sahara, complemented by satellite imagery and back/forward trajectories, show that the most probable dust source areas were (i) southern/central Algeria, northern Mali, and northwestern Niger, and (ii) northern Algeria, southern Tunisia, and northwestern Libya. Scanning and transmission electron microscopy analyses, including $Z$-contrast high angle annular dark field (HAADF) imaging and analytical electron microscopy (AEM), show that clay minerals include abundant structural $\mathrm{Fe}(55 \%$ of the total $\mathrm{Fe}$ ) and typically form nanogranular aggregates covered or interspersed with amorphous/poorly crystalline iron oxyhydroxide nanoparticles (ferrihydrite), which account for $\sim 18 \%$ of the free Fe, the rest being goethite and hematite. These nanogranular aggregates tend to form rims lining large silicate and carbonate particles. Such internally mixed iron-containing phases are the main contributors to the observed absorption of solar and thermal radiation, and along with the abundant coarse/giant particles $(>10 \mu \mathrm{m})$ strongly affect the dust direct radiative
\end{abstract}

forcing. The lack of secondary sulfates in aggregates of unaltered calcite internally mixed with clays/iron-rich nanoparticles shows that iron-rich nanoparticles did not form via atmospheric (acid) processing but were already present in the dust source soils. Such iron-rich nanoparticles, in addition to ironcontaining clay (nano)particles, are the source of the $\sim 20 \%$ soluble (bioavailable) iron in the studied desert dust. The dust particles are a potential health hazard, specifically the abundant and potentially carcinogenic iron-containing palygorskite fibers. Ultimately, we show that different source areas are activated over large desert extensions, and large quantities of complex dust mixtures are transported thousands of kilometers and wet-deposited during such extreme events, which dwarf any other Saharan dust event affecting southwestern Europe. The past, present, and future trends, as well as impacts, of such extreme events must be taken into account when evaluating and modeling the manifold effects of the desert dust cycle.

\section{Introduction}

Aeolian erosion of semi-arid and arid desert surfaces contributes to an estimated $\sim 1000$ to $3000 \mathrm{Tg} \mathrm{yr}^{-1}$ global emission of mineral dust aerosol (Goudie and Middleton, 2001; Engelstaedter et al., 2006; Cakmur et al., 2006). The impact of desert dust is large (Gieré and Querol, 2010): (i) it directly affects atmospheric radiative balance due to scattering and absorption of solar and terrestrial radiation, thereby affecting atmospheric dynamics and climate (Carlson and Benjamin, 1980; Tegen and Lacis, 1996: Ramanathan et 
al., 2001; Tegen, 2003; Balkanski et al., 2007). Indirectly, it also affects climate via its potential for altering atmospheric physics/microphysics (i.e., acting as nuclei for liquid and solid cloud droplets) and the hydrological cycle (Ramanathan et al., 2001). Such direct and indirect forcings strongly depend on mineral dust physicochemical properties, including particle size, shape and composition/mineralogy (Tegen, 2003; Lafon et al., 2006; Formenti et al., 2011; Mahowald et al., 2014; Zhang et al., 2015; Kok et al., 2017); (ii) it supplies sediments to downwind marine and continental areas, affecting the surface albedo of the latter, whereas dust entrainment in source regions is a major erosive agent, strongly affecting soil quality (Goudie and Middleton, 2001); (iii) it also supplies key micronutrients (e.g., iron and phosphorous) to distal ocean and inland water environments, directly affecting the $\mathrm{C}$ cycle via stimulated bioproductivity, and indirectly affecting climate via atmospheric $\mathrm{CO}_{2}$ sequestration (Jickells et al., 2005; Raiswell and Canfield, 2012); (iv) it is involved in a range of heterogeneous reactions with manifold implications (Usher et al., 2003). For instance, carbonates in Saharan dust increase the $\mathrm{pH}$ of precipitation acting as a buffer for acid rain in Europe (Loÿe-Pilot et al., 1986); (v) desert dust storms are a hazard with detrimental effects on transportation (e.g., reduced visibility), infrastructure, and (solar) energy generation (Middleton, 2017), also causing soiling and discoloration of monuments (Comite et al., 2017); (vi) desert mineral dust is a health hazard to humans (Karanasiou et al., 2012; Goudie, 2014). Exposure to desert dust (particulate matter with size $<10 \mu \mathrm{m}, \mathrm{PM}_{10}$ and/or with size $<2.5 \mu \mathrm{m}, \mathrm{PM}_{2.5}$ ) has been associated with morbidity and premature death due to dust-related (or enhanced) cardiovascular and respiratory problems (Perez et al., 2008), as well as several diseases related to dust-borne microorganisms (short-term effects) (Griffin, 2007). In addition, silicosis/pulmonary fibrosis (desert lung) and cancerrelated illnesses have been associated with desert dust exposure (long-term effects) (Giannadaki et al., 2014).

More than half of the worldwide mineral dust aerosol comes from northern Africa (Sahara/Sahel) (Goudie and Middleton, 2001; Prospero et al., 2002; Engelstaedter et al., 2006), with an estimated $\sim 700-1600 \mathrm{Tg}$ of Saharan dust exported yearly across the Mediterranean Sea to Europe and the Near East, the Red Sea to the Near East and Asia, and the North Atlantic Ocean to the Americas (D'Almeida, 1986; Prospero, 1996; Goudie and Middleton, 2001). Although most Saharan dust is transported across the Atlantic Ocean (Carlson and Prospero, 1972), an estimated 80-120 $\mathrm{Tg} \mathrm{yr}^{-1}$ is transported northward across the Mediterranean Sea to Europe (D'Almeida, 1986). It has been pointed out that the strength of the Saharan dust input increased since ca. the mid-20th century due to recurrent droughts in northern Africa (Prospero and Lamb, 2003), anthropogenic-induced desertification (Moulin and Chiapello, 2006), changes in land use, including an increase in cultivable lands in the Sahel region (Mulitza et al., 2010), and other larger-scale phenomena (e.g., atmospheric circulation patterns and/or climate change) (Sala et al., 1996; Moulin et al., 1997). Nonetheless, there is evidence of significant seasonal to decadal variability of Saharan dust strength. Indeed, since the end of the 1980s, a trend towards decreasing Saharan dust across the tropical North Atlantic has been reported (Ridley et al., 2014; Evan et al., 2016), while the strength of Saharan dust affecting southern Europe has reportedly increased in recent decades (Antoine and Nobileau, 2006). However, for the 2001-2013 period, a decreasing strength in Saharan dust affecting the western Mediterranean has been reported (Pey et al., 2013; Vincent et al., 2016), which in one case (2001-2011 period) has been related to negative summer NOA (North Atlantic Oscillation) (Pey et al., 2013). Despite this temporal variability, dust plume intrusions in the Mediterranean area are currently rather common (Escudero et al., 2005; Avila et al., 2007; Cabello et al., 2012; Titos et al., 2017) and most of the temporal variability in desert dust deposition appears to be due to very intense but rare events (Vincent et al., 2016). Desert dust plumes lead to both dry and wet deposition of mineral dust (Escudero et al., 2005). Wet deposition typically occurs as "red rain", "dust rain", "blood rain", or "muddy rain" events that periodically and persistently affect southern Europe (Prodi and Fea, 1979), and most particularly the Iberian Peninsula (Sala et al., 1996; Avila et al., 1997; White et al., 2012), the European region closest to northern Africa. Although known since ancient times (Gieré and Querol, 2010), red rain events have experienced a remarkable increase in their frequency and intensity over the last decades (Sala et al., 1996; Escudero et al., 2005; Fiol et al., 2005; Avila et al., 2007). In some cases they are extreme, with $10-40 \mathrm{~g} \mathrm{~m}^{-2}$ of dust deposited after a single red rain event (Avila et al., 1997, 2007; Fiol et al., 2005), dwarfing the average yearly Saharan dust deposition in southwestern Europe, estimated to be about 3-14 $\mathrm{g} \mathrm{m}^{-2}$ (Goudie and Middleton, 2001). This was the case of the last extreme red rain event that took place in the area of Granada (south of Spain) on 21-23 February 2017.

The global significance and impact of desert-derived mineral dust aerosol has attracted extensive research focused on analyzing dust composition, mineralogy, physical properties, sources, and entrainment-transport-deposition mechanisms and patterns (see reviews by Goudie and Middleton, 2001; Prospero et al., 2002; Scheuvens et al., 2013). Data from these studies have contributed to a better understanding and modeling of the dust cycle, as well as its impact on global atmospheric dynamics, climate, and biogeochemical cycles. However, there are several aspects of the current knowledge that are far from complete. This is the case of the physicochemical and mineralogical features of Saharan dust, which are highly variable and event-specific and, therefore, poorly constrained. Although it has been acknowledged that the mineralogy and the physicochemical features of desert dust particles are relevant factors to be considered in modeling dust and climate, they are in general poorly constrained (For- 
menti et al., 2011; Titos et al., 2017) and have been largely ignored in most models (Krueger et al., 2004). This is likely due to the limited number of studies dedicated to the detailed characterization of desert dust mineralogy and physicochemical features, particularly those of individual particles (Jeong et al., 2016).

Using a multianalytical approach, here we studied Saharan dust samples collected immediately after the extreme red rain event that took place in Granada $\left(37.17806^{\circ} \mathrm{N}, 3.60083^{\circ} \mathrm{W}\right.$; $\sim 680$ m a.s.1.) on 21-23 February 2017. One specific objective of this study was to analyze in detail the content, physical and textural properties, mineralogy, and composition - including individual particles - of the clay fraction $(\varphi<2 \mu \mathrm{m})$. This is typically a major fraction in desert dust, is considered responsible for most of the scattering of sun light, includes most of the bioavailable iron, and due to its long atmospheric residence time is the one that can affect most distant locations (Tegen and Lacis, 1996; Sokolik and Toon, 1999; Lafon et al., 2006; Journet et al., 2008; Formenti et al., 2014a, b; Jeong and Achterberg, 2014; Jeong et al., 2016). Another goal of our study was to compare the mineralogy and physicochemical properties of the clay fraction with those of the two other relevant size fractions, i.e., sand and silt, an aspect that has been generally ignored in previous studies. It should be noted that such an analysis is complex and tedious, and requires a relatively large amount of sample. The studied red rain event thus offered a unique opportunity to collect a sufficient amount of material from a single Saharan dust event so as to perform a detailed multianalytical study of wet-deposited desert dust. In addition, the analysis of the synoptic-scale meteorological conditions during this event, and the identification of transport routes and potential dust source areas (compatible with the results of the mineralogical analysis), were performed using satellite imagery, synoptic reanalysis, dust forecast, and air mass backward/forward trajectory modeling. Ultimately, we strived to shed light on the potential biogeochemical, radiative, and health effects that such extreme Saharan dust events can have locally as well as globally.

\section{Methods}

\subsection{Synoptic situation, satellite data, dust transport modeling, and backward/forward trajectories}

We used the NASA/NOAA Suomi NPP (National Polarorbiting Partnership) satellite's VIIRS (Visible Infrared Imaging Radiometer Suite) and the Terra and Aqua satellites' MODIS (Moderate Resolution Imaging Spectroradiometer) true color imagery to analyze dust transport from the Sahara towards the Iberian Peninsula. This information was complemented by a post hoc synoptic analysis of the evolution of geopotential height and wind field at ground level and $850 \mathrm{hPa}$ over northwestern African and south- western Mediterranean areas. We also analyzed the highlevel $(300 \mathrm{hPa})$ synoptic conditions preceding (and triggering) this event. The reanalysis was performed using the NOAA's NCEP/NCAR Reanalysis Data resource. Backward and forward trajectories of air masses were calculated using the NOAA's Hybrid Single Particle Lagrangian Integrated Trajectory (HYSPLIT) atmospheric transport and dispersion modeling system (Stein et al., 2015). We used 3day multiple (25) backwards trajectories with end-point at 00:00 UTC (23 February 2017) over Granada at 50, 500, and $1000 \mathrm{~m}$ a.g.l. We only report results for $500 \mathrm{~m}$ a.g.l. because no significant differences related to end-point height were observed. Multiple (25) forward trajectories, starting at 50 or $500 \mathrm{~m}$ a.g.l., 72 or $48 \mathrm{~h}$ before the main dust rain event (23 February, 00:00 UTC) were computed for selected point source locations. No significant differences in trajectories were observed depending on height at starting point. Modeling by the Barcelona Dust Forecast (BDF) (Pérez et al., 2011) was used to evaluate intercontinental dust transport and load (resolution $0.1^{\circ} \times 0.1^{\circ}$ ) for the days of the dust event. The model, which provides short- to medium-range dust forecasts for global and regional domains, has been developed by the Barcelona Supercomputer Center (BSC) and NASA, and is fully embedded in the Non-hydrostatic Multiscale Model (NMMB) developed at NCEP (Pérez et al., 2011). Groundlevel measurements of $\mathrm{PM}_{10}$ load in Granada during the dust event were included in this study. Data were collected at two stations within the city of Granada: (i) the Almanjayar and (ii) the Palacio de Congresos weather stations owned and operated by the Consejería de Medioambiente of the Junta de Andalucía (Spain).

\subsection{Dust sample collection and processing for analysis}

Wet-deposited dust was collected at three different locations in the urban area of Granada: (i) the roof of the Science Faculty of the University of Granada $\left(37.1796^{\circ} \mathrm{N}, 3.6096^{\circ} \mathrm{W}\right)$; (ii) the Fuentenueva area (nearby the Science Faculty); and (iii) the Albayzin neighborhood $\left(37.1792^{\circ} \mathrm{N}, 3.5945^{\circ} \mathrm{W}\right)$. In all cases, the wet-deposited dust was allowed to dry before collection from clean horizontal surfaces and/or clean ceramic rain/dust collection dishes $(21 \mathrm{~cm}$ in diameter). After complete evaporation of the rainwater, the dry dust residue was collected (scraped) with the aid of a spatula and/or a brush. Dust collection was performed within the next $24 \mathrm{~h}$ after the red rain event and special care was taken to avoid any dust resuspension during sample collection. Collection areas were measured and the sample mass was determined using a Sartorius Acculab Atilon microbalance (error $\pm 0.001 \mathrm{~g}$ ) after sample drying $\left(60^{\circ} \mathrm{C}\right.$ for $\left.24 \mathrm{~h}\right)$. Note that due to the very limited amount of rainwater that fell during the red rain event $(2 \mathrm{~mm})$ and the depth of the collection devices $(\sim 5$ and $40 \mathrm{~mm}$ in the case of the horizontal surfaces and ceramic dishes, respectively) no loss of the aqueous soluble fraction took place. This ensured that any amount of mineral dust that 
could have dissolved in rainwater during the wet-deposition event would reprecipitate in situ upon drying prior to sample collection.

For clay mineralogical analysis, $\sim 2 \mathrm{~g}$ of collected dust was subjected to carbonate elimination using $0.2 \mathrm{~N}$ acetic acid. Following complete dissolution of the carbonates, the supernatant was eliminated and the dust residue was subjected to rinsing in DI water (five times). To favor particle dispersion, the dust sample was dispersed in $0.1 \mathrm{~g} \mathrm{~L}^{-1}$ sodium hexametaphosphate solution. Following $10 \mathrm{~min}$ sonication of this dispersion, the sand $(\phi>62.5 \mu \mathrm{m})$, silt $(2 \mu \mathrm{m}<$ $\phi<62.5 \mu \mathrm{m})$, and clay $(\phi<2 \mu \mathrm{m})$ fractions were hydrodynamically separated using Stokes' law without (silt and sand fractions) and with (clay fraction) the use of a centrifuge (Kubota KS 8000, set at $1000 \mathrm{rpm} / 5 \mathrm{~min}$ ).

Once the silt and clay fractions were separated, small aliquots of the aqueous dispersions $(\sim 2 \mathrm{~mL})$ were deposited on glass slides and dried under room conditions in order to prepare oriented aggregates for XRD analysis. For the silt and clay fractions four oriented aggregates per sample were prepared: untreated (hereafter denoted air-dried; AD), solvated at $60^{\circ} \mathrm{C}$ for $72 \mathrm{~h}$ in a saturated atmosphere of ethylene glycol (sample denoted EG), or dimethyl sulfoxide (sample denoted DMSO), and $1 \mathrm{~h}$ heat-treated in an electric furnace set at $550^{\circ} \mathrm{C}$ (sample denoted $550^{\circ} \mathrm{C}$ ). These standard treatments were done to facilitate the identification of the different phyllosillicates (clays) in these two size fractions (Moore and Reynolds, 1989).

The total amount of carbonates was determined by calculating the mass difference between the initial nondecarbonated (bulk) sample and the final decarbonated fractions (silt + sand + clay).

\subsection{Analysis of dust}

The mineralogy of solids was determined by X-ray diffraction (XRD) on a PANalytical XPert Pro diffractometer equipped with a Ni filter. The measurement parameters were $\mathrm{Cu} \mathrm{K} \alpha$ radiation, wavelength, $\lambda=1.5405 \AA, 45 \mathrm{kV}, 40 \mathrm{~mA}$, 3 to $70^{\circ} 2 \theta$ exploration range, steps of $0.001^{\circ} 2 \theta$, and a goniometer speed of $0.01^{\circ} 2 \theta \mathrm{s}^{-1}$. Powders (bulk samples prior to and after carbonate elimination via acid dissolution) were back loaded on sample holders to minimize orientation effects, whereas oriented mounts of the clay and silt fractions were directly subjected to XRD analysis without further preparation. Bulk powder samples collected in the three sites indicated above were separately analyzed by XRD prior to any sample treatment. Because these analyses showed no differences in mineralogy and phase content, the three bulk dust samples were mixed together. This enabled us to obtain a representative (homogeneous) and sufficiently large amount of dust sample to perform all subsequent analyses. Mineral phases were identified by comparison with JCPDS (Joint Committee on Powder Diffraction Standards) powder patterns. Semiquantitative phase analysis was performed by the Rietveld method (Rietveld, 1969) using HighScore Plus 2.1.d software from PANalytical. However, due to the high residuals obtained after (semi)quantitative Rietveld analysis (associated with the large number of phases present in the dust samples), it was necessary to also perform semiquantitative analyses using the RIR (reference intensity ratio) method. For this task, we used both reported (JCPDS files) and experimental RIR values determined in-house. Our experimental RIR values were in general comparable to those reported in JCPDS files of the corresponding phases. For the case of clay minerals (oriented mounts prepared after carbonate elimination and size-fraction separation), however, the high dispersion of RIR values reported in the corresponding JCPDS files prompted us to use our own RIR values: this was the case for phases such as palygorskite, smectites (beidellite and/or montmorillonite, and mixed-layer clays), illite, chlorite, and kaolinite. Overall, more consistent results were obtained using the RIR method than using the Rietveld method. In particular, the RIR method enabled us to get total carbonate phase contents that accurately matched the values determined independently by mass analysis of samples prior to and after carbonate elimination following acid attack, and by thermogravimetry (TG).

TG and differential scanning calorimetry (DSC) analyses of the bulk samples (i.e., not subjected to any size separation or carbonate elimination) were performed simultaneously on a Mettler-Toledo TGA/DSC1. Samples of $\sim 40 \mathrm{mg}$ were placed in $\mathrm{Al}$ crucibles and analyzed both in flowing air and $\mathrm{N}_{2}\left(50 \mathrm{~mL} \mathrm{~min}^{-1}\right)$ at a heating rate of $20^{\circ} \mathrm{C} \mathrm{min}^{-1}(25$ to $950^{\circ} \mathrm{C}$ ). We used both an oxidizing (air) and an inert $\left(\mathrm{N}_{2}\right)$ atmosphere in order to determine the total content of organic matter in the dust samples.

Chemical analysis of the bulk dust samples (i.e., prior to any size separation or decarbonation) was performed by means of inductively coupled plasma-optical emission spectrometry (ICP-OES, Perkin-Elmer Optima 8300) for major elements and ICP-mass spectrometry (ICP-MS, PerkinElmer Sciex Elan $5000 \mathrm{MS}$ ) for minor and trace elements. Measurements were taken in triplicate using rhenium and rhodium as internal standards. The instrumental error is \pm 2 and $\pm 5 \%$ for elemental concentrations of 50 and 5 ppm respectively. Note that acid digestion of dust samples ( $\sim 100 \mathrm{mg}$ sample mass) using $\mathrm{HF}$ and $\mathrm{HNO}_{3}$ required for ICP analyses results in the partial loss of Si (Formenti et al., 2011). To properly measure Si concentration, additional $\mathrm{X}$-ray fluorescence (XRF) analysis of major (and some minor/trace) elements was performed on a Bruker AXS S4 Pioneer. Samples were prepared as fused beads by melting about $1 \mathrm{~g}$ of bulk dust with lithium tetra borate flux. The quality of the analysis was monitored with reference materials showing high precision with $1 \sigma=1.0-3.4 \%$ on 16 data sets at the $95 \%$ confidence level.

Additional compositional and micro-/nano-structural features of bulk dust particles (not subjected to any pretreatment) were determined by means of transmission elec- 
tron microscopy (TEM, Phillips CM20, operated at an acceleration voltage of $200 \mathrm{kV}$ and FEI Titan, operated at $300 \mathrm{kV}$ ). Bulk powder samples were dispersed in ethanol, sonicated for $30 \mathrm{~s}$, and fished with holey Formvar ${ }^{\mathrm{TM}} \mathrm{C}$-coated $\mathrm{Cu}$ grids. TEM observations were performed using a $30 \mu \mathrm{m}$ objective aperture. SAED patterns were collected using a $10 \mu \mathrm{m}$ aperture, which allowed collection of diffraction data from a circular area $\sim 0.2 \mu \mathrm{m}$ in diameter. Quantitative analytical electron microscopy (TEM-AEM) analyses were performed in STEM mode using the CM20 with an EDAX solid-state energy dispersive X-ray (EDX) detector. A scan window of $\sim 20 \times 100 \mathrm{~nm}$ was used for the analysis of individual particles. In the case of the Titan, compositional analyses were performed in STEM mode using a High Angle Annular Dark Field (HAADF) detector. In this latter case compositional maps of selected areas were obtained, which also enabled collection of data from individual mineral particles. Albite, biotite, muscovite, spessartine, olivine, and titanite standards were used to obtain K-factors for the transformation of intensity ratios to concentration ratios according to Cliff and Lorimer (1975).

Textural features (particularly, grain size and shape of larger particles) were studied using a field emission scanning electron microscope (FESEM, Auriga, Zeiss) equipped with EDX microanalysis. Bulk dust samples (not subjected to any pre-treatment) were deposited on $\mathrm{Al}$ stubs covered with sticky carbon tape and carbon coated prior to analysis. Gas sorption measurements of bulk dust samples (not subjected to any pre-treatment) were performed on a Micromeritics TriS$\operatorname{tar} 3000$. The surface area (BET method) and pore size distribution (BJH method) (Sing et al., 1985) of dust samples were determined by means of $\mathrm{N}_{2}$ adsorption/desorption at $77 \mathrm{~K}$ following degassing for $3 \mathrm{~h}$ at $80^{\circ} \mathrm{C}$ under vacuum on a Micromeritics FlowPrep device. The particle size distribution (PSD) of bulk dust dispersions in water was determined by laser scattering on a malvern Hydro $2000 \mu$ p equipment. Analysis of each sample was performed in triplicate (successively) under continuous intense sonication and magnetic stirring $(1000 \mathrm{rpm})$ to ensure appropriate dispersion.

Further details on the phases and compositional features of the bulk dust samples (not subjected to carbonate elimination or size separation) were studied using Fourier transform infrared spectroscopy (FTIR; JASCO $6200)$, frequency range $400-4000 \mathrm{~cm}^{-1}(2.5-25 \mu \mathrm{m}$ wavelength range), with $2 \mathrm{~cm}^{-1}$ spectral resolution. The FTIR used is equipped with an attenuated total reflectance (ATR) device for spectra collection without sample preparation (i.e., to minimize artifacts). Additional spectral information of the bulk dust samples, as well as of the different size fractions (obtained after carbonate elimination), was gathered by ultraviolet-visible-near-infrared (UV-Vis-NIR) diffuse reflectance spectroscopy (DRS) analyses on a VARIAN CARY-5E spectrometer equipped with a $110 \mathrm{~mm}$ diameter integrating sphere coated with Halon (Labsphere, Inc.). Analyses were performed in the spectral range 200-
$2000 \mathrm{~nm}$ with $1 \mathrm{~nm}$ resolution. The second derivative of the absorbance curves in the 300-800 nm spectral range was obtained using Microcalc Origin 6.0 computer code (this procedure included pre- and post-smoothing using 20-point adjacent averaging). From the amplitude of the minima at $\sim 435$ and $\sim 565 \mathrm{~nm}$, corresponding to absorption by goethite and hematite, respectively, the relative concentration of these two phases was calculated following the procedure outlined by Scheinost et al. (1998).

Additional dissolution tests and geochemical modeling were performed to evaluate the partial solubilization of the different phases present in the dust subjected to wet deposition (i.e., dissolution in rainwater), as well as their reprecipitation during drying after deposition, prior to dust sample collection. To measure the amount of dissolved carbonates (i.e., the most soluble phases present in the collected dust; see the Results and discussion section) the bulk desert dust was dispersed in ultrapure water (Millipore-MilliQ ${ }^{\circledR}$, resistivity $=18.2 \mathrm{M} \Omega \mathrm{cm}$ equilibrated with air) with an initial $\mathrm{pH}$ of 5.6. Such a $\mathrm{pH}$ corresponds to that of unpolluted rain (Stumm and Morgan, 2003). We used a dust/water mass / vol ratio of $63 \mathrm{mg} / 7 \mathrm{~mL}$ corresponding to the $18 \mathrm{~g}$ of dust per $2 \mathrm{~L}$ of rainwater deposited per square meter during the studied red rain event (see Results and discussion below). The dispersion was subjected to intense magnetic stirring $(200 \mathrm{rpm})$ and the $\mathrm{pH}$ (Metrohm $\mathrm{pH}$ probe) and free $\mathrm{Ca}$ concentration in solution (ion selective electrode, $\mathrm{Ca}^{2+}$ ISE Mettler-Toledo) were continuously monitored during a period of $12 \mathrm{~h}$ (i.e., the approximate time it took for the red rain to dry). Such a leaching test was performed at room $T$. In parallel, we performed computer modeling of the saturation in$\operatorname{dex} \mathrm{SI}\left(\mathrm{SI}=\log _{10}\left(\mathrm{IAP} / \mathrm{K}_{\mathrm{sp}}\right)\right.$, where IAP and $\mathrm{K}_{\mathrm{sp}}$ are the ion activity product and solubility product of a relevant phase, respectively) and the dissolved amount of each phase present in the dust. Geochemical calculations were performed using PHREEQC (ver. 3.3.12) computer code and the llnl.dat database (Parkhurst and Appelo, 2013).

In order to evaluate the fraction of soluble iron in the collected dust samples, $10 \mathrm{mg}$ dust aliquots were subjected to leaching for $2 \mathrm{~h}$ (room $T$ ) either in $500 \mathrm{~mL} \mathrm{MilliQ}{ }^{\circledR}$ water (pH 5.6) or in $500 \mathrm{~mL}$ of $1.1 \mathrm{M}$ ammonium acetate buffer solution (pH 4.7) under continuous magnetic stirring (200 rpm) (Buck et al., 2010; Shi et al., 2011a). The leachate was filtered through a $0.4 \mu \mathrm{m}$ Millipore ${ }^{\circledR}$ filter, acidified to $\mathrm{pH}<2$ with concentrated $\mathrm{HNO}_{3}$, and stored at $5^{\circ} \mathrm{C}$. Fe concentration in leachate solutions was determined using the ICP-OES equipment described above.

\section{Results and discussion}

\subsection{The extreme winter Saharan dust event}

On 20 and 21 February, a large Saharan dust plume coming from northern Africa (off the coast of Algeria and Morocco) 
(a)
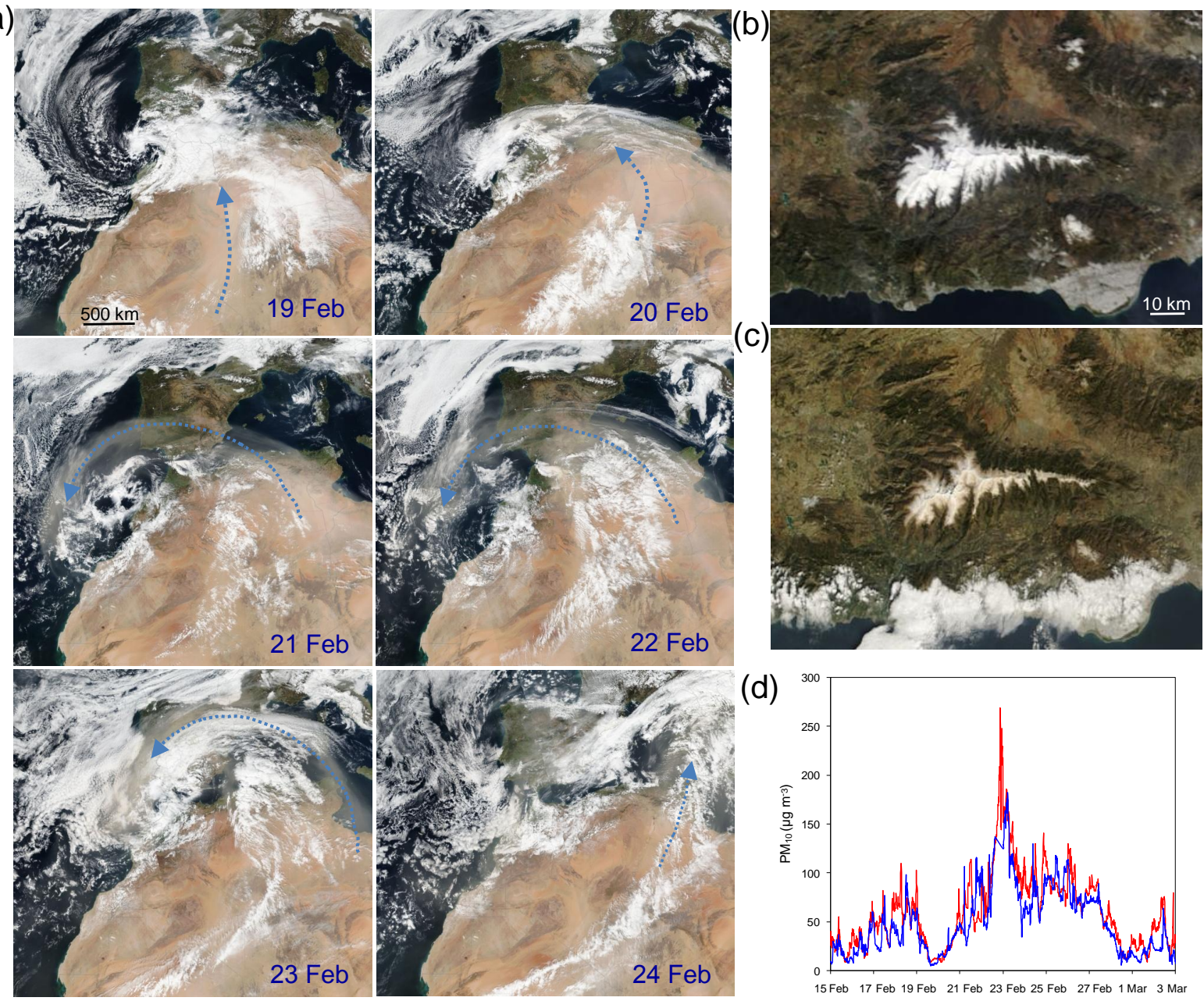

(d)

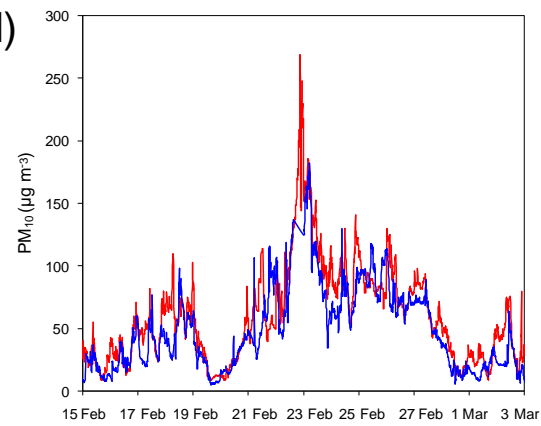

Figure 1. The extreme Saharan dust and red rain event. (a) NASA SUOMI NPP/VIIRS true color images of the Iberian Peninsula and northern Africa during the days of the extreme red rain event. On 19 February dust plumes were visible over northern Mali, northwestern Niger, and southern-central Algeria, which moved north/northeast, reaching the western Mediterranean on 20 February, and wiping in a counterclockwise movement the southern portion of the Iberian Peninsula on 21 February. On 22 and 23 February dust plumes coming from northern Algeria (and Tunisia) continued to sweep the Iberian Peninsula. Finally, on 24 February, the Saharan dust plume moved towards the central Mediterranean. The blue dashed arrow shows the path of the dust plume. (b-c) NASA's Terra MODIS true color images of the Sierra Nevada (Spain) (b) before (15 February 2017, 11:30 UTC) and (c) after (26 February 2017, 11:30 UTC) the extreme Saharan red rain event. Note the brownish color of the snow cap after the red rain event. Images credit: NASA/Earthdata (http//:gibs.earthdata.nasa.gov). (d) Ground-level $\mathrm{PM}_{10}$ concentration at Granada for the days prior to, during, and after the red rain event (the red and blue lines refer to Almanjayar and Palacio de Congresos stations, respectively). Data from Consejería de Medio Ambiente, Junta de Andalucía.

crossed the Alboran Sea (western Mediterranean) and wiped the southern portion of the Iberian Peninsula in a counterclockwise N-NW motion (Fig. 1a). This initial dust intrusion, which was clearly visible in Suomi VIIRS as well as in Terra and Aqua MODIS true color imagery on 21 February (on 20 February the southern portion of the Iberian Peninsula was covered by clouds, thereby precluding the direct observation of the dust plume), caused a minor red rain event in the Granada area during the night of 21 February. Subsequently, a more massive African dust plume penetrated in the southern part of the Iberian Peninsula during 22 Febru- ary (Fig. 1a), leading to significant wet deposition in Granada (and in almost all areas in the southern portion of the Iberian Peninsula) during the night of 22 February and the early hours of 23 February. The volume of precipitation was minor ( $\sim 1-2 \mathrm{~mm})$, but the amount of dust deposited was massive: we measured an average of $18 \pm 8 \mathrm{~g} \mathrm{~m}^{-2}$ deposited in the city of Granada. Note that the relatively high scattering in the amount of deposited dust was due to orientation differences among the different collection sites (i.e., shielding effects of nearby buildings and/or vegetation). Streets, houses, and cars across the city appeared covered by reddish- 
brown mud and in the nearby Sierra Nevada the snow cap displayed a dramatic reddish-brown discoloration (compare the before and after satellite images of the Sierra Nevada shown in Fig. 1b, c). Such an amount of deposited Saharan dust is about 4 times higher than the average input of $5.1 \mathrm{~g} \mathrm{~m}^{-2} \mathrm{yr}^{-1}$ measured by Avila et al. (1997) in northeastern Spain for the period 1981-1992. Remarkably, Avila et al. (1997) reported that just two red rain events accounted for nearly $62 \%$ of the total desert dust mass deposited in the area over 11 years: the extreme events in November 1984 and in March 1991 delivered 16.4 and $19.4 \mathrm{~g} \mathrm{~m}^{-2}$, respectively. These values are in very good agreement with the value reported here.

During the last hours of 22 February and the early hours of 23 February, a maximum ground-level $\mathrm{PM}_{10}$ concentration of $275 \mu \mathrm{g} \mathrm{m}^{-3}$ was measured in the Granada urban area (Fig. 1d), a value more than 5 times higher than the daily limit $\left(50 \mu \mathrm{g} \mathrm{m}^{-3}\right)$ established by Directive 2008/50/EU of the European Union. Surface $\mathrm{PM}_{10}$ values rapidly decreased to values $\sim 50-75 \mathrm{~g} \mathrm{~m}^{-3}$ following the red rain event. Note that Saharan dust events with daily $\mathrm{PM}_{10}>100 \mu \mathrm{g} \mathrm{m}^{-3}$ are considered "extreme" and are infrequent ( $1 \%$ of all dust events) in the western Mediterranean, but more frequent (2-5\%) in the eastern Mediterranean (Pey et al., 2013). Nonetheless, for the case of the Iberian Peninsula, more than nine red rain events with a dust deposition $>1 \mathrm{~g} \mathrm{~m}^{-2}$ per event (i.e., extreme events) were reported for the period 1984-1993 (Avila et al., 1997), and four more between 1996 and 2002 (Avila et al., 2007).

NMMB-BDF modeling showed massive dust plumes initially coming from southern Algeria and northern Mali (and northwestern Niger), with subsequent contributions from northern Algeria, southern Tunisia, and western Libya, entering the Iberian Peninsula on 20 February, and wiping the southern portion of Spain in two successive waves. The second wave was more intense than the first, with an aerosol optical depth, AOD, at $550 \mathrm{~nm}$ of 1.6-3.2. Finally, the dust plume shifted course towards the central Mediterranean on 24 February (Fig. 2). It should be noted that the accuracy of the NMMB-BDF forecasted dust outbreak and its spatiotemporal evolution is remarkable, as demonstrated by the satellite observations (cf. Figs. 1a and 2) and the recent lidar study of this extreme Saharan dust event by Fernández et al. (2018).

Overall, the studied red rain event stands out as one of the most extreme of the last decades. Modeling and satellite imagery demonstrates that the event was associated with a massive desert dust outbreak affecting a large portion of the central- and north-western Sahara. Entrained Saharan dust was rapidly transported to the Iberian Peninsula where massive wet deposition of desert dust took place.

\subsection{Synoptic situation and backward/forward trajectories}

The synoptic-scale meteorological situation during the extreme dust event was characterized by a marked northwestern African depression, nearly centered on the leeside of the Atlas Mountains (eastern Morocco-western Algeria). Such a depression was bounded by two anticyclones, one centered in the North Atlantic (Azores area) and another centered in Libya (Fig. 3 and Fig. S1 in Supplement Sect.). Air masses were advected by strong winds with westward direction in the area of northwestern Niger and northern Mali that turned north upon entering the southern border of Algeria, heading straight north/northeast towards the southeastern part of the Iberian Peninsula (Fig. 3b, d). Advected air masses turned counterclockwise upon reaching the mid portion of the Iberian Peninsula and then moved west into the Atlantic Ocean off the coast of Portugal, and then to the south, following the cyclonic wind field. Supplement Fig. S1 shows the temporal (daily) and spatial evolution of the cyclone based on NOAA/ESRL reanalysis of geopotential height and wind field at $850 \mathrm{hPa}$. Remarkably, the center of the depression remained stationary over the same area (northwestern Africa) for nearly 4 days (19-22 February 2017).

Escudero et al. (2005) reported that major Saharan dust episodes affecting the Iberian Peninsula are associated with (a) a northern African high-pressure system (located at surface or upper levels), (b) an Atlantic depression, or (c) a northern African depression. The latter synoptic scenario is associated with dust outbreaks which in $87 \%$ of the cases led to red rain. These red rain events tend to occur during winterspring and autumn, with dust typically coming from Algeria (mostly from northern areas, although dust in some events reportedly came from central Algeria) (Avila et al., 2007). Conversely, in summer, dry deposition prevails, associated with a high thermal anticyclone system in northern Africa (Rodriguez et al., 2001; Escudero et al., 2005). The amount of dust deposited per event is smaller in this latter scenario. In our case, a strong northwestern Saharan depression was responsible for the Saharan dust entrainment and transport to the Iberian Peninsula. The synoptic scenario has strong similarities to a Sharav cyclone (Bou Karam et al., 2010). Cyclogenesis was triggered by an upper level (i.e., $300 \mathrm{hPa}$ ) N-S trough west of the Iberian Peninsula which favored the injection of strong cold northerly winds to the warmer northern African troposphere (Fig. S2), thereby favoring the conditions for baroclinic instability. A very similar overall synoptic situation has been previously reported for other major red rain events taking place in the Spanish Mediterranean area (Sala et al., 1996), inland within the southern and northeastern parts of the Iberian Peninsula (Avila et al., 1997, 2007; Rodriguez et al., 2001), and in the western-central Mediterranean (Fiol et al., 2005). Remarkably, two recent major winter dust events affecting the western Mediterranean and associated with northern African cyclones took place on 20-23 

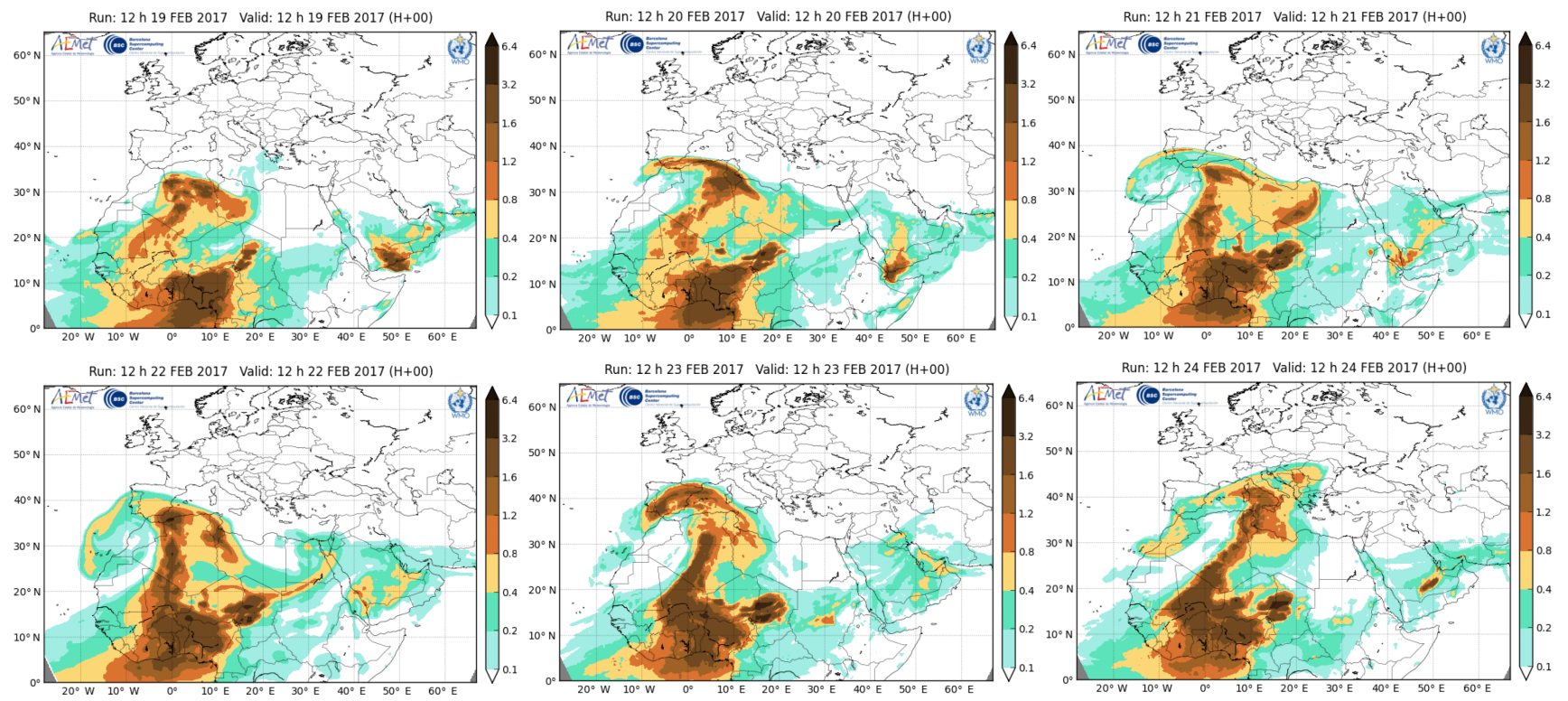

Figure 2. NMMB-BSC dust forecast aerosol optical depth (AOD) at $550 \mathrm{~nm}$ for the days before, during, and after the extreme red rain event. Images from the Barcelona Dust Forecast Center.
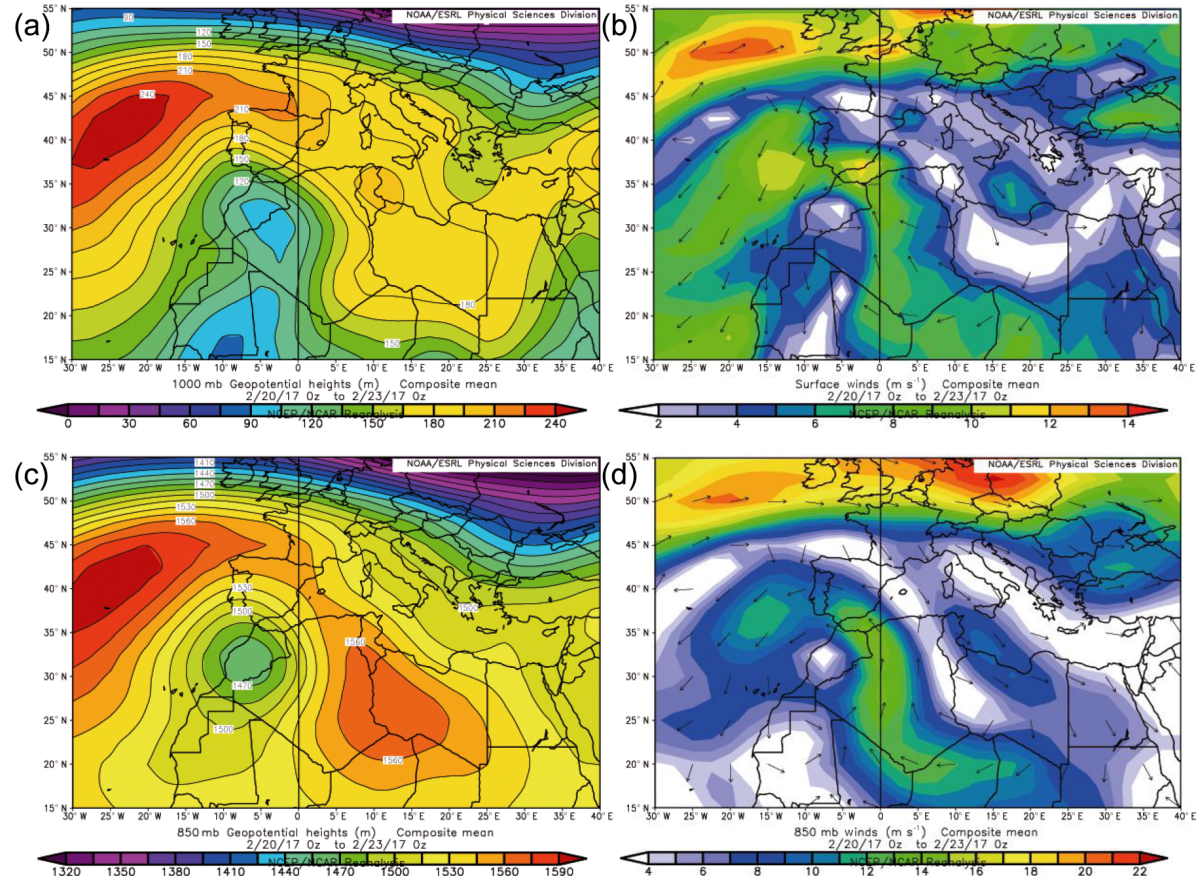

Figure 3. Synoptic-scale meteorological situation during the red rain event based on NOAA/ESRL reanalysis. Averaged geopotential high (a, c) and wind field (b, d) for 20-23 February 2017 at both ground level (1000 hPa) and $850 \mathrm{hPa}(\sim 1500 \mathrm{~m}$ a.s.1.) are displayed.

February 2007 (Bou Karam et al., 2010) and on 20-25 February 2016 (Titos et al., 2017). These observations suggest that there is a recurrent pattern in the spatio-temporal synoptic conditions (e.g., northern African cyclones) leading to such extreme (winter) Saharan dust outbreaks and associated red rain events.
The backward and forward trajectory analyses showed that the air masses arriving at Granada during the studied event entrained dust over a broad area spanning from central and southern Algeria, the northern part of Mali, and the northwestern part of Niger to the north of Algeria, south of Tunisia, and western Libya (Fig. 4). This broad area in- 
(a) Backward traj NOAA HYSPLIT MODEL

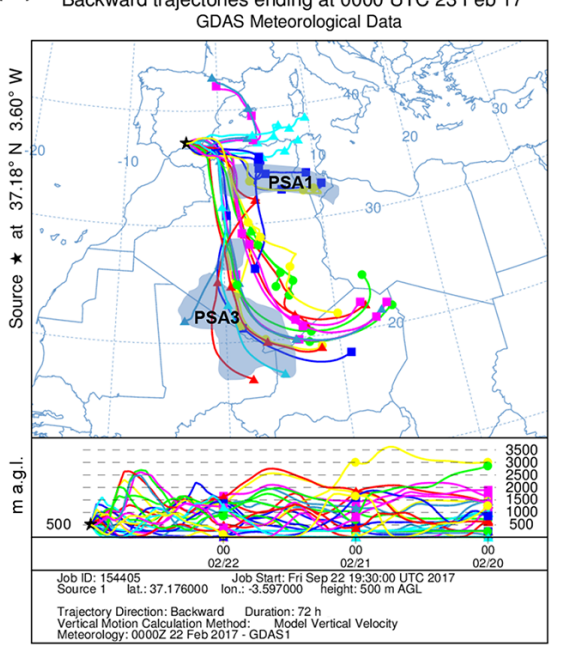

(d)

NOAA HYSPLIT MODEL
(d) Forward trajectories starting at OODOO UTC 20 Feb 17

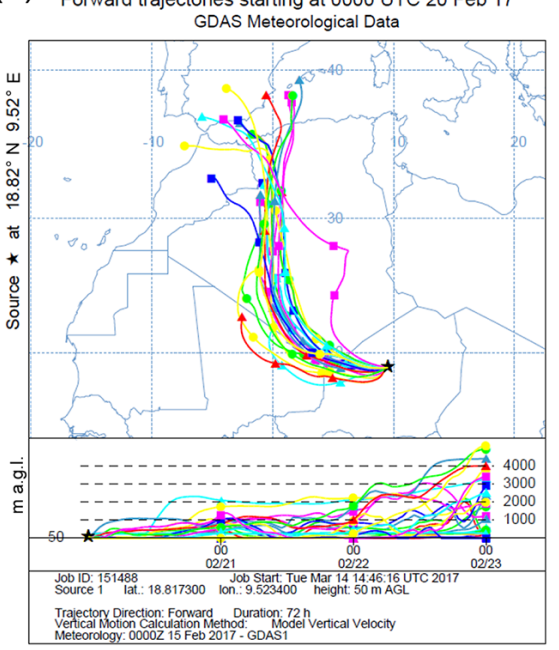

(b) NOAA HYSPLIT MODEL

(b) Forward trajectories starting at 0000 UTC 21 Feb 17

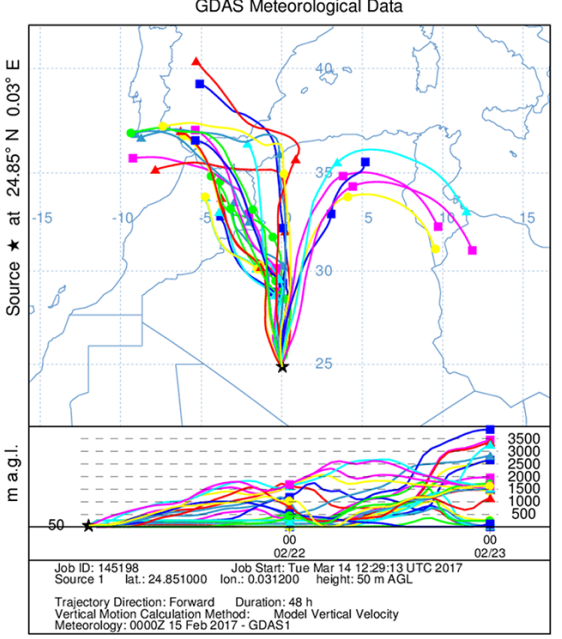

(e) NOAA HYSPLIT MODEL

(e) Forward trajectories starting at OODO UTC 20 Feb 17

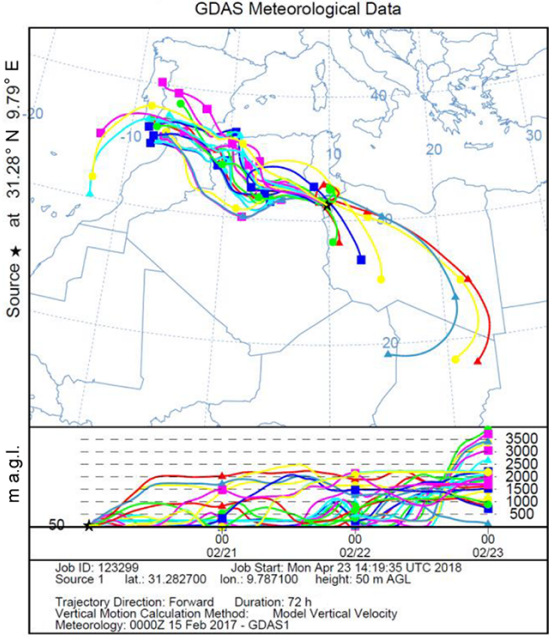

(c) FOAA HYSPLIT MODEL

(C) Forward trajectories starting at 0000 UTC 21 Feb 17

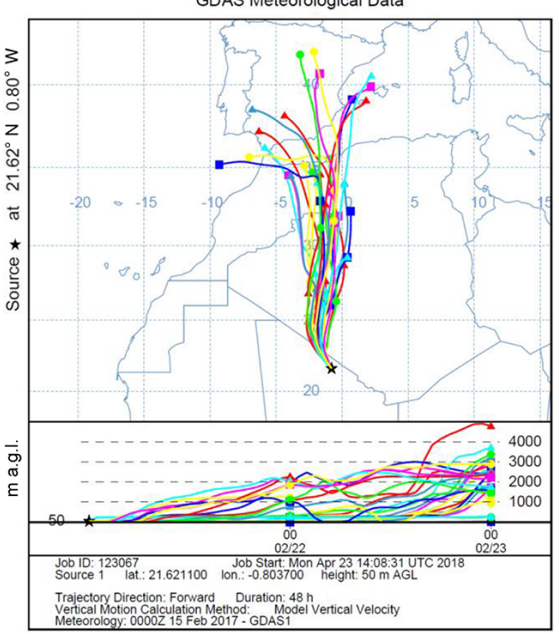

(f) NOAA HYSPLIT MODEL

(f) Forward trajectories starting at 0000 UTC 20 Feb 17 GDAS Meteorological Data

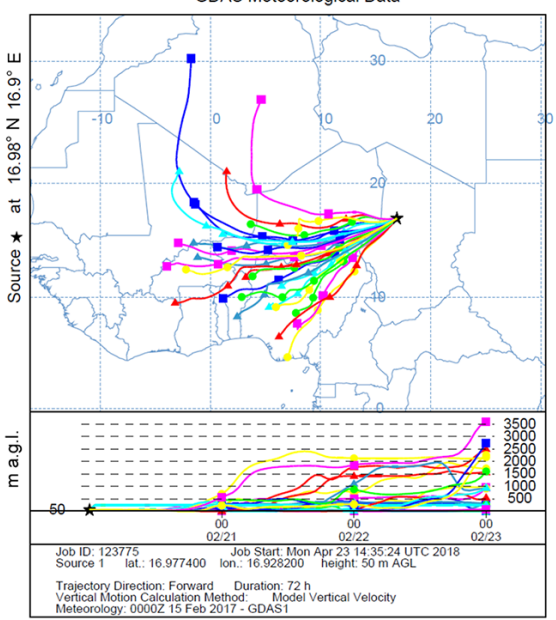

Figure 4. Results of NOAA's HYSPLIT modeling of (a) $72 \mathrm{~h}$ multiple (25) back-trajectories for air masses arriving at Granada on 23 February 2017 (00:00 UTC) and (b-f) forward multiple (25) trajectories for selected dust source areas. Shaded areas in (a) show potential source areas PSA1 and PSA3.

cludes two well-known Saharan dust potential source areas (PSAs) as defined by Formenti et al. (2011) and Scheuvens et al. (2013): (i) PSA1, which covers the zone of chotts (ephemeral lakes) and dry lakebeds south of the Tell Atlas in northeastern Algeria, southern Tunisia, and northwestern Libya. This area is characterized by a relatively high illite, palygorskite, and carbonate content, and (ii) PSA3, which is one of the largest, most persistent, and most intense dust source areas in the Sahara (Goudie and Middleton, 2001; Prospero et al., 2002). It is located in the central-southern section of Algeria, and spreads along the basins located southwest of the Ahaggar massif, the northern part of Mali, and the frontier with Niger (e.g., Adrar des Iforas). Dust entrained from this area is characterized by relatively high il- lite, kaolinite, and smectite contents, with minor amounts of palygorskite (Scheuvens et al., 2013). The importance of these two major source areas, particularly the second one, has been recognized by several authors (e.g., D'Almeida, 1996; Goudie and Middleton, 2001; Prospero et al., 2002). However, previous studies did not recognize the contribution of such a distant area as PSA3 to extreme dust events affecting western Europe. Avila et al. (1997) reported that three main source areas were active during red rain events affecting the Iberian Peninsula: (i) western Sahara (between $26-30^{\circ} \mathrm{N}$ and $14-8^{\circ} \mathrm{W}$ ), (ii) Moroccan Atlas (between $30-35^{\circ} \mathrm{N}$ and $8-0^{\circ} \mathrm{W}$ ), and (iii) central Algeria (between $26-30^{\circ} \mathrm{N}$ and $4^{\circ} \mathrm{W}-5^{\circ} \mathrm{E}$ ). Avila et al. (1997) report that the latter source area is activated by a depression over the Iberian Peninsula 
or over northern Africa. Such a source area is the one most closely matching the potential source areas identified here. However, our back- and forward-trajectory analysis shows that dust was mobilized from Saharan regions located much further south as well as from northern areas. We also considered the possibility that dust reaching the Iberian Peninsula could be entrained from PSA5, that is, the Bodélé depression (Formenti et al., 2011; Scheuvens et al., 2013), which is considered the single most active dust source area in the world (Goudie and Middleton, 2002; Prospero et al., 2002). However, our forward-trajectory analysis (Fig. 4f) demonstrated that no dust entrained from this source area during the days preceding the studied dust event reached the Iberian Peninsula.

In summary, the synoptic scenario leading to the studied extreme red rain event appears to be recurrent, typically occurring in late winter or early spring, and being associated with a northern African depression. Remarkably, this situation can mobilize and wet-deposit huge amounts of Saharan dust entrained from distant southern areas in the Sahara, about $3000 \mathrm{~km}$ away from the Iberian Peninsula, as well as from closer areas in northern Africa.

\subsection{XRD analysis: linking mineralogy with potential dust source areas}

The analysis of the bulk dust deposit (powder samples) showed the presence of (in order of decreasing abundance) (Table 1) clay minerals (see below for details on individual clay minerals and their content), quartz $\left(\mathrm{SiO}_{2}\right)$, calcite $\left(\mathrm{CaCO}_{3}\right.$ ), plagioclase (albite, $\left.\mathrm{NaAlSi}_{3} \mathrm{O}_{4}\right)$, K-feldspar (microcline, $\left.\mathrm{KAlSi}_{3} \mathrm{O}_{4}\right)$, dolomite $\left(\mathrm{CaMg}\left(\mathrm{CO}_{3}\right)_{2}\right)$, goethite $(\alpha$ $\mathrm{FeOOH})$, hematite $\left(\alpha-\mathrm{Fe}_{2} \mathrm{O}_{3}\right)$, and rutile $\left(\mathrm{TiO}_{2}\right)$ (Fig. 5a). Note that phase amounts determined by XRD (RIR or Rietveld methods) are not considered to be purely quantitative, but rather semiquantitative due to the errors associated with this technique (typically $\pm 5 \mathrm{wt} \%$ ) (Formenti et al., 2011). Note also that amorphous phases (e.g., amorphous silica - in diatoms - and amorphous iron oxyhydroxides; see TEM results below) cannot be detected using XRD, and their content was not negligible, as shown by the broad hump at $18-32^{\circ} 2 \theta$ in the XRD pattern (Fig. 5a). We observed that the Rietveld method did not allow the quantification of oxides, plagioclase, and clays other than illite and kaolinite (Fig. S3). It also grossly overestimated the amounts of carbonate phases, i.e., $32 \pm 1 \mathrm{wt} \%$, a value more than twice the amount determined using the RIR method ( $14 \pm 1 \mathrm{wt} \%$ ), or by measuring the mass differences after acid elimination of carbonates (13 $\pm 1 \mathrm{wt} \%$ ), or by TG analysis $(14.7 \pm 0.2 \mathrm{wt} \%$ ) (see below). The use of the Rietveld method for quantifying such complex multiphase dust samples is therefore not advised. In contrast, the RIR method yielded more reliable results, especially in the case of carbonate phases and clay minerals.

The detected mineral phases and contents are in general typical for Saharan dust deposited all across Europe, dur- ing both dry- and wet-deposition events (Scheuvens et al., 2013), as well as those reported for African dust deposited on different areas across the tropical North Atlantic (Glaccum and Prospero, 1980; Menéndez et al., 2014; Patey et al., 2015). This is not unexpected because these phases are the most common in northwestern African arid and semi-arid soils (Scheuvens et al., 2013; Journet et al., 2014). Avila et al. (1997) reported a very similar mineral composition for the case of Saharan dust deposited after red rain events on the northeastern part of the Iberian Peninsula. However, the authors did not report the presence of goethite, hematite, and rutile.

The total amount of clays measured here $(\sim 47 \mathrm{wt} \%)$ is smaller than the average value reported by Avila et al. (1997) ( $\sim 64 \mathrm{wt} \%$ ), or the values of $60-90 \mathrm{wt} \%$ reported for Saharan dust collected in Africa or after long-range transport (Formenti et al., 2014a), although it approaches the average value of $52 \mathrm{wt} \%$, and is well within the range 34-66 wt \%, reported by Patey et al. (2015) for northern African dust deposited in the tropical North Atlantic (Cape Verde). This is likely due to the fact that very intense Saharan dust events, such as the one studied here, typically mobilize larger particles with a relatively lower clay content of $\sim 50 \mathrm{wt} \%$ (Caquineau et al., 2002; Formenti et al., 2014a).

The XRD pattern of the sand fraction (after elimination of carbonates) showed intense reflections corresponding to quartz (main phase), with minor reflections corresponding to nearly all other identified phases (Fig. $5 \mathrm{~b}$ and Table 1 ). It was unexpected to find clays and iron oxyhydroxides within this fraction, especially considering that acid dissolution of the carbonates and thorough washing were performed prior to size separation. Apparently, clays and iron oxyhydroxides are intimately associated (cemented) with the coarser quartz and feldspar grains (see SEM and TEM results below). Abundant quartz along with small amounts of feldspars and abundant clay minerals were detected in the silt fraction (Fig. 5b and Table 1). Conversely, very small amounts of quartz were detected in the clay fraction (Fig. 5b), where clay minerals were the most abundant phases, along with iron oxyhydroxides.

Figure $5 \mathrm{c}$ shows the XRD patterns of oriented aggregates of the clay fraction. An intense Bragg peak at $10.4 \AA$ which did not change position following EG and DMSO solvation, and which collapsed to $10 \AA$ upon heat treatment at $550^{\circ} \mathrm{C}$, was observed. These are standard features of the 110 Bragg peak of palygorskite $\left(\left(\mathrm{Mg}, \mathrm{Al}_{2}\right)_{2} \mathrm{Si}_{4} \mathrm{O}_{10}(\mathrm{OH}) 4\left(\mathrm{H}_{2} \mathrm{O}\right)\right)$ (Moore and Reynolds, 1989). Note that in some publications this reflection has been mistakenly assigned to illite $\left(\mathrm{K}(\mathrm{Al}, \mathrm{Mg}, \mathrm{Fe})_{2}(\mathrm{Si}, \mathrm{Al})_{4} \mathrm{O}_{10}(\mathrm{OH})_{2}\right)$ (e.g., Prodi and Fea, 1979). In addition, we also observed the $d_{200}$ spacing of palygorskite at $6.4 \AA$, unambiguously confirming its presence. The intense peak at $7.17 \AA$, which did not shift position upon EG and DMSO solvation, and which disappeared upon heat treatment, corresponded to the 001 reflection of kaolinite $\left(\mathrm{Al}_{2} \mathrm{Si}_{2} \mathrm{O}_{5}(\mathrm{OH})_{4}\right)$. There was a poorly defined broad 
Table 1. Semiquantitative XRD analysis of Saharan dust powder samples (wt $\% ; \pm 1 \sigma)$.

\begin{tabular}{lrrrrrrrrr}
\hline Sample & Qtz & Kfd & Plg & Cal & Dol & Goe & Hem & Rut & Clay minerals \\
\hline Bulk RIR $_{\text {RIR }}^{\mathrm{a}}$ & $23 \pm 1$ & $6 \pm 1$ & $7 \pm 1$ & $12 \pm 2$ & $2 \pm 1$ & $1.7 \pm 0.8$ & $0.5 \pm 0.4$ & $0.8 \pm 0.3$ & $47 \pm 3^{\mathrm{b}}$ \\
Bulk Rietveld $^{\mathrm{c}}$ & $24 \pm 1$ & $5 \pm 1$ & - & $24 \pm 1$ & $8 \pm 1$ & - & - & - & $44 \pm 2$ \\
Sand $^{\mathrm{d}}$ & $73 \pm 5$ & $5 \pm 2$ & $3 \pm 1$ & - & - & $1 \pm 1$ & - & - & $18 \pm 3^{\mathrm{b}}$ \\
Silt $^{\mathrm{d}}$ & $51 \pm 3$ & $5 \pm 2$ & $4 \pm 2$ & - & - & $1 \pm 1$ & $1 \pm 1$ & - & $38 \pm 4^{\mathrm{b}}$ \\
Clay $^{\mathrm{d}}$ & $7 \pm 2$ & - & - & - & - & $3 \pm 2$ & $2 \pm 1$ & - & $88 \pm 5^{\mathrm{b}}$ \\
\hline
\end{tabular}

${ }^{a}$ Values obtained using the RIR method. ${ }^{b}$ Values determined considering the intensity of the general Bragg reflection of phyllosilicates at $4.49 \AA$.

${ }^{c}$ Values obtained using the Rietveld method. ${ }^{d}$ This size-fraction powder sample was subjected to carbonate elimination. Legend: Qtz: quartz; Kfd: microcline; Plg: plagioclase; Cal: calcite; Dol: dolomite; Goe: goethite; Hem: hematite; Rut: rutile.
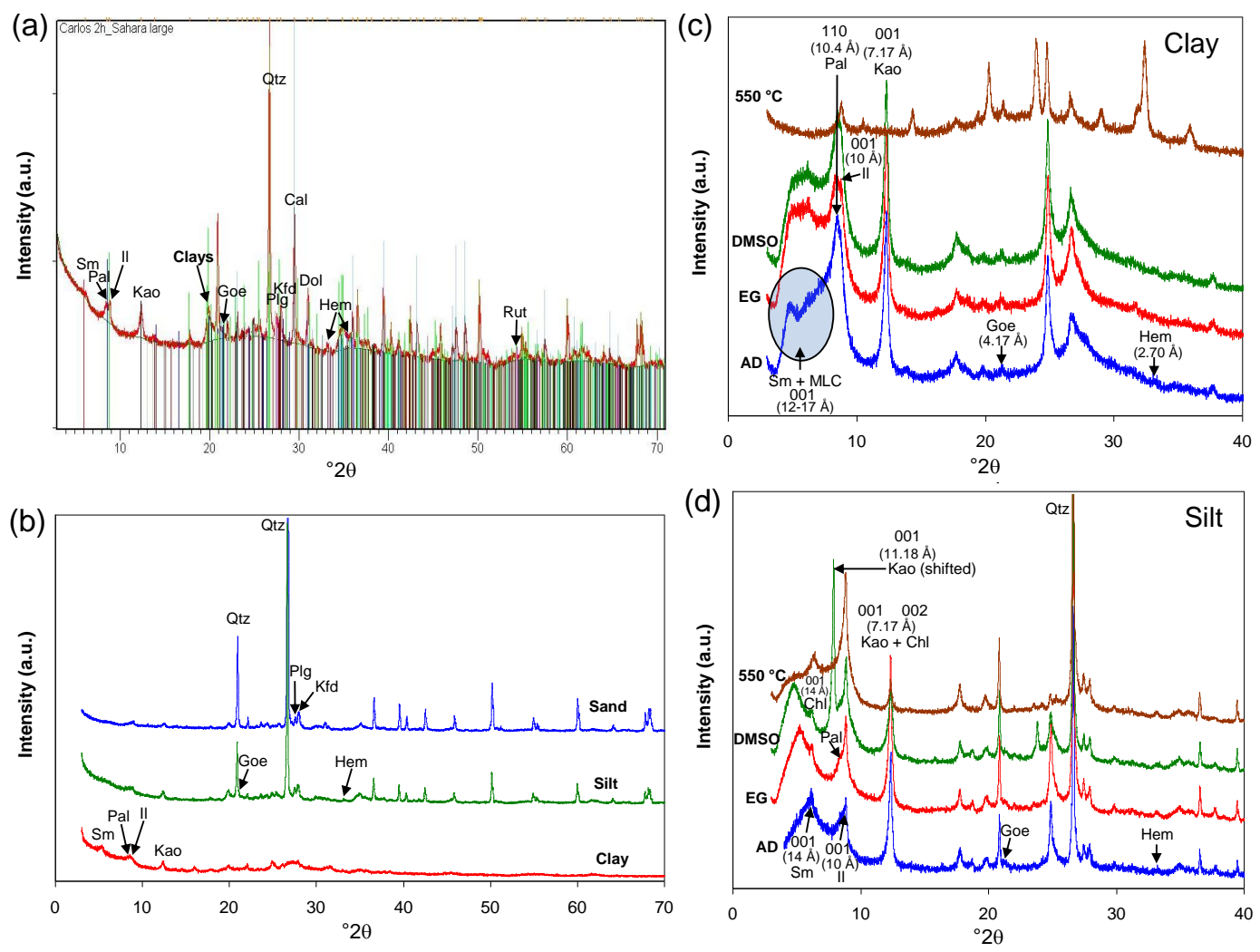

Figure 5. XRD analysis of Saharan dust: (a) XRD pattern of the bulk sample showing the presence of smectites (Sm), palygorskite (Pal), illite (Il), kaolinite (Kao), goethite (Goe), quartz (Qtz), K-feldspar (Kfd), plagioclase (Plg), calcite (Cal), dolomite (Dol), rutile (Rut), and hematite (Hem). The general reflection of clay minerals (Clays) at $4.49 \AA$ is also indicated. Vertical color lines show the peak position of the different phases (only the main peaks corresponding to each phase are labeled). (b) XRD patterns of the sand, silt, and clay fractions (decarbonated). (c, d) XRD patterns of oriented aggregates of the clay and silt fractions, respectively (with different treatments). The $h k l$ index and $d$-spacing (in $\AA$ ) of the clay minerals' main reflections are indicated in (c, d). Chl: chlorite; MLC: mixed-layer clays.

band at $12-18 \AA$ that shifted position towards higher $d$ spacings upon EG and DMSO treatments, and collapsed to $10 \AA$ upon heat treatment. These features are indicative of swelling clays (smectites), most likely montmorillonite ((Na, $\mathrm{Ca})_{0.3}(\mathrm{Al}, \mathrm{Mg}, \mathrm{Fe})_{2} \mathrm{Si}_{4} \mathrm{O}_{10}(\mathrm{OH})_{2} n\left(\mathrm{H}_{2} \mathrm{O}\right)$ ) (see TEM-AEM results below), and mixed-layer clays (MLC, interstratified illite-smectite; see TEM-AEM results below), accounting for the broad reflection centered at $d$-spacings $\sim 14-17 \AA$ and $\sim 12 \AA$, respectively (AD sample). Note, however, that the broadness of the Bragg peaks precluded an unambiguous identification of any individual swelling clay. Finally, a shoulder located on the right of the 110 Bragg peak of palygorskite was observed at $10 \AA$, best seen in EG-solvated samples, pointing to the presence of illite (001 reflection), confirmed by the appearance of its 002 and 003 order reflections at $5 \AA$ and $3.33 \AA$, respectively.

Some mineralogical changes were detected in the silt fraction as compared to the clay fraction (Fig. 5d). The 001 
reflection of illite was more intense than the 110 reflection of palygorskite, pointing to a relative increase in the abundance of illite in this coarser fraction. Kaolinite expanded upon DMSO treatment as shown by the shifting of the 001 peak at 7.14 to $11.18 \AA$. This is a standard feature of this clay mineral which enables its distinction from chlorite, which also has a strong reflection at $\sim 7.1 \AA$ (GonzálezGarcía and Sánchez-Camazano, 1968). However, the formation of a DMSO-kaolinite intercalation complex is dependent on kaolinite crystallinity, as shown here by the fact that kaolinite in the clay fraction, which displayed a very broad 001 reflection (due to poor crystallinity), did not expand. These observations suggest size fractionation of kaolinite particles from two different sources, with the higher crystallinity coarser phase in the silt fraction likely coming from a closer-to-Europe source area (i.e., PSA1), and the less crystalline kaolinite in the clay fraction likely coming from a more distant source (i.e., PSA3). Alternatively, it could be argued that the two types of kaolinite come from an area where mixing of dust from different source areas had occurred (Guieu et al., 2002). Finally, it was observed that lattice expansion of swelling clays (smectite and MLC) upon EG and DMSO treatment unveiled the presence of a Bragg peak at $14 \AA$ which upon heat treatment remained unaltered. The corresponding second-order 002 reflection at $7.1 \AA$ was also visible after heat treatment. This behavior is characteristic of chlorite $\left(\left(\mathrm{Mg}, \mathrm{Fe}^{++}\right)_{5} \mathrm{Al}\left(\mathrm{Si}_{3} \mathrm{Al}\right) \mathrm{O}_{10}(\mathrm{OH})_{8}\right)$, whose presence was masked by the broad 001 reflection of swelling clays at $\sim 14 \AA$ and the 001 reflection of kaolinite at $7.1 \AA$ in the oriented $\mathrm{AD}$ mount or in the bulk powder sample.

The results of the semiquantitative XRD analysis of the clay minerals in the bulk fraction (powder samples) as well as in the clay and silt fractions (oriented mounts) are presented in Table 2. Apparently, the most abundant clay mineral in the bulk sample was illite. However, the analysis of oriented mounts showed that the most abundant clay was palygorskite, illite being the second most abundant clay mineral. This discrepancy can be explained considering that the RIR (or the Rietveld) method for (ideally non-oriented) illite fails to fully detract from the contribution of the main reflection of (abundant) quartz at $3.33 \AA$, which overlaps the 003 main reflection of illite. To this effect, one has to add the intensity increase related to preferential orientation of this phyllosilicate in the bulk powder sample. As a result, an overestimation of illite takes place. More reliable results are thus obtained using oriented mounts and in-house experimental RIR values referred to as the 001 reflections (or 110, in the case of palygorskite) of the clay minerals. The amount of kaolinite was relatively high in the silt and clay fractions, but still much lower than that of illite. The amount of chlorite, only present in the silt fraction, was low $(\sim 5 \mathrm{wt} \%)$, whereas the amounts of smectite and MLC were relatively high. Note that MLC were only identified in the clay fraction. Finally, these results show that, contrary to common assumptions regarding the lack of abundant clay minerals in the silt frac- tion (Journet et al., 2014), these phases are very abundant in this coarser fraction. Note also that because the mass of the silt fraction was 2.06 times that of the clay fraction (as revealed by the results of the hydrodynamic size separation showing sand $=2 \mathrm{wt} \%$, silt $=68 \mathrm{wt} \%$, and clay $=30 \mathrm{wt} \%$ ), the amount of smectites, which along with MLC typically concentrate in the clay fraction, was relatively high in the silt fraction. Nonetheless, if we consider the unit mass of silt and clay fractions, the amount of smectite in the silt fraction $(11 \%)$ is lower than the amount of smectite plus MLC in the clay fraction $(15 \%)$.

Most of the phases detected by XRD, with the exception of carbonates and some of the clays, cannot be used as a reliable indicator for dust source identification because they are common to all northern African dust source areas (Scheuvens et al., 2013; Formenti et al., 2014a; Journet et al., 2014). Calcite and dolomite are recognized as good indicators of a northern and northwestern Saharan origin (Avila et al., 1997; Scheuvens et al., 2013), although southern Algeria and the Mali-Algeria border are areas that also contribute significant amounts of carbonates to Saharan dust (Scheuvens et al., 2013). Interestingly, the TEM analysis (see below) showed the presence of abundant fibrous calcite, which typically forms in playa and/or ephemeral (and paleo) lakes in arid regions (Wanas, 2012). This points to PSA1 (chotts in northern Algeria-Tunisia) as the most likely source area for this mineral.

The illite / kaolinite (I/K) ratio has been used to identify Saharan dust source regions (Caquineau et al., 2002). I / K > 2 has been associated with northwestern Saharan source areas, I $/ \mathrm{K}<0.5$ with southern Saharan and Sahelian source areas, and intermediate values with central Saharan source areas. The I/ $\mathrm{K}$ ratio in our dust samples ranged between 1.68 (silt fraction) and 2.07 (clay fraction) (we ignore here the I / K ratio of the bulk powder sample, because the illite content is overestimated for the reasons discussed above). Considering the wt $\%$ of each size fraction (see above), the overall I / K ratio of the clay plus silt fractions is 1.77 . This points to a central Saharan source area (i.e., southern-central Algeria). However, and in agreement with satellite imagery, BSA dust forecast, and backward-/forward-trajectory analyses, the existence of two types of kaolinite with low (no expansion with DMSO) and high crystallinity (expansion with DMSO) suggests the possibility of mixing of dust entrained from both southern (low I / K ratio) and northern (high I / K ratio) Saharan areas (i.e., PSA3 and PSA1). Indeed, the relatively high carbonate content and abundant palygorskite point to an additional north(western) Saharan source. Palygorskite has been recognized as a reliable indicator of a Saharan provenance (Coudé-Gaussen, 1991; Scheuvens et al., 2013), and has been detected in red rain events not only in the Iberian Peninsula (Avila et al., 1997), but also in the western (Fiol et al., 2005), central (Molinaroli, 1996), and eastern Mediterranean areas (Ganor et al., 2009), the Alps (De Angelis and Gaudichet, 1991), the Netherlands (Reiff et 
Table 2. Semiquantitative analysis (RIR method) of clay minerals (wt \%). Values in parentheses show the wt \% content of each type of clay mineral in the bulk sample. Note that the contents of individual clay minerals determined from XRD analysis of the bulk (powder) sample are subjected to a very high uncertainty. More reliable semiquantitative results are obtained from oriented aggregates (OA).

\begin{tabular}{lrrrrrr}
\hline Sample & Ill & Pal & Sm & Kao & MLC & Chl \\
\hline Bulk (powder) & $47 \pm 2(22)$ & $24 \pm 3(11)$ & $15 \pm 4(7)^{\mathrm{a}}$ & $14 \pm 1(7)^{\mathrm{b}}$ & - & - \\
Clay fraction (OA) & $29 \pm 1(4.2)$ & $43 \pm 2(6.3)$ & $8 \pm 1(1.2)$ & $14 \pm 1(2)$ & $7 \pm 2(1)$ & - \\
Silt fraction (OA) & $32 \pm 1(10.3)$ & $33 \pm 3(10.7)$ & $11 \pm 1(3.5)$ & $19 \pm 2(6.2)$ & - & $6 \pm 2(1.9)$ \\
Total silt + clay fractions (OA) & $(14.5)$ & $(17)$ & $(4.7)$ & $(8.2)$ & $(1)$ & $(1.9)$ \\
\hline
\end{tabular}

${ }^{a}$ Includes the contribution of MLC and Chl. ${ }^{b}$ Includes the contribution of Chl. Legend: Ill: illite; Pal: Palygorskite; Sm: smectite; Kao: kaolinite; MLC: mixed-layer clay; Chl: chlorite.

al., 1986), and the British Isles (Bain and Tait, 1977). Palygorskite is a common clay in soils of the northwestern Sahara (PSA2), as well as northern Algeria and Tunisia (PSA1) (Scheuvens et al., 2013). Nonetheless, occurrences of palygorskite, which typically forms in saline lakes and alluvial sediments of arid regions (Singer and Galan, 1984), have also been documented in central and southern Algeria, as well as in northern Mali (PSA3) (Coudé-Gaussen, 1991; Scheuvens et al., 2013). Remarkably, the amount of palygorskite in our studied dust samples is exceptionally high (17 wt \% of the bulk sample; see Table 2). Previous studies of Saharan dust deposited in the central Mediterranean (Mallorca and Sardinia) reported palygorskite values $\leq 5 \mathrm{wt} \%$ (Molinaroli, 1996; Fiol et al., 2005), although Avila et al. (1997) observed a concentration of up to $12 \mathrm{wt} \%$ in red rains in northwestern Spain. It is likely that in our case, the close proximity to northern Africa and the intensity of the dust event favored the entrainment of palygorskite-rich dust from the northern Algeria and Tunisia areas, and its transport with minimal segregation of the silt-sized palygorskite particles prior to their deposition in southern Spain. Alternatively, it might be argued that in previous studies the amount of palygorskite was underestimated due to the difficulty in quantifying this mineral using XRD. Such a problem is rooted in the general lack of reliable and accurate RIR values for palygorskite: this is why we experimentally determined the RIR value of palygorskite. The same applies for quantitative Rietveld analysis of palygorskite due to the difficulty in obtaining accurate structural factors for clay minerals in general, and for this clay mineral in particular. We will show below that appropriate characterization and quantification of this mineral in Saharan dust are of great significance due to its potential health effects. Finally, it is worth commenting on the chlorite to kaolinite ratio (Chl / K), which has also been proposed for discriminating Saharan dust source regions (Scheuvens et al., 2013). Values $<0.3$ have been reported for southern Algeria and northern Mali, while higher values have been observed in soils from the northern and northwestern Sahara (see the compilation by Scheuvens et al., 2013). We obtained $\mathrm{Chl} / \mathrm{K} \sim 0.2$, a value which is consistent with a southern Algerian and/or northern Mali source region.
Overall, and in agreement with previous studies that pointed out that major Saharan dust outbreaks affecting large desert areas typically involve mixing of dust entrained from different active dust source areas (Skonieczny et al., 2011; Formenti et al., 2014a), our mineralogical analysis, in combination with satellite imagery, NMMB-BSC dust forecast, and forward- and backward-trajectory analyses, shows that this is the case here too, with PSA1 and PSA3 as the most probable dust source areas, although we cannot rule out the possibility that dust could originate from a larger zone than PS1 and PS3. Despite the difficulty in accurately pin-pointing the different source areas down to a local scale during such an extreme event, our results show that it is still possible to identify different regional dust signatures that help constrain potential dust source areas.

\subsection{Chemical composition}

Table 3 shows the results of XRF and ICP analysis of the dust samples (chemical composition of bulk dust). Both techniques yielded consistent and comparable results. $\mathrm{Si}$ and Al were the two most abundant elements, which indicates that quartz and aluminosilicates (clays and feldspars) are the main mineral phases in Saharan dust (Goudie and Middleton, 2001). The Si / Al ratio of 3.68 (note: all ratios calculated using the average values of XRF and ICP results) falls within the range of values reported for Saharan dust source areas and Saharan dust deposited in western and central Mediterranean areas (Scheuvens et al., 2013). It is in good agreement with the value (3.92) reported for soils in southern Algeria (Guieu and Thomas, 1996). The latter is consistent with the PSA3 source area, as discussed above. This value is, however, larger than the $\mathrm{Si} / \mathrm{Al}$ values (1.6-3.0) reported by Formenti et al. (2014a) for Saharan dust and soils. Likely, the higher Si content in our samples is due to the favored entrainment and transport of abundant coarse $\mathrm{SiO}_{2}$ particles during such an extreme event. Although a $\mathrm{Si} / \mathrm{Al}$ ratio of 3.68 is also consistent with a PS5 source area (i.e., the Bodélé depression) (Formenti et al., 2014a), as stated above, such a source area is ruled out here because the forwardtrajectory analysis (Fig. 4f) showed that no dust entrained from this area reached the Iberian Peninsula. The relatively 
Table 3. Chemical composition of Saharan dust deposited in Granada during an extreme red rain event.

\begin{tabular}{|c|c|c|c|c|c|c|c|c|c|c|}
\hline \multicolumn{11}{|c|}{ Major/minor elements (wt \%) } \\
\hline & $\mathrm{Si}$ & $\mathrm{Al}$ & $\mathrm{Fe}$ & $\mathrm{Mg}$ & $\mathrm{Ca}$ & $\mathrm{Na}$ & $\mathrm{K}$ & $\mathrm{Ti}$ & $\mathrm{P}$ & \\
\hline $\mathrm{XRF}$ & 24.05 & 6.62 & 3.69 & 1.24 & 5.72 & 1.66 & 1.53 & 0.45 & 0.04 & \\
\hline $\mathrm{ICP}$ & nd & 6.44 & 3.43 & 1.48 & 6.29 & 1.62 & 1.57 & nd & 0.06 & \\
\hline \multicolumn{11}{|c|}{ Minor/trace elements (ppm) } \\
\hline & $\mathrm{Ba}$ & $\mathrm{Sr}$ & $\mathrm{Mn}$ & $\mathrm{Zn}$ & $\mathrm{V}$ & $\mathrm{Cr}$ & Co & $\mathrm{Ni}$ & $\mathrm{Pb}$ & $\mathrm{S}$ \\
\hline $\mathrm{XRF}$ & nd & 162 & 400 & nd & nd & 78 & nd & 51 & nd & nd \\
\hline $\mathrm{ICP}$ & 529 & 231 & 741 & 367 & 103 & 84 & 16 & 44 & 27 & 390 \\
\hline
\end{tabular}

nd: not determined.

high $\mathrm{Ca}$, and to a lesser extent $\mathrm{Mg}$, content shows that carbonates (calcite and dolomite) are abundant. Note, however, that such elements are also present as octahedral or interlayer cations in clay minerals, especially smectites and MLC $(\mathrm{Mg}$ and $\mathrm{Ca}$ ), palygorskite $(\mathrm{Mg}$ ), and chlorite $(\mathrm{Mg})$ (see AEM results below). The $\mathrm{Ca} / \mathrm{Al}$ and $\mathrm{Mg} / \mathrm{Al}$ ratios of 0.21 and 0.92 , respectively, agree with those reported for Saharan dust from Algerian source areas deposited in southern Europe (Avila et al., 2007; Scheuvens et al., 2013). Fe is the fourth most abundant element, with an average concentration of $3.56 \pm 0.18 \mathrm{wt} \%$, being present both in phyllosilicates (see TEM-AEM results below) and in iron oxyhydroxides. This value matches that of the average Fe content in the continental crust (3.5 wt \%) (Taylor and McLennan, 1985) and falls within the range $\sim 2-11 \mathrm{wt} \%$ reported for Saharan dust and soils (Zhang et al., 2015), but is slightly lower than the average value of $4.45 \mathrm{wt} \% \mathrm{Fe}$ proposed as characteristic of Saharan dust (Guieu et al., 2002), or the range of values (4.3$6.1 \mathrm{wt} \% \mathrm{Fe}$ ) reported by Lafon et al. (2006) for dust and soil samples from the Sahel, southern Morocco, the central Sahara, and Tunisia. Nonetheless, previous studies have reported that the total iron content of Saharan dust deposited in Europe ranges between 3.5 and $5.6 \mathrm{wt} \% \mathrm{Fe}$ (Goudie and Middleton, 2001). Moreover, the $\mathrm{Fe} / \mathrm{Al}$ ratio of 0.54 in our samples falls within the range of values $(0.50-0.57)$ reported for red rains in northeastern Spain (Avila et al. 1998, 2007). Similarly, the $(\mathrm{Ca}+\mathrm{Mg})$ / Fe ratio is 2.06 , a value that matches that reported by Avila et al. (2007) for Saharan dust from central Algeria deposited in the northeastern Iberian Peninsula during red rain events. The contents of $\mathrm{K}$ and $\mathrm{Na}$ are consistent with the presence of K-feldspar, plagioclase, and clay minerals (i.e., abundant K-containing clays such as illite and MLC). The amount of Ti is in good agreement with the amount of rutile detected using XRD $\left(\sim 1 \mathrm{wt} \% \mathrm{TiO}_{2}\right)$. Regarding minor/trace elements, the amounts of $\mathrm{Ba}, \mathrm{Mn}, \mathrm{Zn}$, and $\mathrm{Sr}$, associated with carbonates, as well as $\mathrm{Ni}, \mathrm{Cr}, \mathrm{P}$, and $\mathrm{V}$, associated with silicates, are in good agreement with those reported for dust in red rains coming from northern Saharan sources (Avila et al., 2007). Interestingly, the Pb con- tent $(27 \mathrm{ppm})$ is very low and nearly identical to the average values $(24 \mathrm{ppm})$ in Saharan soils with negligible anthropogenic perturbation (Guieu et al., 2002). Typically, mixing of Saharan dust plumes with polluted air masses (i.e., with anthropogenic perturbations) leads to a significant increase in the $\mathrm{Pb} / \mathrm{Al}$ ratio in dust wet-deposited in the central and western Mediterranean (Guieu et al., 2002). However, in our case the $\mathrm{Pb} / \mathrm{Al}$ ratio of $3.78 \times 10^{-4}$ is very similar to the $\mathrm{Pb} / \mathrm{Al}$ of $3.41 \times 10^{-4}$ reported by Guieu et al. (2002) for Saharan end-members. Similarly, the amount of S, an element commonly associated with anthropogenic pollution, is very low. This value $(0.04 \mathrm{wt} \% \mathrm{~S})$ is almost 2 orders of magnitude lower than those reported by Avila et al. (2007) for red rains in the northeastern Iberian Peninsula, and is identical to that of western Saharan desert soil (Castillo et al., 2008). In addition, $\mathrm{V}$ and $\mathrm{Ni}$, which are typically enriched in anthropogenic combustion aerosols (Sholkovitz et al., 2009), showed a V / Al ratio of $0.1 \times 10^{-2}$ and a $\mathrm{Ni} / \mathrm{Al}$ ratio of $0.06 \times 10^{-2}$. These values are very similar to the corresponding values of the continental crust $\left(\mathrm{V} / \mathrm{Al}=0.08 \times 10^{-2}\right.$ and $\mathrm{Ni} / \mathrm{Al}=0.05 \times 10^{-2}$ ) (Taylor and McLennan, 1985; Sholkovitz et al., 2009). These results demonstrate that the close proximity of the southern Iberian Peninsula to northern Africa and the rapid, intense dust advection during this Saharan dust event led to negligible contamination from polluted (e.g., European) sources (Lyamani et al., 2005).

In summary, the content of major, minor, and trace elements in our studied samples is fully consistent with the reported composition of Saharan dust samples (Scheuvens et al., 2013), and closely matches the composition of dust deposited during red rain events in the western Mediterranean, especially those of an "eastern" provenance, as defined by Avila et al. (2007), i.e., those whose source areas are located in the northern and central parts of the Sahara (Algeria, Libya, and Tunisia). These compositional results are thus consistent with the results of previous sections pointing to PSA1 and PSA3 as the main source regions for the dust deposited in Granada during the studied event. 


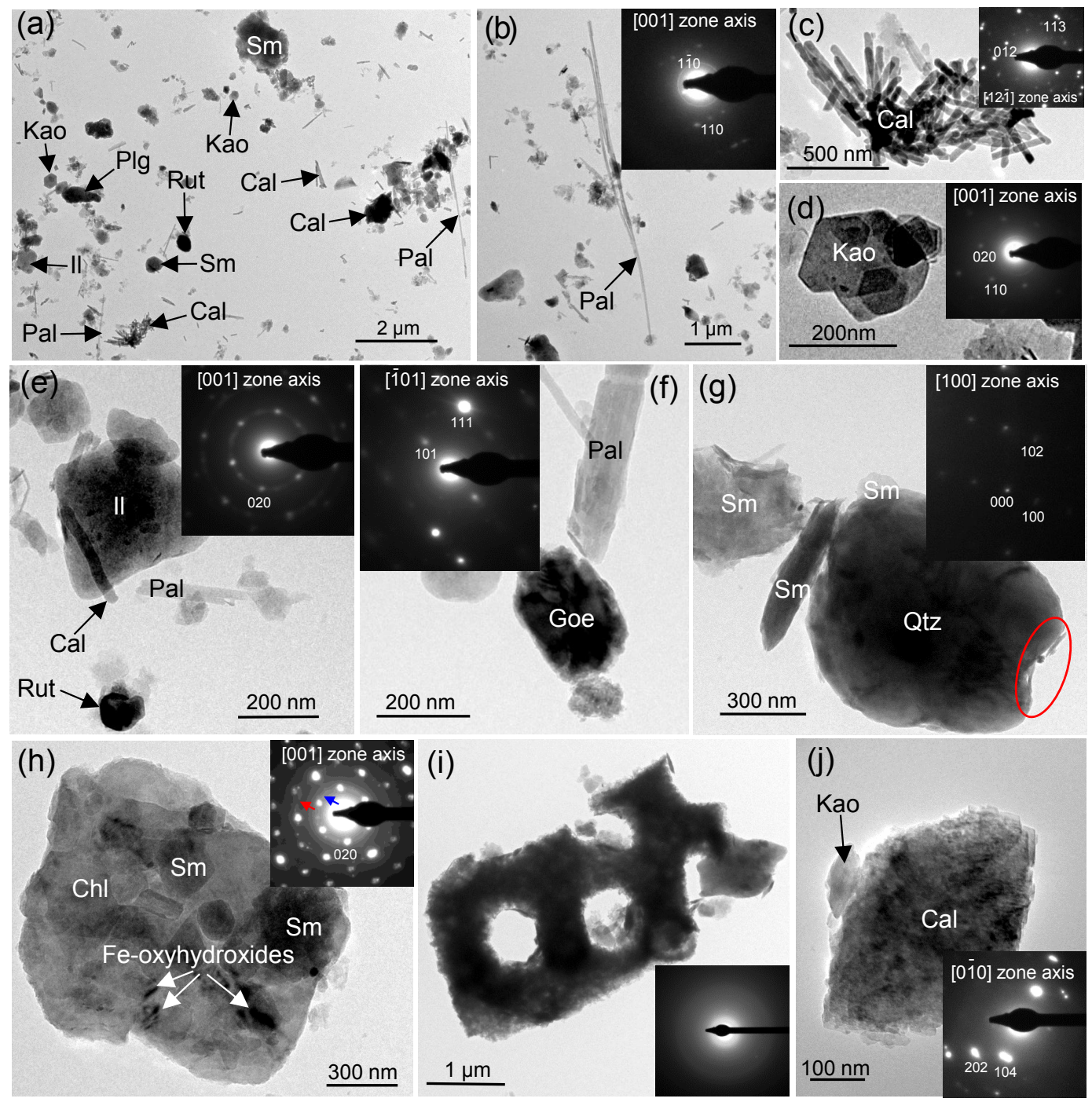

Figure 6. TEM photomicrographs of Saharan dust particles. (a) General low-magnification overview of the particles. Note the abundance of fibrous particles. The long ones are palygorskite $(\mathrm{Pal})$, while the short ones $(\sim 0.5 \mu \mathrm{m})$ are calcite $(\mathrm{Cal})$. The larger particles or aggregates corresponds to feldspars (plagioclase, Plg), illite (Il) and smectites (Sm). The smaller particles include kaolinite (Kao) and rutile (Rut). (b) Detail of elongated palygorskite fiber. The [001] zone axis SAED pattern is shown in inset. (c) Aggregate of fibrous calcite (SAED pattern in inset). (d) Plate-like kaolinite particles (SAED pattern in inset). (e) Illite (SAED in inset), rutile, palygorskite and fibrous calcite. (f) Goethite (Goe) (SAED pattern in inset) and palygorskite. (g) Quartz (Qtz) grain (SAED in inset) surrounded by smectites (Sm). The red circled area shows clay minerals plus iron oxyhydroxide nanoparticles forming a rim around the quartz grain. (h) Chlorite (Chl) (SAED in inset) with adhered smectite and iron oxyhydroxide nanoparticles. The blue and the red arrows in the SAED pattern show the diffuse Debye rings corresponding to the reflections with $d$-spacing 4.49 and $2.5 \AA$, respectively (see the discussion in the main text). (i) Amorphous silica structure (diffuse haloes in SAED pattern in inset). This is part of the skeleton of a diatom. (j) Rhombohedral calcite crystal (SAED in inset) surrounded by kaolinite.

\subsection{TEM-AEM analyses}

TEM identification of individual mineral particles was performed combining information provided by morphology, AEM microanalysis, and selected area electron diffraction (SAED). Figure 6 shows representative TEM images of dust particles and aggregates. Abundant fibrous particles were observed, either with size $>1-5 \mu \mathrm{m}$, made up of $\mathrm{Si}$,
$\mathrm{Mg}$, and $\mathrm{Al}$ (EDX results) with a SAED pattern matching that of palygorskite (Fig. $6 a, b, e, f$ ), or with size $\sim 0.5-$ $1 \mu \mathrm{m}$, identified as calcite by their high $\mathrm{Ca}$ content and SAED pattern (Fig. 6a, c). Abundant non-fibrous clay mineral particles were also identified, which based on their composition (EDX results) and SAED pattern were kaolinite (Fig. 6a, d, j), illite (Fig. 6a, e), smectite (Fig. 6a, g-h), and chlorite (Fig. 6h). Goethite particles up to $\sim 250 \mathrm{~nm}$ 
in size were also identified by EDX and SAED (Fig. 6f) along with scattered iron-rich nanoparticles $<100 \mathrm{~nm}$ in size (identified by EDX microanalysis), typically associated with clay minerals (Fig. 6h). These nanoparticles did not produce any diffraction spots in the SAED pattern: only the diffraction spots of the underlying clay minerals were observed along with diffuse Debye rings at $4.5 \AA$, corresponding to the general $h k 0$ reflection of (poorly crystalline) clay minerals, and at $\sim 2.5 \AA$ and at $\sim 1.5 \AA$, which can be ascribed to amorphous and/or poorly crystalline two-line ferrihydrite $\left(\mathrm{Fe}_{5} \mathrm{HO}_{8} 4 \mathrm{H}_{2} \mathrm{O}\right)$ (Jambor and Dutrizac, 1998), with contributions of higher-order $h k 0$ reflections of the clay minerals (Fig. 6h, inset). Amorphous and/or poorly crystalline ironrich nanoparticles, possibly ferrihydrite, in desert dust have been previously reported (Shi et al., 2009, 2011b, 2012), typically forming coatings on clay minerals (Wagner et al., 2012) or appearing dispersed in the clay matrices of clayrich particles (Jeong et al., 2016). Feldspars (plagioclase) were also identified (Fig. 6a). Interestingly, we observed silica particles with a complex structure (septa) which were amorphous to the electron beam (i.e., their SAED showed no diffraction spots or Debye rings, but diffuse haloes characteristic of an amorphous phase) (Fig. 6i). These are standard features of mineralized skeletons of diatoms, which are abundant in dust from the Bodélé (Formenti et al., 2011), but also occur in fluvial deposits and ephemeral lakes, as well as paleolake basins all across the Sahara (Shi et al., 2011b), especially in central-southern Algeria and Tunisia, and are found in Saharan dust deposited in marine sediments and continental Europe (Gasse et al., 1989). Large quartz grains, typically covered by phyllosilicates and iron oxyhydroxide rims, were also identified (Fig. $6 \mathrm{~g}$ ). The presence of clayand iron-rich coatings on large quartz and/or feldspars, as well as on carbonate grains, appears to be a general feature of Saharan dust particles (Jeong et al., 2016). Finally, calcite rhombohedra (Fig. 6j), as well as very small $(\sim 100 \mathrm{~nm})$ rutile and scarce ilmenite $\left(\mathrm{FeTiO}_{3}\right)$ crystals (identified by both SAED and EDX microanalysis), were also observed.

Table 4 shows average values for the structural formula of the different clay minerals identified by TEM-AEM (see Table $\mathrm{S} 1$ for a complete list of all individual AEM analyses). Microanalysis results confirmed the presence of illite, palygorskite, kaolinite, smectite, and MLC. Due to its scarcity and mixing with other clay phases, we could not collect any clean and reliable AEM analysis for chlorite. Illite had a composition typical for this clay mineral, with a substantial phengitic component as shown by the relatively high $\mathrm{Fe}$ and $\mathrm{Mg}$ content in the octahedral layer (Weaver and Pollard, 1973). Most palygorskite analyses (Table S1) had excess Si and relatively low $\mathrm{Al}$ and $\mathrm{Mg}$ in octahedral sites. This is due to beam damage during AEM analysis of this beam-sensitive mineral. Nonetheless, the average structural formula of palygorskite obtained here is standard for this fibrous clay, with a slightly elevated $\mathrm{Fe}$ content not unusual for this fibrous clay (Weaver and Pollard, 1973). The AEM analysis of kaolinite revealed a slight $\mathrm{Al}$ deficit and very small amounts of $\mathrm{Fe}$, an element that substitutes $\mathrm{Al}$ in the octahedral layer, especially in the case of poorly crystalline kaolinite (Mestdagh et al., 1980). We identified a smectitic phase with a composition compatible with montmorillonite. The relatively high $\mathrm{Al}$ content in tetrahedral positions, resulting in a reduced amount of $\mathrm{Si}$, and the abundant $\mathrm{Al}$ and $\mathrm{Fe}$ in octahedral positions, point to beidellitic and nontronitic contributions (i.e., solid solution between the extreme terms montmorillonite and beidellite, with a minor nontronitic component) (Weaver and Pollard, 1973). In addition, we identified a MLC with a relatively high $\mathrm{K}$ content in the interlayer, which is consistent with an illitesmectite mixed-layer phase (with a relatively low content of illite layers), also with a relatively high Fe content. MLC can be distinguished from smectite by its lower Si content and corresponding higher $\mathrm{Al}$ content in tetrahedral positions, as well as by its higher $\mathrm{K}$ content. It is also distinguished from illite by the reduced $\mathrm{K}$ content and interlayer charge.

All analyzed clay minerals contained significant amounts of $\mathrm{Fe}$, an important finding regarding its biogeochemical (e.g., iron bioavailability) and radiative implications. It could be argued, however, that the intimate mixing/attachment of Fe-rich nanoparticles with/on clay minerals might yield an excess of Fe during AEM analyses. With a few exceptions (see below), this is considered unlikely: special care was taken to collect AEM analysis only from areas of the clay mineral particles free of Fe-rich nanoparticles. In any case, we carefully checked our individual AEM analyses in order to identify possible contamination with $\mathrm{Fe}$. Analyses that showed an anomalously high $\mathrm{Fe}$ content incompatible with previous analyses of clays in Saharan dust (Díaz-Hernandez and Párraga, 2008; Jeong and Achterberg, 2014; Jeong et al., 2016) were not considered for the determination of the average structural formulae reported in Table 4. Similarly, analyses that did not yield an appropriate sum of octahedral cations (i.e., out of the range 1.8-2.2) were not used for the calculation of the structural formulae presented in Table 4.

The average $\mathrm{Fe}$ content in the clay minerals varied between $1.7 \mathrm{wt} \%$ in kaolinite and $5.2 \mathrm{wt} \%$ in illite, with intermediate values of $2.7,3.4$, and $4.8 \mathrm{wt} \%$ in MLC, palygorskite, and smectite, respectively. These values are consistent with those reported by Jeong and Achterberg (2014) and Jeong et al. (2016) for clay minerals in Saharan dust analyzed using TEM-AEM. Overall, the average Fe content for all clay minerals analyzed here is $3.53 \mathrm{wt} \%$. If one considers that there is also chlorite, which has a typical Fe content of $\sim 14 \mathrm{wt} \%$ in desert dust (Jeong and Achterberg, 2014), then the average Fe content in our studied clays rises to $5.27 \mathrm{wt} \%$. This latter value is in very good agreement with the average $5.4 \mathrm{wt} \%$ Fe content of clay minerals in Saharan dust analyzed by Jeong and Achterberg (2014).

Further detailed textural and compositional insights were obtained using the HAADF and EDX detectors of the Ti$\tan$ TEM operated in STEM mode. Figures 7 and 8 (as well as Figs. $4 \mathrm{~S}$ and $5 \mathrm{~S}$ ) show dark field HAADF images ( $Z$ - 
Table 4. Structural formulae of clay minerals in Saharan dust from TEM-AEM analysis.

\begin{tabular}{|c|c|c|c|c|c|c|c|c|c|}
\hline \multicolumn{10}{|c|}{ Illite based on $\mathrm{O}_{10}(\mathrm{OH})_{2}$} \\
\hline $\mathrm{Si}$ & $\mathrm{Al}^{\mathrm{IV}}$ & $\mathrm{Al}^{\mathrm{VI}}$ & $\mathrm{Mg}$ & $\mathrm{Fe}$ & Sum oct. ${ }^{1}$ & $\mathrm{~K}$ & $\mathrm{Ca}$ & $\mathrm{Na}$ & Sum int. ${ }^{2}$ \\
\hline $3.46 \pm 0.10$ & $0.54 \pm 0.10$ & $1.49 \pm 0.28$ & $0.20 \pm 0.01$ & $0.37 \pm 0.33$ & $2.06 \pm 0.04$ & $0.46 \pm 0.17$ & $0.06 \pm 0.08$ & $0.06 \pm 0.08$ & $0.63 \pm 0.06$ \\
\hline \multicolumn{10}{|c|}{ Palygorskite based on $\mathrm{O}_{10} \mathrm{OH}$} \\
\hline $4.08 \pm 0.17$ & & $0.63 \pm 0.25$ & $1.10 \pm 0.42$ & $0.24 \pm 0.19$ & $1.97 \pm 0.11$ & $0.04 \pm 0.04$ & $0.03 \pm 0.03$ & & \\
\hline \multicolumn{10}{|c|}{ Kaolinite based on $\mathrm{O}_{5}(\mathrm{OH})_{4}$} \\
\hline $2.01 \pm 0.02$ & & $1.91 \pm 0.08$ & $0.01 \pm 0.03$ & $0.06 \pm 0.05$ & & & $0.01 \pm 0.01$ & & \\
\hline \multicolumn{10}{|c|}{ Smectite based on $\mathrm{O}_{10}(\mathrm{OH})_{2}$} \\
\hline $3.58 \pm 0.15$ & $0.42 \pm 0.15$ & $1.54 \pm 0.20$ & $0.23 \pm 0.08$ & $0.34 \pm 0.14$ & $2.11 \pm 0.07$ & $0.14 \pm 0.05$ & $0.10 \pm 0.07$ & & $0.33 \pm 0.12$ \\
\hline \multicolumn{10}{|c|}{ Illite-smectite mixed layer based on $\mathrm{O}_{10}(\mathrm{OH})_{2}$} \\
\hline $3.46 \pm 0.29$ & $0.54 \pm 0.29$ & $1.67 \pm 0.14$ & $0.34 \pm 0.11$ & $0.19 \pm 0.08$ & $2.20 \pm 0.11$ & $0.22 \pm 0.11$ & $0.04 \pm 0.02$ & & $0.29 \pm 0.16$ \\
\hline
\end{tabular}

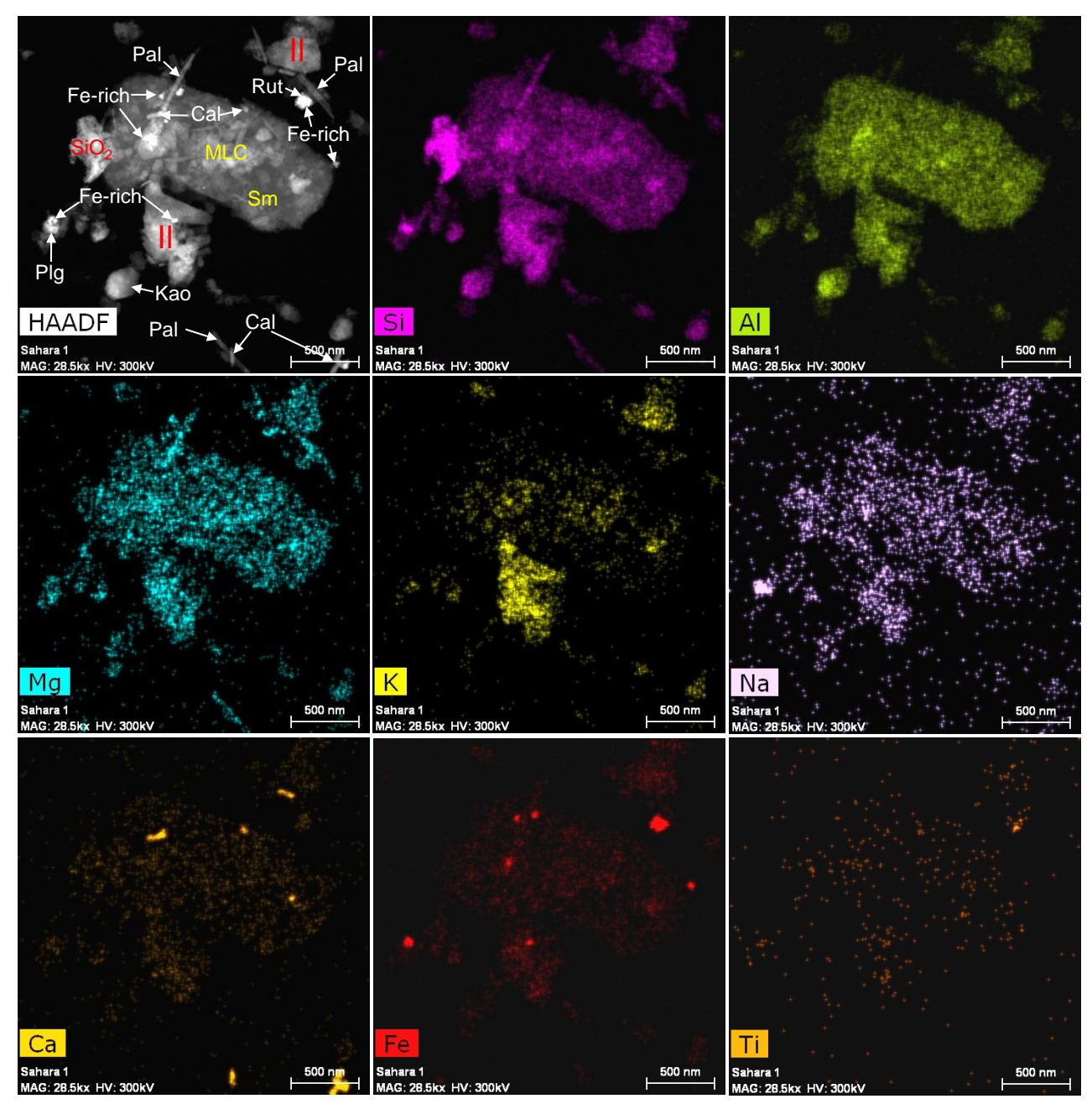

Figure 7. STEM-HAADF photomicrographs and corresponding EDX elemental maps of Saharan dust particles forming a micrometer-sized aggregate. Based on the compositional analysis, particles of palygorskite (Pal), calcite (Cal), iron oxyhydroxides (Fe-rich), rutile (Rut), illite (II), smectite ( $\mathrm{Sm})$, kaolinite (Kao), silica $\left(\mathrm{SiO}_{2}\right)$, which according to SAED results is amorphous (i.e., diatoms), plagioclase (Plg), and mixed-layer clays (MLC) were identified. 


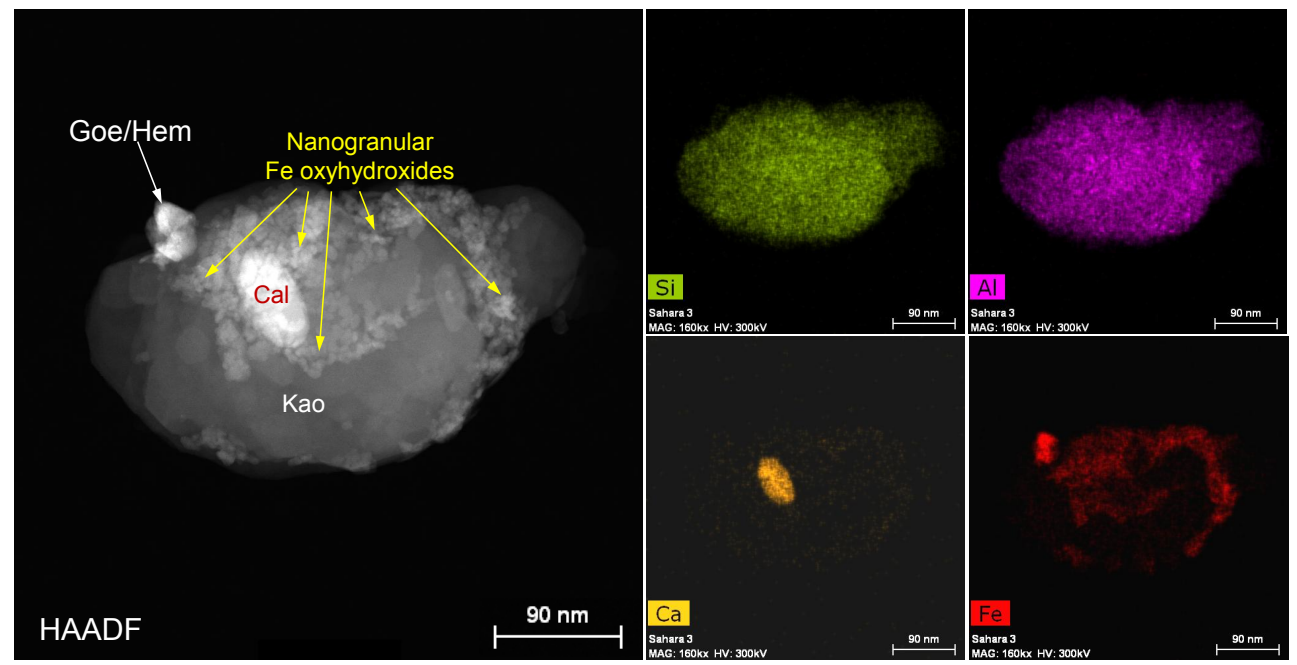

Figure 8. STEM/HAADF photomicrograph and corresponding EDX elemental maps of a kaolinite (Kao) particle internally mixed with a nearly rhombohedral-shaped goethite or hematite (Goe/Hem) crystal, a calcite (Cal) particle, and aggregates of Fe-rich nanoparticles (nanogranular Fe oxyhydroxides), likely ferrihydrite.

contrast) and corresponding elemental maps of representative aggregates and individual particles. Most abundant particles appeared as micrometer-sized aggregates made up of internally mixed silicate (quartz and amorphous silica), aluminosilicate (feldspars), carbonate (calcite), and abundant phyllosilicate particles (mainly kaolinite, illite, palygorskite, smectite, and MLC), interspersed or covered with abundant iron-rich (nano)particles as well as scarce titanium oxide (nano)particles. Note that dust aerosols can be internally or externally mixed. Internal mixing refers to aggregates formed by mineral particles of different composition, while external mixing involves different mineral particles existing separately. The internal mixing of such phases, in particular iron oxyhydroxides/clay minerals, has been previously observed using standard TEM imaging (Jeong and Achterberg, 2014; Jeong et al., 2016) as well as energy-loss TEM tomography (Deboudt et al., 2012). Most of the iron-rich particles embedded and dispersed within the micrometer-sized clayrich aggregates, as well as those covering or attached to individual clay particles, were $<100 \mathrm{~nm}$ in size (Fig. 8). The tendency of iron oxyhydroxides to concentrate in the smallest $(<100-200 \mathrm{~nm})$ size fraction, typically forming nanogranular coatings or "nanoclusters" attached to clay minerals, appears to be a general feature of Saharan dust (Lieke et al., 2011; Wagner et al., 2012; Zhang et al., 2015). Such iron oxyhydroxide nanoparticles were texturally different from the much larger individual goethite crystals (compare Figs. $6 \mathrm{f}$ and 8). These observations further suggest that these ironrich nanoparticles are amorphous or poorly crystalline ferrihydrite (Shi et al., 2009).

Interestingly, elemental maps of dust aggregates also revealed that $\mathrm{Ca}$-rich particles corresponding to calcite were commonly associated with the abundant Fe-rich nanoparti- cles and clay minerals, forming internally mixed aggregates (Figs. 7, 8, S4, S5). This contradicts the common assumption regarding calcite mixing state in Saharan dust, which is considered to be external (Shi et al., 2012). Moreover, no nitrogen enrichment (i.e., formation of calcium nitrates) (Krueger et al., 2004) or sulfur-containing phases (such as gypsum) resulting from the reaction of acid pollutant gases with carbonates were detected (Figs. 7, 8, S4, S5). This is in agreement with the above-reported very low $\mathrm{Pb}, \mathrm{V}$, and Ni concentrations, showing negligible mixing with air masses including anthropogenically derived pollutants.

\subsection{Textural features of Saharan dust: FESEM, PSD, and $\mathrm{N}_{2}$ sorption analyses}

Figure 9a-d shows representative FESEM photomicrographs of dust mineral particles. Abundant particles $\sim 3$ to $\sim 30 \mu \mathrm{m}$ in size (silt fraction) were observed. Interestingly, the larger particles (Fig. 9a) were typically ellipsoidal in shape with angular, sharp edges, all common features of coarse Saharan dust particles (Wagner et al., 2012; Jeong et al., 2016). They were made up of an aggregate of smaller, wellcemented (i.e., the aggregates were intact after sonication), micrometer-sized particles (Fig. 9b). The latter, in turn, displayed very rough surfaces made up of nanoparticle aggregates (Fig. 9c, d). EDX microanalyses showed that with the exception of some large quartz grains (showing $\mathrm{O}$ and $\mathrm{Si}$ with trace amounts of $\mathrm{Al}$ and $\mathrm{Fe}$ in the EDX spectrum), or carbonates (showing $\mathrm{O}$ plus $\mathrm{Ca}$-calcite-, or $\mathrm{Ca}$ and $\mathrm{Mg}$ dolomite-, with trace amounts of $\mathrm{Al}, \mathrm{Mg}, \mathrm{Si}$, and $\mathrm{Fe}$ in the EDX spectrum), the majority of the particles did not display a clear single-phase EDX spectrum (see inset in Fig. 9b), but included significant amounts of $\mathrm{Ca}, \mathrm{Mg}, \mathrm{Al}, \mathrm{Si}, \mathrm{K}, \mathrm{Na}$, 

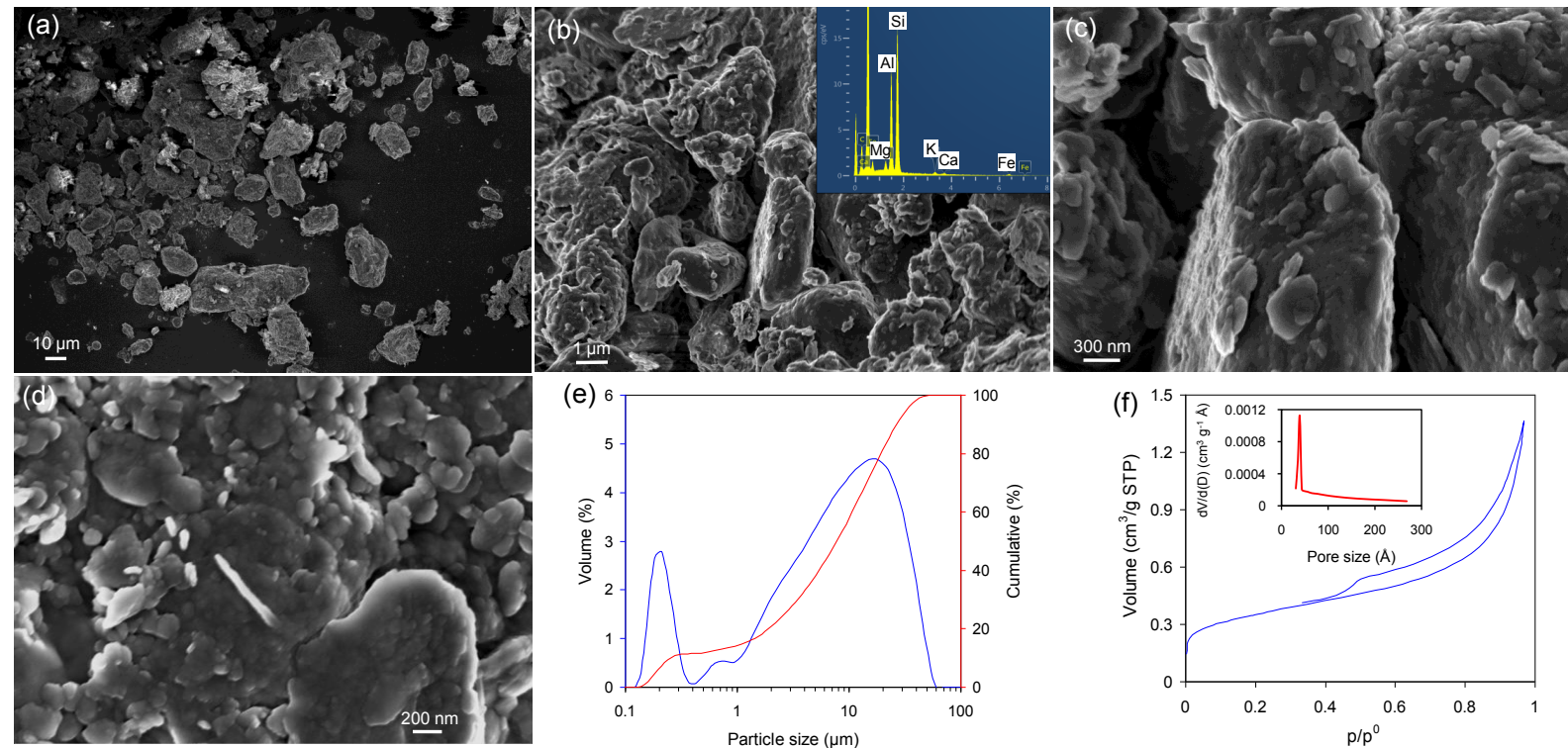

Figure 9. FESEM photomicrographs of Saharan dust particles. Large particles (a) are made up of smaller, micrometer-sized particles (b) which in turn are covered by nanoparticles (c). (d) Detail of the nanogranular surface texture of dust particles. The inset in (b) shows a representative EDX spectrum (corresponding to the particle in the center of the image) showing a high content of $\mathrm{Si}, \mathrm{Al}$, and $\mathrm{Mg}$, with small amounts of $\mathrm{K}, \mathrm{Ca}$, and $\mathrm{Fe}$. Very similar spectra are recorded for most of the areas in the sample, demonstrating that the larger particles (quartz, carbonates, and minor amounts of feldspars) are covered by clays and iron oxyhydroxide (nano)particles. (e) Particle size distribution (vol \% PSD and cumulative curves) and (f) nitrogen sorption isotherm of dust particles. The inset shows the BJH pore size distribution.

and $\mathrm{Fe}$ (and Ti). This is likely due to the contributions of clay minerals and iron oxyhydroxides (and rutile) nanoparticles that covered nearly all dust particles and aggregates (i.e., these phases were internally mixed). Surface coatings of clays and oxyhydroxides (as well as other amorphous phases) reportedly mask the identity of underlying mineral grains (Engelbrecht et al., 2016). These results suggest that great care should be taken when using SEM-EDX for the chemical analysis and/or mineralogical identification of individual desert dust particles.

Figure 9e shows the volume particle size distribution (PSD) of the Saharan dust determined by laser scattering. A polymodal PSD was observed, with a principal mode at $17 \mu \mathrm{m}$, a secondary mode at $0.2 \mu \mathrm{m}$, and additional less marked modes at 2 and $0.7 \mu \mathrm{m}$. A very similar polymodal PSD has been previously reported for Saharan dust transported during major outbreaks (D'Almeida and Schütz, 1983; Menéndez et al., 2014; Titos et al., 2017), including those involving red rains (Sala et al., 1996; Guieu et al., 2002). The samples studied had 24,75 , and 1 vol \% clay, silt, and sand content, respectively. In general, these values were in agreement with the wt $\%$ content of the different size fractions determined following hydrodynamic size separation. However, some differences were observed, especially in the case of the clay fraction (i.e., $24 \mathrm{vol} \%$ vs. $30 \mathrm{wt} \%$ ). The latter can be explained by the fact that iron oxyhydroxides, with a density $\rho$ nearly double than that of clay minerals (i.e., $\rho$ of goethite, $4.3 \mathrm{~g} \mathrm{~cm}^{-3}$, and hematite, $5.3 \mathrm{~g} \mathrm{~cm}^{-3}$, vs. $\rho$ of clay minerals, $\left.\sim 2.6-2.8 \mathrm{~g} \mathrm{~cm}^{-3}\right)$, were preferentially concentrated in the clay fraction (see the XRD and TEM results, above).

Figure 9f shows the $\mathrm{N}_{2}$ sorption isotherm of Saharan dust. It was of type IV, typical for mesoporous materials such as clay minerals, and showed a type H3 hysteresis loop (Sing et al., 1985). The latter is due to the presence of slit-shaped pores associated with aggregates of plate-like (nano)particles (Sing et al., 1985), such as the clay minerals present in the Saharan dust. The average surface area was $25 \pm 1 \mathrm{~m}^{2} \mathrm{~g}^{-1}$. The main contributors to such a relatively high surface area are the smallest particles, that is, clays (especially smectites and MLC) and iron oxyhydroxides (Elert et al., 2015). $\mathrm{N}_{2}$ sorption measurements yielded a pore volume of $0.039 \pm 0.002 \mathrm{~cm}^{3} \mathrm{~g}^{-1}$. The pore size distribution determined using the BJH method (inset in Fig. 9f) was unimodal with a maximum at $5 \mathrm{~nm}$. The presence of relatively abundant (nano)pores, an aspect of desert dust that has been typically ignored, is of relevance due to their effect on the dust's reactivity and hygroscopicity because they would strongly contribute to the exposed surface area of aggregates, making them more reactive to atmospheric processing. Such pores could also affect the dust radiative properties (Kemppinnen et al., 2015).

Combined, FESEM, PSD, and $\mathrm{N}_{2}$ sorption analyses show that although clay-sized particles constitute a significant fraction of the Saharan dust, and strongly contribute to its overall porosity and surface area, coarser particles are particularly 
abundant. For instance, 42 vol $\%$ of the dust particles were $>$ $10 \mu \mathrm{m}$ in size. Although abundant coarse and even giant particles have been reported for major Saharan dust events involving dust entrainment and transport under strong wind conditions (Jeanicke and Schütz, 1978; D'Almeida and Schütz, 1983; Coude-Gaussen et al., 1987; Goudie and Middleton, 2001; Otto et al., 2007; Weinzierl et al., 2009; Menéndez et al., 2014), most analyses of Saharan dust typically report values $<10 \mu \mathrm{m}$ (Reid et al., 2003; Lyamani et al., 2005; Mahowald et al., 2014). Note, however, that PSD analyses of Saharan dust are commonly performed using cascade impactors or optical inversion techniques (e.g., AEronet RObotic NETwork, AERONET), which either typically exclude particles with size $>10 \mu \mathrm{m}$ or underestimate their vol \% (Raiswell, 2011). Conversely, in our case, a possible bias towards larger particle sizes might occur due to the use of a laser scattering system for PSD analysis (Reid et al., 2003). However, this effect appears to be minor as demonstrated our SEM observations showing the presence of abundant particles larger than $10 \mu \mathrm{m}$ (Fig. 9a). It could be argued that the larger particles observed here may result from aggregation phenomena taking place after in-cloud and/or below-cloud scavenging during the red rain event (Mahowald et al., 2014) or during drying of the deposited red rain. Coarsening due to aggregation of Saharan dust particles scavenged within cloud droplets followed by drying prior to dry deposition has been claimed responsible for the formation of the so-called "iberulites" (Cuadros et al., 2015; Díaz-Hernández and Párraga, 2008; Díaz-Hernández and Sánchez-Navas, 2016). Iberulites are nearly spherical, clay-rich giant particles $(\sim 100 \mu \mathrm{m}$ in diameter) that are dry deposited in Spain typically during summer Saharan dust events. However, we observed no iberulite-like aggregates in our wet-deposited samples. According to Fiol et al. (2005) such giant spherical structures rapidly disaggregate upon contact with water. In contrast, the coarse and giant aggregates observed here show sharp edges (Fig. 9a), typical for airborne desert dust (Weinzierl et al., 2009), resulting from saltation-sandblasting at entrainment areas (CoudeGaussen et al., 1987; Mahowald et al., 2014). Such aggregates are strongly cemented, as demonstrated by the fact that they do not disaggregate by sonication during PSD analysis (i.e., no size reduction was observed over the course of successive PSD analysis: -3 replicas per analysis) or by sonication prior to TEM analysis. These results suggest that irreversible aggregation (i.e., coarsening) due to cloud processing during the red rain event or during drying following wet deposition is not a significant process affecting the PSD of the Saharan dust studied here. Our results showing very coarse particles (even giant ones) are consistent with the results of several studies on Saharan dust analyzed during major outbreaks in different areas. Analysis of Saharan dust both at ground stations and aloft (i.e., airborne measurements such as those of SAMUN and FENNEC aircraft campaigns), typically show similar PSD with a significant contribution of coarse and even giant particles (Weinzierl et al., 2009; Ryder et al., 2013; Titos et al., 2017). In agreement with our results, the recent lidar analysis of the extreme Saharan dust event of February 2017 shows that the Ångström exponent of the dust over Granada reached values close or equal to zero, meaning that the dust particles in this event were extremely coarse (Fernández et al., 2018).

\subsection{Dissolution tests and geochemical modeling}

It could be argued that some of the textural and structural features of the most soluble phases identified here, such as the fibrous carbonates or the amorphous/poorly crystalline ferrihydrite nanoparticles, could be the result of dissolution/reprecipitation processes undergone by the dust particles during the wet scavenging and the subsequent drying prior to sampling. Similarly, it could be argued that reprecipitation of carbonates could lead to the cementation of the aggregates, thereby playing a role in the formation of the coarse/giant aggregates identified with SEM and laser scattering PSD analyses. However, dissolution tests using MilliQ $^{\circledR}$ water with pH 5.6 (i.e., that of unpolluted rainwater) and a dust / solution mass / vol ratio equal to that of the red rain event (i.e., $18 \mathrm{~g}$ dust $/ 2 \mathrm{~L}$ rainwater) showed that the amount of calcium dissolved upon equilibration at $\mathrm{pH} 8$ was only $0.22 \mathrm{mmol}$ (Fig. S6). This value corresponds to the dissolution of $2.1 \mathrm{wt} \%$ of the total amount of calcite in the bulk dust. Such a very limited amount of dissolved calcite, which would reprecicipitate upon drying, could not have resulted in the formation of the abundant fibrous calcite observed here. In addition, such a dissolved amount represents only $0.25 \mathrm{wt} \%$ of the total mass of the bulk dust: its reprecipitation could not therefore lead to any significant cementation effect that might alter the dust particle size distribution. Reprecipitation of dissolved calcium carbonate during drying of the red rain would only lead to a very limited regrowth of existing calcite crystals (i.e., regrowth on an existing calcite crystal would by the most energetically favorable situation). Such a limited amount of dissolved calcite is consistent with our PHREEQC computer modeling results (Fig. S6 and Table S2). The amount of dissolved Ca following equilibrium (at the final $\mathrm{pH}$ of 8 ) of the different phases present in the dust (with their corresponding mass fractions determined by XRD analysis) is just $0.24 \mathrm{mmol}$. This value, representing $2.3 \mathrm{wt} \%$ dissolved calcite, is in excellent agreement with that of the dissolution experiment. In the case of the iron oxyhydroxides, PHREEQC modeling showed that in simulations considering just goethite and hematites, a negligible $3 \times 10^{-8}$ and $9 \times 10^{-9}$ wt $\%$ dissolution for the former and latter phase, respectively, took place. Conversely, with the additional presence of ferrihydrite, $0.31 \mathrm{wt} \%$ of this phase dissolved. Reprecipitation of such a very small amount of dissolved Fe cannot account for the abundant amorphous/poorly crystalline ferrihydrite nanoparticles observed using TEM. It follows that other processes have to be responsible for the 
formation of such Fe-containing nanoparticles, as we will discuss below.

Interestingly, PHREEQC modeling (Table S2) also shows that the SI values for the rest of the phases present in the dust, with the exception of K-feldspar, smectite, rutile and palygorskite, were $>0$. This means that the system was supersaturated with respect to them and, therefore, they could not undergo dissolution. In the case of K-feldspar, rutile and smectite, the calculated dissolved amount was almost negligible. However, in the case of palygorskite, the amount dissolved was $5.2 \mathrm{wt} \%$. The release of $\mathrm{Mg}$ from this clay explains why the modeled system was supersaturated with respect to dolomite (which did not dissolve). Nonetheless, this latter result has to be taken with care, because the solubility product used for PHREEQC modeling of the dissolution of palygorskite was that of the very similar (compositionally and structurally) sepiolite, which may or may not be exactly the same of palygorskite. Note that we used the solubility product of sepiolite because to the best of our knowledge, there is currently no reported value for the solubility product of palygorskite. Note also that we did not include MLC and chlorite in the PHREEQC simulations, because in the first case there is no solubility product reported for the specific composition observed here, and in the latter case, we do not have the actual structural formula for this phase. In any case, their amount in the bulk dust is very minor and should not have any significant impact in the outcome of the PHREEQC modeling.

The results discussed above refer to the dissolution of the wet-deposited dust in the limited amount of rainwater that fell during the red rain event. Deposition of the Saharan dust in a larger volume of water (e.g., seawater) would therefore result in a much larger dissolved amount of the different phases present in the dust. The latter is important when considering the biogeochemical impact of such a red rain event on inland and sea/ocean waters.

\subsection{TG-DSC and spectroscopic analyses}

TG-DSC analyses showed a first weight loss between 100 and $700{ }^{\circ} \mathrm{C}$ corresponding to the dehydration and dehydroxylation of clay minerals (Guggenheim and van Groos, 2001) (Fig. 10). A minor contribution to such a weight loss was due to the dehydroxylation of ferrihydrite and goethite, which reportedly occurs at $\sim 150$ and $\sim 280-400^{\circ} \mathrm{C}$, respectively (Jambor and Dutrizac, 1998). These dehydroxylation processes are endothermic, as shown by the endothermic broad band in the DSC trace. Organic matter also decomposes in this $T$ interval (Elert et al., 2015). The presence of organics led to a weight loss difference of $\sim 0.6-1.1 \mathrm{wt} \%$ between runs carried out in air and in inert $\mathrm{N}_{2}$ atmospheres (Fig. 10). Organic carbon undergoes oxidative combustion in air, which was reflected here by an exothermic peak at $350{ }^{\circ} \mathrm{C}$ in the DSC trace. Such an exothermic peak was absent in the run carried out in $\mathrm{N}_{2}$. Note that the above-indicated weight loss

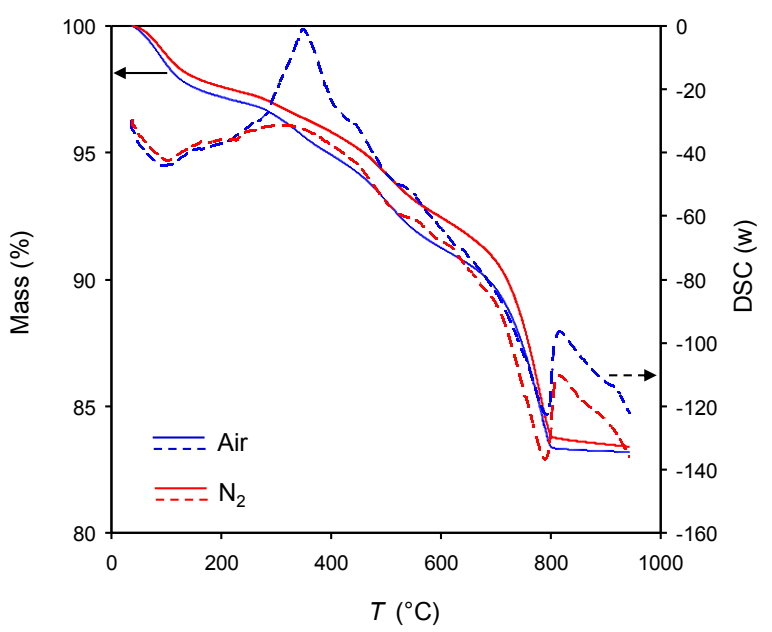

Figure 10. TG/DSC traces of Saharan dust collected in air (blue curves) and in inert $\mathrm{N}_{2}$ (red curves) atmospheres.

values only represent a fraction of the organic carbon present in the Saharan dust, because upon oxidative combustion, elemental carbon will be produced (charring effect) which we could not quantify. In any case, the values presented above are consistent with reported average value of organic carbon in Saharan dust aerosol (e.g., 1.7 wt \%: Gonçalves et al., 2014). Analysis of organic matter in desert dust has shown that the elemental plus organic carbon content is on average $<2$ wt $\%$, with a large compositional variability (Jaenicke and Schütz, 1978; Eglinton et al., 2002; Gonçalves et al., 2014). Elemental carbon is typically associated with biomass burning (Eglington et al., 2002), whereas organic carbon has been associated with more or less decomposed biological residues, including micro-organisms and microbial biofilms, as well as humic substances (Conen et al., 2011). Microorganisms and organic residues in desert dust aerosol, which tend to cover mineral grains, have been suggested to be efficient atmospheric ice nuclei, thereby having an important indirect radiative forcing effect (Conen et al., 2011).

At $T>700^{\circ} \mathrm{C}$ carbonates (first dolomite and subsequently calcite) decompose into $\mathrm{CaO}$ (or $\mathrm{CaO}+\mathrm{MgO}$ in the case of dolomite), releasing $\mathrm{CO}_{2}$ (Rodriguez-Navarro et al., 2009, 2012). This is an endothermic process, as shown by the DSC traces. By measuring the total weight loss in the 700$950{ }^{\circ} \mathrm{C}$ interval, the total amount of carbonates was calculated to be $14.7 \pm 0.2 \mathrm{wt} \%$, a value in very good agreement with the values determined by XRD (RIR) and weight loss following acid treatment.

Figure 11a shows the FTIR spectrum of the collected desert dust. The broad band centered at $\sim 3400 \mathrm{~cm}^{-1}$ corresponded to $v \mathrm{OH}$ stretching of interlayer (solvation) $\mathrm{H}_{2} \mathrm{O}$ of clay minerals, and structural water in ferrihydrite (Russell, 1979). The sharper peaks at 3693 and $3617 \mathrm{~cm}^{-1}$, and the shoulder at $3637 \mathrm{~cm}^{-1}$, corresponded to the $v \mathrm{OH}$ stretching of well-ordered (crystalline) gibbsite layers of diocta- 

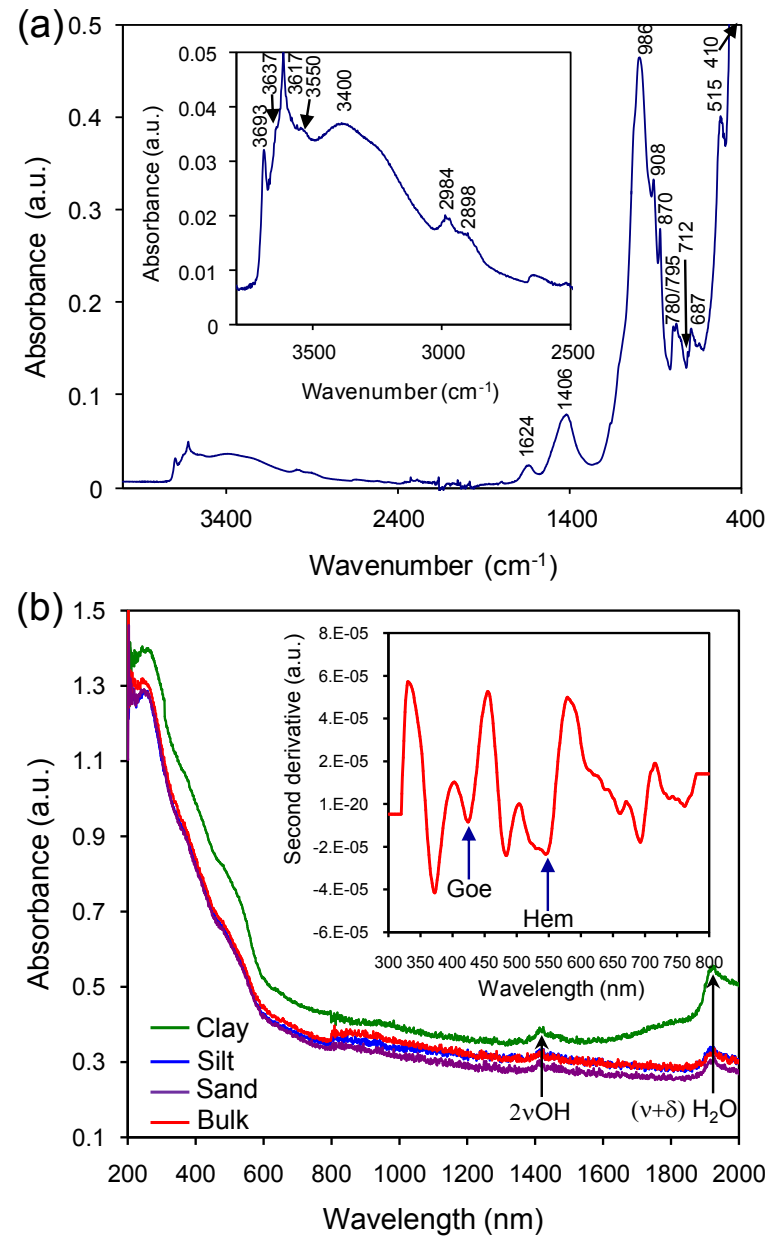

Figure 11. Spectral features of Saharan dust. (a) ATR-FTIR spectrum of dust. The inset shows absorbance values for high wavenumbers (IR spectral region with lower wavelength values: $2.6-4 \mu \mathrm{m}$ ). Wavenumbers of main absorbance bands are indicated; (b) UVVis-NIR spectra of bulk Saharan dust, and its three size fractions (clay, silt and sand).The inset shows the second derivative of the absorbance spectrum of the bulk sample. Blue arrows show the bands used for the calculation of goethite (Goe) and hematite (Hem) relative contents in the bulk sample.

hedral phyllosilicates. The three bands are characteristic of kaolinite. We could not resolve the broader smectite and illite bands at $3650-3550 \mathrm{~cm}^{-1}$. The small broad band at $3550 \mathrm{~cm}^{-1}$ corresponds to the $v \mathrm{OH}$ stretching of the brucite layer in palygorskite (inset in Fig. 11a). Note, however, that ferrihydrite also has a characteristic $v \mathrm{OH}$ stretching band at $\sim 3615 \mathrm{~cm}^{-1}$ (Russell, 1979). We could not resolve the $v \mathrm{OH}$ band of goethite at $\sim 3150 \mathrm{~cm}^{-1}$, because it was masked by the broad $\mathrm{OH}$ band of clay minerals. However, the bands corresponding to the $\delta \mathrm{OH}$ in-plane deformation at $870 \mathrm{~cm}^{-1}$ and the $\gamma \mathrm{OH}$ at $780 \mathrm{~cm}^{-1}$ (Schwertmann et al., 1985) were observed, confirming the presence of this iron oxyhydroxide. Note, however, that the band at $870 \mathrm{~cm}^{-1}$ can also have the contribution of the $v_{2}$ out-of-plane vibration of $\mathrm{CO}_{3}^{2-}$ groups in calcite and dolomite. The small bands at 2898 and $2984 \mathrm{~cm}^{-1}$ corresponded to the C-H stretching of organic matter, thereby confirming the TG results showing the presence of organics in the Saharan dust. However, the lack of other well-defined bands precluded an unambiguous identification of the specific organic compounds in the dust. Nonetheless, the presence of a band at $1624 \mathrm{~cm}^{-1}$, which can be ascribed to both $\delta \mathrm{OH}$ bending (which should be centered at $1644 \mathrm{~cm}^{-1}$ ) and $\mathrm{COO}^{-}$symmetric stretching, points to the presence of carbohydrates (e.g., polysaccharides) with carboxylic functional groups. The latter would be consistent with the presence of microbial exopolymeric substances and/or humic substances (Conen et al., 2011). The broad band at $1406 \mathrm{~cm}^{-1}$ corresponded to the $v_{3}$ anti-symmetric stretching of $\mathrm{CO}_{3}^{2-}$ groups in both calcite and dolomite. The presence of calcite was confirmed by the very small $v_{4}$ bending band of $\mathrm{CO}_{3}^{2-}$ groups at $712 \mathrm{~cm}^{-1}$. The strong band at $986 \mathrm{~cm}^{-1}$ and the shoulder at $1030 \mathrm{~cm}^{-1}$ corresponded to the $\mathrm{Si}-\mathrm{O}$ stretching of phyllosilicates, while the shoulder at $1090 \mathrm{~cm}^{-1}$ corresponded to the $\mathrm{Si}-\mathrm{O}$ stretching of quartz. The small peak at $908 \mathrm{~cm}^{-1}$ corresponded to the Al-OH deformation of kaolinite. The doublet at 780 and $795 \mathrm{~cm}^{-1}$ corresponded to the $\mathrm{Si}-\mathrm{O}$ bending of quartz (note that these latter bands overlap with those of goethite). The strong band at $515 \mathrm{~cm}^{-1}$ corresponded to the Al-O-Si deformation in illite and smectites (Di Biagio et al., 2014). Finally, the very strong band at $\sim 410 \mathrm{~cm}^{-1}$ corresponded to the $\mathrm{FeO}_{6}$ lattice mode of iron oxyhydroxides, including goethite, hematite, and ferrihydrite.

The results of the FTIR analysis confirm the presence of the different mineral phases identified using XRD and TEMAEM, as well as the presence of organic matter. They also show that this type of dust aerosol possesses strong longwave absorption, especially at thermal IR $(6-24 \mu \mathrm{m})$ due to the abundant silicate, aluminosilicate and carbonate phases, along with minor iron oxyhydroxides. Absorption of IR radiation by desert dust has a direct positive (warming) radiative forcing and, most importantly, it does not only operate during the day, as in the case of solar radiation, but also at night due to (terrestrial) thermal emission (Di Biaggio et al., 2014).

Figure 11b shows the UV-Vis-NIR absorption spectra of the bulk dust and its three size fractions. In all cases, a strong increase in absorption at $\lambda<600 \mathrm{~nm}$ was observed, and the absorbance was systematically higher for the clay fraction. The observed increase in the absorbance of the $\mathrm{OH}$ stretching overtone $(1412 \mathrm{~nm})$ and the combination band of $\mathrm{H}_{2} \mathrm{O}(1920 \mathrm{~nm})$ of the clay fraction (Gionis et al., 2006), compared to those of the coarser fractions, are consistent with the higher amount of clay minerals and iron oxyhydroxides in this finer fraction, both being responsible for the systematically higher shortwave absorbance. Remarkably, retrieved spectra $(\lambda<1 \mu \mathrm{m})$ of the imaginary part of the complex refractive index, $k$, for several Saharan dust samples 
(Wagner et al., 2012) show strong similarities to the UV-VisNIR spectra shown here.

The UV-Vis-NIR spectra of the studied samples are standard for Saharan dust and have been associated with the presence of iron oxides, mainly goethite and hematite (Wagner et al., 2012; Formenti et al., 2014b). These oxides show a remarkable increase in $k$ values at $\lambda<600 \mathrm{~nm}$ due to strong absorption associated with ligand-to-metal (i.e., O-to$\mathrm{Fe}$ ) charge transfer transitions (Sherman and Waite, 1985). This is also the case for rutile, which has values of $k$ for UV radiation on the same order of magnitude of hematite (Utry et al., 2015), and should also contribute to the absorption spectra reported here. Note, however, that iron in the structure of clay minerals also contributes to the absorption of shortwave solar radiation because such octahedrally coordinated $\mathrm{Fe}^{3+}$ can also experience charge transfer transitions. UV-Vis spectroscopic analyses of clays such as illite, kaolinite, palygorskite, and smectites, with Fe contents very similar to those of the corresponding clays studied here, show strong absorption at $\lambda<600 \mathrm{~nm}$ due to oxo-to-iron (III) charge transfer (Karickhoff and Bailey, 1973).

From the second derivative of the UV-Vis spectrum (inset in Fig. 11b), the contents of goethite and hematite were calculated to be $49 \pm 1 \%$ and $51 \pm 1 \%$, respectively. Our XRD results showed a higher goethite content of $\sim 77 \mathrm{wt} \%$. We consider, however, the UV spectroscopy results more reliable, due to the relatively high error associated with the semiquantitative XRD analysis. The goethite content calculated using the second derivative of the UV-Vis spectrum is consistent with but slightly lower than the contents reported by Formenti et al. (2014b) for Saharan dust. The authors found goethite contents ranging from $52 \mathrm{up}$ to $78 \mathrm{wt} \%$. This discrepancy might likely be due to differences in the dust source areas. Note that an accurate evaluation of the content of these two oxyhydroxides is of outmost importance when determining the direct radiative effect of desert dust, because the optical properties and, particularly, $k$ values of hematite and goethite differ significantly, the former phase showing stronger absorption at short wavelengths (Zhang et al., 2015).

\subsection{Iron significance: bioavailability}

Iron in desert dust is a key player in a range of global biogeochemical processes. Iron is an essential micronutrient for all organisms, but is typically depleted in some inland water bodies, such as oligotrophic lakes (Vrede and Tranvik, 2006), and a large portion of open ocean waters (Jickells et al., 2005). Desert dust can supply iron to such areas, especially open ocean waters, enabling the proliferation of a range of microorganisms (e.g., phytoplankton) and the sequestration of $\mathrm{CO}_{2}$ as biomass, thereby directly affecting primary production and indirectly influencing climate (Jickells et al., 2005). However, for its bioavailability, iron must be soluble or at least in a colloidal, poorly crystalline nanosized state, which has been defined as filterable or soluble iron, which passes through a 0.2 or $0.4 \mu \mathrm{m}$ filter (see the review by Raiswell and Canfield, 2012). But iron in desert dust minerals is typically insoluble (Shi et al., 2009). Three types of iron in desert dust have been defined (Shi et al., 2012): (i) amorphous or poorly crystalline iron oxyhydroxides (e.g., ferrihydrite), which form the most soluble iron fraction in desert dust; (ii) crystalline iron oxyhydroxides (goethite, hematite, and magnetite) that are highly insoluble. These two groups form the so-called free iron; and (iii) structural iron, which is incorporated into the crystalline structure of aluminosilicates, mainly in clay minerals, and which is also insoluble. Remarkably, the amount of soluble Fe in desert dust, expressed as the fractional iron solubility, FFS (i.e., fraction of soluble iron vs. total iron), typically increases during longrange transport from values $\sim 0.1 \%$ to up to $\sim 80 \%$ (Journet et al., 2008; Mahowald et al., 2009; Shi et al., 2012). It has been proposed that this is due to (i) mixing with anthropogenic (Sholkovitz et al., 2009, 2013) and/or biomass (Guieu et al., 2005; Paris et al., 2010) combustion aerosol with higher solubility than mineral dust (Mahowald et al., 2009); (ii) physical size sorting due to preferential deposition of the larger particles during transport, thereby increasing the relative amount of smaller particles with a higher surface-to-volume ratio and enhanced Fe solubility (Baker and Jickells, 2006). Note, however, that recent research has shown that size sorting has a very minor effect (if any) on $\mathrm{Fe}$ solubility (Shi et al., 2011b); and (iii) various atmospheric processes including photoreduction (which according to Zhu et al. (1999) has only a minor effect), organic-mediated complexation (Paris and Desboeufs, 2013), and chemical (acid) in-cloud and/or aerosol processing (Shi et al., 2009, 2012). Such an atmospheric processing, as well as the ultimate fate of iron once desert dust is deposited in distant locations, is strongly linked to where and how iron is incorporated into different desert dust minerals with different structure, solubility, crystallinity, and particle size. However, as pointed out by Raiswell and Canfield (2012), few studies of aeolian dust contain any detailed characterization of the iron mineralogy.

Our XRD results showed the presence of $1.41 \mathrm{wt} \%$ free $\mathrm{Fe}$ in crystalline iron oxyhydroxides (goethite and hematite). Our AEM analysis of individual clay minerals showed that structural $\mathrm{Fe}$ was also abundant in the Saharan dust particles. Considering the average $\mathrm{Fe}$ content in the different clay minerals identified here (Table 4) and their fractional content in the bulk sample (Table 2), the structural iron in the clay minerals amounts to $1.98 \mathrm{wt} \% \mathrm{Fe}$, that is, $55.6 \%$ of the average total $\mathrm{Fe}$ (see Table S3 for details regarding the calculation of structural $\mathrm{Fe}$ ). This yields a total (free + structural) iron content of $3.39 \mathrm{wt} \%$. This value is lower than the average total iron content of $3.56 \mathrm{wt} \%$ determined by ICP-OES (3.43 wt \%) and XRF (3.69 wt \%) analyses (see Table 3). It could be argued that the missing $\mathrm{Fe}(0.17 \mathrm{wt} \%)$ is incorporated in other silicates such as feldspars. However, the amount of Fe in such phases is either very low or negligible. If we consider the values of $0.13-0.54 \mathrm{wt} \% \mathrm{Fe}$ in feldspars 
reported by Journet et al. (2008) and the fractional content of feldspars (0.13) in our dust samples, this yields 0.01$0.07 \mathrm{wt} \%$ structural $\mathrm{Fe}$ in such tectosilicates. These values cannot account for the missing iron. It could also be argued that the missing iron is in the carbonates. However our AEM analyses of carbonate phases showed no Fe (Fig. S7). It follows that the missing (free) iron has to be incorporated in the amorphous and/or poorly crystalline ferrihydrite detected using TEM-SEAD, which cannot be quantified as free iron by XRD because this latter technique does not identify amorphous phases. The amorphous and/or poorly crystalline ferrihydrite would thus amount to an average of $11 \%$ of the free iron (i.e., $4.9 \%$ of the total iron). If we consider the lowest and highest values of total iron determined by ICPOES and FRX analyses, then we obtain that the amount of amorphous and/or poorly crystalline ferrihydrite can range between 2.9 and $18.5 \%$ of the free iron (i.e., $1.3-8.2 \%$ of the total iron). It should be noted that these values, calculated based on the amount of iron in each $\mathrm{Fe}$-containing phase determined by XRD and the Fe content in clay minerals determined from TEM-AEM analyses, are subjected to significant uncertainty. Therefore, the amount of structural and free iron, including the amount of amorphous and/or poorly crystalline $\mathrm{Fe}$-oxyhydroxides (ferrihydrite) presented above are not intended to be purely quantitative results, but a (rough) estimate of the Fe speciation in the studied dust. Nonetheless, these results confirm TEM observations showing that the amount of nanosized amorphous and/or poorly crystalline ferrihydrite is not negligible.

Interestingly, leaching experiments using a small dust / solution mass / vol ratio, as it is commonly done in studies on dust aerosol $\mathrm{Fe}$ solubility (e.g., Journet et al., 2008; Buck et al., 2010; Shi et al., 2011a, 2012) showed that in the case of MilliQ ${ }^{\circledR}$ water (pH5.6) and an ammonium acetate buffer solution $(\mathrm{pH} 4.7)$ the values of FFSs were $22.7 \pm 1.1 \%$ and $17.9 \pm 0.9 \%$, respectively (i.e., average value of $\sim 20 \%$ ). These values are a factor of two larger than the highest value for amorphous and/or poorly crystalline ferrihydrite presented above. This could either means that our calculation of the amount of amourphous and/or poorly crystalline ferrihydrite was too conservative, or that there is another source for soluble $\mathrm{Fe}$ of, at least, a similar magnitude than that of nanosized ferrihydrite. The latter is the most likely case, being clays the most likely source of such a soluble Fe (Journet et al., 2008).

The amount of structural $\mathrm{Fe}$ in our studied dust is consistent with, although slightly higher than the values of $\sim 40$ $50 \%$ commonly reported for Saharan dust (Formenti et al., $2011,2014 a, b)$. Structural iron in clays has been proposed as an important potential source of bioavailabable Fe (Journet et al., 2008; Formenti et al., 2014a). In dioctahedral clays, such as illite and kaolinite, as well as montmorillonite and MLC, iron is present in the octahedral layer as $\mathrm{Fe}^{3+}$, alone or in association with minor amounts of $\mathrm{Fe}^{2+}$ (Weaver and Pollard, 1973; Mestdagh et al., 1980; Johnston and Cardile,
1987). In the case of palygorskite, which has a mixed di- and trioctahedral character, $\mathrm{Mg}^{2+}$ in the octahedral layer can be substituted by both $\mathrm{Fe}^{2+}$ and $\mathrm{Fe}^{3+}$ (Gionis et al., 2006). In trioctahedral chlorite iron is incorporated as $\mathrm{Fe}^{2+}$ substituting $\mathrm{Mg}^{2+}$ in octahedral positions both in the $2: 1$ structural unit and in the interlayer brucite layers (Weaver and Pollard, 1973). Interestingly, Cwiertny et al. (2008) observed a correlation between $\mathrm{Fe}^{2+}$ content in aluminosilicates and increased FFS after acid processing of desert dust, and Schroth et al. (2009) concluded that $\mathrm{Fe}^{2+}$-bearing silicates are more soluble than iron oxyhydroxides, being the former an important source of bioavailable soluble iron. In addition to the effect that $\mathrm{Fe}^{2+}$ may have on the potential solubility of structural iron, a significant amount of our studied clay particles with relatively high Fe content were $<100 \mathrm{~nm}$ in size, which makes them significantly more soluble than larger particles (Raiswell and Canfield, 2012). These compositional and size effects may favor the release of soluble structural iron upon atmospheric processing, and/or post-atmospheric processing once the dust particles are deposited in the ocean or in inland water bodies. Overall, it is very likely that the relatively high FFS (i.e., $\sim 20 \%$ ) of the Saharan dust determined by our leaching tests is not only related to the presence of soluble nanosized $\mathrm{Fe}$-oxyhydroxides (i.e., amorphous and/or poorly crystalline ferrihydrite), but also to the presence of Fe-containing clays, which are considered as an important contributor to the pool of soluble Fe (Journet et al., 2008; Cwiertny et al., 2008).

In agreement with previous studies, the free iron in our samples is mainly present as hematite and goethite (Lázaro et al., 2008; Shi et al., 2012; Formenti et al., 2014b). However, we detected a significant amount of amorphous/poorly crystalline ferrihydrite with a calculated upper bound of $8.2 \%$ of the total iron, which is in very good agreement with the upper bound value of $7.4 \%$ reported by Shi et al. (2011b) for Saharan soils. These values are, however, markedly smaller than the ferrihydrite content of $\sim 71 \%$ reported by Schroth et al. (2009) for northern African dust deposited on a buoy in the northeastern Atlantic Ocean. The existence of such a huge concentration of ferrihydrite in Saharan dust has been, however, questioned by Shi et al. (2011b) and Raiswell and Canfield (2012) on the basis that the quantification of such an amorphous or poorly crystalline phase is difficult. The authors also state that the very low FFS $(<1 \%)$ reported by Schroth et al. (2009) is not consistent with such a huge amount of ferrihydrite, because experimental evidence shows that ferrihydrite nanoparticles are significantly more soluble than clay minerals and/or crystalline goethite or hematite. Shi et al. (2012) conclude that ferrihydrite nanoparticles, such as those identified here, are the most likely source of soluble and bioavailable Fe in desert dust. How, where, and when such Fe-rich nanoparticles are formed has been a matter of intensive research and discussion. Two not mutually exclusive possibilities have been considered: (i) iron-rich nanoparticles are already present in the dust source region, 
and are formed due to (limited) weathering of crystalline iron-containing phases such as clays (see above) and/or iron oxyhydroxides (goethite and hematite) (Shi et al., 2011b; Raiswell, 2011), and/or (ii) they are formed during dust transport via atmospheric processing (Shi et al., 2012).

With a few exceptions (e.g., Shi et al., 2011b), the presence of amorphous or poorly crystalline iron oxyhydroxides such as ferrihydrite in Saharan dust source regions has been overlooked (e.g., Lafon et al., 2006; Debout et al., 2012; Formenti et al., 2014b). It is considered unlikely that metastable ferrihydrite could survive in the source region without rapidly transforming into more stable goethite or hematite (Shi et al., 2012). Nonetheless, ferrihydrite has been shown to remain untransformed for a few hundred days at STP conditions (Raiswell and Canfield, 2012), and silica, clay minerals, and a range of organic substances (all present in Saharan soils and dust) reportedly contribute to its stabilization (Jambor and Dutrizac, 1998). It is thus very likely that the amorphous iron oxyhydroxide and/or poorly crystalline ferrihydrite nanoparticles in our dust samples were already present in the entrained soil. Indeed, dissolution of iron-containing clay minerals following intermittent exposure to aqueous solutions during, for instance, rain events, fluvial transport and/or flooding in (ephemeral) lake waters, is a plausible mechanism for the formation of iron-rich nanoparticles (ferrihydrite) in the dust source areas (Shi et al., 2011b; Canfield and Raiswell, 2012). This is consistent with results by Poulton and Raiswell (2005) showing that clay minerals in natural riverine environments commonly are associated with iron-rich nanoparticles.

Regarding the second hypothesis for the formation of iron-rich nanoparticles in Saharan dust, numerous field and laboratory studies have shown that atmospheric processing strongly contributes to the formation of soluble iron (Shi et al., 2012). Shi et al. (2009) showed that Saharan dust wet deposited in the western Mediterranean included highly soluble, bioavailable, and poorly crystalline nanosized two-line ferrihydrite, which contained trace concentrations of $\mathrm{Al}, \mathrm{Cr}$, $\mathrm{Si}$ and $\mathrm{Ca}$. The latter might indicate formation by atmospheric processing of clay minerals. The authors found no such nanosized ferrihydrite in Saharan dust dry deposited in the eastern Mediterranean (collected during a different event and presumably coming from a different source area). Parallel experiments using Saharan soils and pure synthetic goethite confirmed that precipitation of nanosized ferrihydrite occurs after acid leaching, favored during (partial) drying and formation of wet mineral aerosols, and subsequent $\mathrm{pH}$ increase during simulated in-cloud processing (Shi et al., 2009, 2012). These observations might suggest that acid cloud processing during wet deposition led to the formation of iron rich nanoparticles. However, the lack of spatial and temporal relationship between the wet and dry deposition events studied by Shi et al. (2009) precludes drawing any final conclusion regarding whether the iron nanoparticles were already present in the entrained desert dust prior to wet deposition or were the result of atmospheric processing. In any case, a prerequisite for in-cloud and aerosol acid processing of iron-containing phases is the interaction with acid pollutant gases (e.g., $\mathrm{SO}_{2}$ and $\mathrm{NO}_{x}$ ), and the absence of carbonates or their external mixing. Ito and Feng (2010) underlined that internally mixed carbonates will buffer atmospheric acid-processing of iron-containing phases, thereby strongly limiting the formation of potentially bioavailable, poorly crystalline or amorphous iron phases. Our HAADF analyses (Figs. 7, 8) clearly show that carbonates were internally mixed with iron oxyhydroxide nanoparticles and were not affected by acid dissolution. Moreover, we detected no sulfate by-products such as gypsum or (calcium) nitrates. It follows that the iron-rich nanoparticles in the Saharan dust deposited during the studied red rain event must have already been present in the source areas. This is an important result when considering the bioavailability of Fe in Saharan dust. It shows that a significant fraction of $\mathrm{Fe}$ in Saharan dust is already present in the source region as potentially bioavailable nanosized amorphous and/or poorly crystalline iron oxyhydroxides (Shi et al., 2011b). It also shows that the presence of acid gases and their associated atmospheric acidprocessing of iron-phases is not absolutely necessary to have nanosized, more soluble and potentially more bioavailable Fe-rich phases in desert dust. Our results suggest that the importance of such anthropogenic acid gases in enabling the delivery of soluble and bioavailable $\mathrm{Fe}$ in desert dust to open oceans, and their subsequent impact on $\mathrm{CO}_{2}$ drawdown $(\mathrm{Li}$ et al., 2012) might be overestimated.

Another important aspect to consider regarding the bioavailability of iron-containing phases is their interaction with organic compounds such as carboxylic acids, or more complex molecules having different functional groups. They can complex Fe, facilitating the dissolution of ironcontaining phases (especially clay minerals) and its bioavailablity (see review by Shi et al., 2012), as demonstrated for the case of several organic acids, such as oxalic and humic acids (Paris and Desboeufs, 2013). Our TG/DSC and FTIR results showed the presence of organic carbon. It is however not clear what role such organic carbon played in the possible processing of iron oxyhydroxides during Saharan dust transport and scavenging. We can only hypothesize that the presence of abundant functional groups (e.g., carboxylic groups) in such organics could enable the complexation of $\mathrm{Fe}$ and facilitate its bioavailability.

Finally, it should be pointed out that the FFS of the studied Saharan dust $(\sim 20 \%)$ is in the same range as (or even higher than) the FFS reported for aerosol deposited in the Mediterranean (10-11\%), tropical North Atlantic (3-35\%), and Barbados (6\%) (data compiled in Fan et al., 2006). Note, however, that in most cases reported in the literature, anthropogenic inputs and/or atmospheric processing likely contributed to the measured FFS. Aerosol samples collected in the tropical North Atlantic directly associated with air masses arriving from northern Africa and with no anthropogenic 
mixing have FFS values of only $0.4-2 \%$ (Sholkovitz et al. 2009), although higher values of 3-17\% have also been reported (Buck et al., 2010). In our case, mixing with anthropogenic combustion aerosols or atmospheric acid processing is ruled out. The high FFS of our samples, very similar to the upper bound reported by Buck et al. (2010), is mainly due to the structural/textural, compositional, and mineralogical features of the dust present in the source areas activated during this extreme event. Due to the magnitude of the event, and the relatively high FFS of the Saharan dust, the biogeochemical impact of its deposition in inland waters as well as in the Mediterranean and North Atlantic waters affected by the event could have been very significant.

\subsection{Effects of mineralogy, mixing state, and PSD on dust direct radiative forcing}

Scattering and absorption of incoming solar (shortwave) and outgoing thermal (longwave) radiation by desert dust aerosol have a cooling effect at land surface and a warming effect at tropospheric levels (Carlson and Benjamin, 1980; Alpert et al., 1998). However, the magnitude and even the sign of the direct radiative forcing are not well constrained. While some researchers consider that the net radiative forcing of mineral dust on the climate system is negative (Gieré and Querol 2010; Allen et al., 2016), others report that under specific scenarios the direct forcing can be positive (Carlson and Benjamin, 1980), leading to regional (Overpeck et al., 1996) or even global warming (Kok et al., 2017). The uncertainties regarding the sign and magnitude of the direct radiative forcing of desert dust are rooted in the fact that they depend on many poorly constrained factors such as: (i) the characteristics of mineral dust (concentration, vertical distribution, PSD, shape, internal/external mixing, and composition/mineralogy) and (ii) external variables such as surface albedo below dust plumes, temperature at ground level, and presence/absence of clouds (Balkanski et al., 2007; Kemppinen et al., 2015). Composition/mineralogy and particle size, as well as mixing state, appear to be the most critical factors controlling dust direct radiative forcing (Zhang et al., 2015).

Regarding composition/mineralogy, iron-containing phases play a key role in the absorption and scattering of solar and terrestrial radiation (Tegen and Lacis, 1996; Sokolik and Toon, 1999; Zhang et al., 2015). However, most models for the direct radiative forcing of desert dust typically only consider the presence of hematite (e.g., Balkanski et al., 2007; Wagner et al., 2012). Our results, as well as those of others (e.g., Formenti et al., 2014b; Zhang et al., 2015), show that this is an oversimplification that may have an important impact on the outcome of such models, because in addition to hematite, goethite and iron oxyhydroxide nanoparticles (ferrihydrite) are also present in significant amounts in Saharan dust. In addition, their actual mixing state is another important aspect of desert dust that has been generally overlooked in climate models. While an external mixing of (alumino)silicates and iron oxyhydroxide particles in proportions typically found in desert dust has a net negative radiative forcing, their internal mixing can lead to a net positive radiative forcing due to a change in the effective refractive index resulting in enhanced absorption (Sokolik and Toon, 1999). The latter situation is the one observed here: iron oxyhydroxides, generally forming nanosized aggregates and concentrated in the clay fraction, are internally mixed with carbonate, silicate, and aluminosilicate particles (SEM and TEM results). This appears to be a general feature of Saharan (Deboudt et al., 2012; Wagner et al., 2012; Jeong et al., 2016) and Asian (Jeong and Achterberg, 2014) desert dust. We observed that iron oxyhydroxides are the main contributors to the strong absorption of UV-Vis radiation regardless of size fraction (Fig. 11), which is consistent with our electron microscopy observations showing aggregates of iron-containing nanoparticles closely cemented with clay minerals, and covering (i.e., internal mixing) larger silt- and sand-sized particles (Figs. 6-8). Note, however, that clay minerals containing structural iron can also contribute to the absorption of shortwave solar radiation as indicated above. A few models consider the light absorption behavior of illite alone or internally mixed with iron oxyhydroxides, showing that illite actually displays relatively strong shortwave absorption (Zhang et al., 2015). However, no model has ever considered the effect that structural iron has on the absorption properties of other typical clay minerals present in desert dust, such as smectites, kaolinite, palygorskite, chlorite, and MLC. It should be noted that the combined effect of clay minerals and iron oxyhydroxides is actually responsible for the shortwave radiative effects of the studied Saharan dust. The longwave radiative effect, basically absorption of thermal radiation, is mainly associated with silicate and aluminosilicate phases (including clay minerals) as well as carbonate phases. It could be argued that the combined shortwave and longwave scattering/absorption of internally mixed clay minerals/iron oxyhydroxides/(alumino)silicates or carbonates will be the relevant and overall radiative effect of the Saharan dust. According to Sokolic and Toon (1999), such an internal mixing would likely have a net positive direct radiative forcing under specific circumstances (i.e., surface albedo, dust load, vertical distribution, and surface $T)$.

In addition to these compositional/mineralogical and mixing effects on dust radiative forcing, another critical aspect to be considered is the PDS of desert dust. Smaller particles (i.e., clay fraction) are more effective in scattering solar radiation than larger ones. The latter, in turn, are more effective in absorbing energy (solar and thermal) (Tegen, 2003; Otto et al., 2007). Most models of dust radiative forcing typically consider the smallest particles only (geometric diameter $<10 \mu \mathrm{m}$ ) (Tegen and Lacis, 1996; Tegen, 2003). Such small sizes, however, do not represent the actual size of dust particles in major dust events, which in turn are the 
ones that most significantly contribute to entrain and transport desert mineral dust (Skonieczny et al., 2011; Mahowald et al., 2014; Kok et al., 2017). Indeed, one of the causes of uncertainty in climate models is that the size distribution of dust particles is poorly constrained and typically the amount of smaller particles is overestimated (Kok, 2011). Although large $(>10 \mu \mathrm{m})$ particles have been considered to settle by gravitational forces within hours after entrainment (Tegen, 2003), experimental evidence shows that large, and even giant particles with size $>50 \mu \mathrm{m}$, can be transported for days over distances of several thousands of km (Pitty, 1968; Franzén, 1989; Betzer et al., 1988). Experimental observations have also shown that during intense dust events a significant amount of large particles $(>30 \mu \mathrm{m})$ are transported for more than $12 \mathrm{~h}$ (Ryder et al., 2013), and fast gravitational settling seems to be prevented by atmospheric processes involving upward air movement due to solar heating of the dust and/or intermittent turbulence (Maring et al., 2003). Underestimating the contribution of large, long-range transported desert dust particles (geometric diameter $>10 \mu \mathrm{m}$ ), has a direct impact in the outcome of radiative forcing models as well as in the estimation of global dust emissions (Kok, 2011). Models would overestimate cooling by fine particles due to their scattering of solar radiation, neglecting the fact that coarser particles can induce a net warming by absorbing both solar and thermal radiation (Otto et al., 2007; Kok et al., 2017). Also, most global circulation models are tuned to match radiative measurements, so that an overestimation of the radiative cooling induced by clay-sized particles will be compensated by a reduction in the modeled quantity of emitted dust (Kok, 2011). Recent modeling results indicate that a positive direct radiative forcing at the top-of-the-atmosphere (TOA), leading to global warming, can be achieved when realistically considering the amount of very coarse (geometric diameter $>10 \mu \mathrm{m}$ ) mineral dust particles (Kok et al., 2017), which are quite abundant close to source areas and, as shown by our results, can reach far downwind regions during extreme dust events. It is thus very likely that coarse desert dust would have a net positive radiative forcing close to source areas and over continental land. Although the residence time of such larger particles is only a few tens of hours, their persistent emission and transport may have a significant radiative effect not only locally or regionally, but also globally. This is particularly relevant under a global warming scenario resulting in increased desert dust strength as predicted by recent modeling results (Kok et al., 2018).

It could be argued that the studied extreme Saharan dust event is a rare one, whose time span is limited and, therefore, its impact on the direct radiative forcing should be also limited. However, these extreme events are recurrent, and typically take place in southern Europe and the Mediterranean area on a yearly basis (e.g., Avila et el., 2007; Cabello et al., 2012; Titos et al., 2017). This suggests that extreme dust events can have an impact on the atmospheric radiative budget regionally and, in the long term, even globally.

\subsection{Health hazard}

Most studies on the impact of Saharan mineral dust on human health have focused on its short-term effects. In particular, a positive relationship between hospital incidences and mortality, and desert dust outbreaks have been established, especially for the case of $\mathrm{PM}_{10}$ (Perez et al., 2008). Nevertheless, both a negative and a positive correlation between desert dust $\mathrm{PM}_{10}$ and mortality has been established (Karanasiou et al., 2012; Zhang et al., 2016). However, although there is a current lack of detailed knowledge, recent research shows that there is a clear positive correlation between exposure to natural mineral dust $\mathrm{PM}_{2.5}$ and human mortality associated with respiratory and cardiovascular health issues (Zhang et al., 2016). Modeling of the impact of dust $\mathrm{PM}_{2.5}$ estimates that the global fraction of cardiopulmonary deaths caused by desert dust aerosols is $\sim 1.8 \%$, this value being $\sim 15-50 \%$ in countries of the so-called "dust belt" (Giannadaki et al., 2014). These studies suggest that the clay fraction of desert dust can be the one that has the most deleterious effects in the short term.

Little is known, however, about the long-term health effects of desert dust exposure and inhalation. This could be the case of the potential fibrogenic and carcinogenic risk of such inhalable mineral particles. Such a potential long-term health effect of desert dust has been, however, generally ignored. One exception is the study by Giannadaki et al. (2014) who found a link between cardiovascular and lung cancer death with desert dust $\mathrm{PM}_{2.5}$. Nonetheless, the authors ignored the role of larger particles and the actual mineralogy of dust was not taken into account for health-risk evaluation. Overall, the role of specific minerals in desert dust, particularly the abundant clay minerals, and among them, the fibrous clays, was not considered. Moreover, the possible link between such potentially carcinogenic fibrous minerals and $\mathrm{Fe}$, an element which has been associated with increased risk for cancer development following exposure to fibrous minerals due to its capacity to generate free radicals via the Fenton reaction (Nolan et al., 1991; Ghio et al., 2004), was not evaluated.

Several studies have focused on the evaluation of the potential health risk of clay minerals and associated phases present in dust (Plumlee et al., 2006). For instance, kaolinite has been reported to be a potential respiratory hazard. However, quartz, typically associated with clay minerals such as kaolinite, seems to play an overruling role in the respiratory illnesses associated with clay dust inhalation (Carretero et al., 2006). Indeed, silica dust inhalation has been shown to be fibrogenic and carcinogenic (Ding et al., 2002). Palygorskite, which is the most abundant clay mineral in the studied Saharan dust samples, is a non-regulated fibrous mineral reported to be carcinogenic and cytotoxic especially if fiber length is over $5 \mu \mathrm{m}$ (Rödelsperger et al., 1987), even if its content is less than $1 \%$ in mineral dust (Nolan et al., 1991). There are, however, conflicting results regarding the health effects 
of palygorskite. While a few studies have shown no toxicity to human embryonic intestinal cells or low toxicity to rat pleural mesothelial cells, palygorskite has been reported to induce hemolysis and cytotoxicity in mouse, rat, and rabbit macrophages, and bovine and human endothelial cells (see Larson et al., 2016, and references therein). Moreover, inhalation tests in rats have shown that large palygorskite fibers can induce bronchoalveolar hyperplasia, alveolar tumors, and mesothelioma (Donaldson and Borm, 2006). Iron presence either in the mineral structure or elsewhere (adsorbed colloidal particles) seems to enhance its carcinogenic potential (Nolan et al., 1991). This is highly relevant for the palygorskite fibers in Saharan dust deposited in the Iberian Peninsula and studied here, as well as for all the southern and eastern European areas where abundant palygorkite in desert dust has been detected. Importantly, in addition to their abundance in Saharan dust, as shown here, and their high crystallinity and fiber length over several $\mu \mathrm{m}$, they include structural iron and are associated with abundant poorly crystalline (colloidal) iron oxyhydroxides, typically attached to the clay mineral surfaces (Fig. S8). Note, however, that not all palygorskite fibers are equally hazardous. Poorly crystalline, small fibers (less than $1 \mu \mathrm{m}$ long) have been shown to be non-carcinogenic (Larson et al., 2016).

It could be argued that such an extreme event as the one studied here is rare and of a short time span, and that therefore its health impact should not be significant. Despite its short time span, intense dust events have been demonstrated to have a direct impact on patient hospitalization and death rates (Perez et al. 2008; Karanasiou et al., 2012). We thus want to stress that recurrent extreme events such as the one studied here and those taking place in the Mediterranean area in an almost yearly basis over the last years/decades, plus the continuous high dust loads in Northern Africa, can indeed have a significant short- and long-term health impact. Due to its relevance, we would like to conclude pointing out that the possible link between palygorskite fibers/iron-rich nanoparticles in desert dust and their long-term health effects should be the focus of further research.

\section{Conclusions}

We have studied with an unprecedented level of detail the physicochemical and compositional features (chemistry, mineralogy, size, and mixing state, as well as radiativerelevant properties) of Saharan dust particles wet deposited following an extreme winter red rain event that affected southern Spain during 21-23 February 2017.

This event was triggered by a northern African cyclone, a recurrent synoptic situation leading to major Saharan dust outbreaks, often resulting in red rains and affecting the western Mediterranean area especially in winter and early spring. Such an extreme aeolian event accounts for most of the total yearly dust depositional flux to the Iberian Peninsula. Likely, major and extreme events like the one studied here also represent the most significant pulse(s) for the global desert dust mass transported in the atmosphere. The data presented and discussed here are thus of high significance to constrain input values, including dust composition, mineralogy, mixing state, and size, as well as depositional fluxes, for more realistic dust and climatic models.

Abundant clay minerals (palygorskite, illite, smectite, mixed-layer clays, kaolinite, and chlorite), quartz, and carbonates (calcite and dolomite), with minor amounts of $\mathrm{K}$ and Na-feldspars, iron oxyhydroxides (goethite, hematite, and amorphous/poorly crystalline ferrihydrite), rutile, and ilmenite were identified.

The specific mineralogy of phyllosilicates and the abundance of carbonates, complemented by the analysis of satellite imagery and back/forward trajectories, helped us to identify two probable dust source areas: (i) southern/central Algeria, northern Mali, and northwestern Niger (PSA3), and (ii) northern Algeria, southern Tunisia, and northwestern Libya (PSA1). Activation of different source areas resulted in complex dust mixtures during extreme Saharan dust events such as the one studied here.

Detailed HAADF imaging and AEM analysis of individual clay mineral particles showed that they include abundant structural iron and are typically associated with nanogranular aggregates of iron oxyhydroxide nanoparticles. Clays plus iron-rich nanoparticles of amorphous and/or poorly crystalline ferrihydrite tend to form rims lining quartz, carbonates, and feldspars (internally mixed).

The internal mixing of calcite and clay minerals/iron-rich nanoparticles, and the absence of secondary calcium sulfates or nitrates, as well as the $\mathrm{Pb} / \mathrm{Al}, \mathrm{V} / \mathrm{Al}$, and $\mathrm{Ni} / \mathrm{Al}$ ratios very close to those of the average continental crust, demonstrate that mixing with anthropogenic aerosol did not occur and acid cloud processing of iron-containing clays and/or crystalline iron oxyhydroxides was not the main source for amorphous and/or poorly crystalline ferrihydrite nanoparticles. Our results show that the formation of such iron-rich nanoparticles, which are an important potential source of bioavailable iron, already occurred in the dust source areas. Furthermore, our leaching tests show that about half of the $\sim 20 \%$ soluble Fe comes from nanosized amorphous and/or poorly crystalline $\mathrm{Fe}$-oxyhydroxides (ferrihydrite), the rest corresponding to structural $\mathrm{Fe}$ released upon dissolution of clay minerals. The claim that pollutant acid gases are a prerequisite for iron bioavailability in Saharan dust, implying that current reduction in anthropogenic acid gas pollutants may have a negative feedback on atmospheric $\mathrm{CO}_{2}$ sequestration in ocean waters, should be reconsidered.

Iron-containing clays and iron oxyhydroxides internally mixed with silicate and carbonate particles are responsible for the strong absorption of solar (UV-Vis) and thermal (IR) radiation of the studied Saharan dust. These internally mixed phases form abundant aggregates with size $>10 \mu \mathrm{m}$. Such abundant coarse and even giant particles can have a signif- 
icant impact on the direct radiative forcing of Saharan dust, likely inducing a net warming effect. Despite the fact that the case studied here corresponds to a single event of just a few days spam, the intensity and recurrent nature of such extreme events affecting southern Europe and the Mediterranean area, as well as the predicted extreme weather situations under a global warming scenario, suggest that such a type of extreme Saharan dust events might have strong regional (i.e., northern Africa and south-western Europe) and even global climate implications.

The presence of abundant, inhalable, micrometer-sized palygorskite fibers associated with Fe-rich nanoparticles in Saharan dust might pose a significant health hazard. This health issue should be considered in order to take appropriate preventive measures when extreme Saharan dust plumes reach densely populated areas (e.g., stay-indoors warnings, use of respirator masks).

Our results validate the multianalytical approach used here, as it enables the analysis of the mineralogical and physicochemical properties of Saharan dust mineral aerosols with an unprecedented level of completeness and detail. Such a level of completeness and detail is necessary to disclose sources areas and processes affecting transported desert dust, and to fully evaluate and model the multiple effects and impacts of desert dust.

Ultimately, we show that extreme events involving red rains dwarf any other standard wet and dry Saharan dust deposition events taking place in the western Mediterranean. Their past, present, and future trends and impacts should thus be taken into account when modeling and evaluating the manifold effects of the desert dust cycle.

Data availability. Data used in this study are available from the authors upon request (carlosrn@ugr.es).

\section{The Supplement related to this article is available online at https://doi.org/10.5194/acp-18-10089-2018- supplement.}

Author contributions. CRN designed the study. CRN and KE performed the analyses with the help of FDL. FDL performed leaching tests and PHREEQC computer modeling. CRN prepared the paper with contributions from all co-authors.

Competing interests. The authors declare that they have no conflict of interest.

Acknowledgements. This work was supported by the Spanish Government (grant CGL2015-70642-R), the Junta de Andalucía (research group RNM-179), and the University of Granada (Unidad Científica de Excelencia UCE-PP2016-05). We thank the personnel of the Centro de Instrumentación Científica (CIC; University of Granada) for analytical assistance. We gratefully acknowledge the NOAA Air Resources Laboratory (ARL) for the provision of the HYSPLIT transport and dispersion model and READY website (http://www.ready.noaa.gov, last access: 2 June 2018) used here. We also thank NASA/NOAA for Suomi NPP VIIRS as well as Terra and Aqua MODIS satellite imagery gathered using the Land Atmosphere Near real-time Capability for EOS (LANCE) system and services from the Global Imagery Browse Services (GIBS), both operated by the NASA Earth Observing System Data and Information System (EOSDIS). Reanalysis of the synoptic-scale meteorological scenario was provided by the US Department of Commerce I National Oceanic and Atmospheric Administration Earth System Research Laboratory I Physical Sciences Division, NOAA, http://www.esrl.noaa.gov/psd/data/composites/hour/ (last access: 15 February 2018). We thank Javier Cuadros and an anonymous referee for their insightful comments and suggestions that helped to improve the overall quality of this contribution.

Edited by: Markus Ammann

Reviewed by: Javier Cuadros and one anonymous referee

\section{References}

Allen, R. J., Landuyt, W., and Rumbold, S. T.: An increase in aerosol burden and radiative effects in a warmer world, Nat. Clim. Change, 6, 269-274, 2016

Alpert, P. A., Kaufman, Y. J., Shay-El, Y., Tanre, D., Da Silva, A., Schubert, S., and Joseph, J. H.: Quantification of dust-forced heating of the lower troposphere, Nature, 395, 367-370, 1998.

Antoine, D. and Nobileau, D.: Recent increase of Saharan dust transport over the Mediterranean Sea, as revealed from ocean color satellite (SeaWiFS) observations, J. Geophys. Res.-Atmos., 111, D12214, https://doi.org/10.1029/2005JD006795, 2006.

Avila, A., Queralt-Mitjans, I., and Alarcón, M.: Mineralogical composition of African dust delivered by red rains over northeastern Spain, J. Geophys. Res., 102, 21977-21996, 1997.

Avila, A., Alarcon, M., and Queralt, I.: The chemical composition of dust transported in red rains - its contribution to the biogeochemical cycle of a holm oak forest in Catalonia (Spain), Atmos. Environ., 32, 179-191, 1998.

Avila, A., Alarcón, M., Castillo, S., Escudero, M., García Orellana, J., Masqué, P., and Querol, X.: Variation of soluble and insoluble calcium in red rains related to dust sources and transport patterns from North Africa to northeastern Spain, J. Geophys. Res., 112, D05210, https://doi.org/10.1029/2006JD007153, 2007.

Bain, D. C. and Tait, J. M.: Mineralogy and origin of dust fall on Skye, Clay Mineral, 12, 353-355, 1977.

Baker, A. R. and Jickells, T. D.: Mineral particle size as a control on aerosol iron solubility, Geophys. Res. Lett., 33, L17608, https://doi.org/10.1029/2006GL026557, 2006.

Balkanski, Y., Schulz, M., Claquin, T., and Guibert, S.: Reevaluation of Mineral aerosol radiative forcings suggests a better agreement with satellite and AERONET data, Atmos. Chem. Phys., 7, 81-95, https://doi.org/10.5194/acp-7-81-2007, 2007.

Betzer, P. R., Carder, K. L., Duce, R. A., Merrill, J. T., Tindale, N. W., Uematsu, M., Costello, D. K., Young, R. W., Feely, R. A., Breland, J. A., Bernstein, R. E., and Greco, A. M.: Long-range 
transport of giant mineral aerosol particles, Nature, 336, 568571, 1988.

Bou Karam, D., Flamant, C., Cuesta, J., Pelon, J., and Williams, E.: Dust emission and transport associated with a Saharan depression: February 2007 case, J. Geophys. Res.-Atmos., 115, D00H27, https://doi.org/10.1029/2009JD012390, 2010.

Buck, C. S., Landing, W. M., and Resing, J. A.: The solubility and deposition of aerosol Fe and other trace elements in the North Atlantic Ocean: observations from the A16N CLIVAR/CO 2 repeat hydrography section, Mar. Chem., 120, 57-70, 2010.

Cabello, M., Orza, J. A. G., Barrero, M. A., Gordo, E., Berasaluce, A., Cantón, L., Dueñas, C., Fernández, M. C., and Pérez, M.: Spatial and temporal variation of the impact of an extreme Saharan dust event, J. Geophys. Res.-Atmos., 117, D11204, https://doi.org/10.1029/2012JD017513, 2012.

Cakmur, R. V., Miller, R. L., Perlwitz, J., Geogdzhayev, I. V., Ginoux, P., Koch, D., Kohfeld, K. E., Tegen, I., and Zender, C. S.: Constraining the magnitude of the global dust cycle by monitoring the difference between a model and observations, J. Geophys. Res., 111, D06207, https://doi.org/10.1029/2005JD005791, 2006.

Caquineau, S., Gaudichet, A., Gomes, L., and Legrand, M.: Mineralogy of Saharan dust transported over northwestern tropical Atlantic Ocean in relation to source regions, J. Geophys. Res.Atmos., 107, D154251, https://doi.org/10.1029/2000JD000247, 2002.

Carlson, T. N. and Prospero, J. M.: The large-scale movement of Saharan air outbreaks over the Northern Equatorial Atlantic, J. Appl. Meteorol., 11, 283-297, 1972.

Carlson, T. N. and Benjamin, S. G.: Radiative heating rates for Saharan dust, J. Atmos. Sci., 37, 193-213, 1980.

Carretero, M. I., Gomes, C. S. F., and Tateo, F.: Clays and human health, in: Handbook of Clay Science, edited by: Berfgaya, F., Theng, B. K. G., Lagaly, G., Development in Clay Science, 1, 717-741, Elsevier, Amsterdam, 2006.

Castillo, S., Moreno, T., Querol, X., Alastuey, A., Cuevas, E., Herrmann, L., Mounkaila, M., and Gibbons, W.: Trace element variation in size-fractionated African desert dusts, J. Arid Environ., 72, 1034-1045, 2008.

Cliff, G., and Lorimer, G.: The quantitative analysis of thin specimens, J. Microscopy, 103, 203-207, 1975.

Comite, V., de Buergo, M. Á., Barca, D., Belfiore, C. M., Bonazza, A., La Russa, M. F., Pezzino, A., Randazzo, L., and Ruffolo, S. A.: Damage monitoring on carbonate stones: Field exposure tests contributing to pollution impact evaluation in two Italian sites, Construc. Build. Mater., 152, 907-922, 2017.

Conen, F., Morris, C. E., Leifeld, J., Yakutin, M. V., and Alewell, C.: Biological residues define the ice nucleation properties of soil dust, Atmos. Chem. Phys., 11, 9643-9648, https://doi.org/10.5194/acp-11-9643-2011, 2011.

Coudé-Gaussen, G.: Les poussières en suspension, John Libbey Eurotext, Paris, 1991.

Coude-Gaussen, G., Rognon, P., Bergametti, G., Gomes, L., Strauss, B., Gros, J. M., and Le Coustumer, M. N.: Saharan dust on Fuerteventura Island (Canaries): Chemical and mineralogical characteristics, air mass trajectories, and probable sources, J. Geophys. Res.-Atmos., 92, 9753-9771, 1987.

Cuadros, J., Díaz-Hernández, J. L., Sánchez-Navas, A., and GarciaCasco, A.: Role of clay minerals in the formation of atmospheric aggregates of Saharan dust, Atmos. Environ., 120, 160-172, 2015.

Cwiertny, D. M., Baltrusaitis, J., Hunter, G. J., Laskin, A., Scherer, M. M., and Grassian, V. H.: Characterization and acid-mobilization study of iron-containing mineral dust source materials, J. Geophys. Res.-Atmos., 113, D05202, https://doi.org/10.1029/2007JD009332, 2008.

D’Almeida, G. A.: A model for Saharan dust transport, J. Clim. Appl. Meteorol., 24, 903-916, 1986.

D'Almeida, G. A. and Schütz, L.: Number, mass and volume distributions of mineral aerosol and soils of the Sahara, J. Clim. Appl. Meteorol., 22, 233-243, 1983.

De Angelis, M. and Gaudichet, A.: Saharan dust deposition over Mont Blanc (French Alps) during the last 30 years, Tellus B, 43, 61-75, 1991.

Deboudt, K., Gloter, A., Mussi, A., and Flament, P.: Red-ox speciation and mixing state of iron in individual African dust particles, J. Geophys. Res.-Atmos., 117, D12307, https://doi.org/10.1029/2011JD017298, 2012.

Díaz-Hernández, J. L., and Párraga, J.: The nature and tropospheric formation of iberulites: pinkish mineral microspherulites, Geochim. Cosmochim. Acta, 72, 3883-3906, 2008.

Díaz-Hernández, J. L., and Sánchez-Navas, A.: Saharan dust outbreaks and iberulite episodes, J. Geophys. Res.-Atmos., 121, 7064-7078, 2016.

Di Biagio, C., Boucher, H., Caquineau, S., Chevaillier, S., Cuesta, J., and Formenti, P.: Variability of the infrared complex refractive index of African mineral dust: experimental estimation and implications for radiative transfer and satellite remote sensing, Atmos. Chem. Phys., 14, 11093-11116, https://doi.org/10.5194/acp-14-11093-2014, 2014.

Ding, M., Chen, F., Shi, X., Yucesoy, B., Mossman, B., and Vallyathan, V.: Diseases caused by silica: mechanisms of injury and disease development, Int. Immunopharmacol., 2, 173-182, 2002.

Donaldson, K. and Borm, P. (eds.): Particle toxicology. CRC Press, Boca Raton FL, 2006.

Eglinton, T. I., Eglinton, G., Dupont, L., Sholkovitz, E. R., Montluçon, D., and Reddy, C. M.: Composition, age, and provenance of organic matter in NW African dust over the Atlantic Ocean, Geochem. Geophys. Geosyst., 3, 1-27, 2002.

Elert, K., Pardo, E. S., and Rodriguez-Navarro, C.: Influence of organic matter on the reactivity of clay minerals in highly alkaline environments, Appl. Clay Sci., 111, 27-36, 2015.

Engelbrecht, J. P., Moosmüller, H., Pincock, S., Jayanty, R. K. M., Lersch, T., and Casuccio, G.: Technical note: Mineralogical, chemical, morphological, and optical interrelationships of mineral dust re-suspensions, Atmos. Chem. Phys., 16, 10809-10830, https://doi.org/10.5194/acp-16-10809-2016, 2016.

Engelstaedter, S., Tegen, I., and Washington, R.: North African dust emissions and transport, Earth Sci. Rev., 79, 73-100, 2006.

Escudero, M., Castillo, S., Querol, X., Avila, A., Alarcón, M., Viana, M. M., Alastuey, A., Cuevas, E., and Rodríguez, S.: Wet and dry African dust episodes over Eastern Spain, J. Geophys. Res., 110, D18S08, https://doi.org/10.1029/2004JD004731, 2005.

Evan, A. T., Flamant, C., Gaetani, M., and Guichard, F.: The past, present and future of African dust, Nature, 531, 493-495, 2016. 
Fan, S. M., Moxim, W. J., and Levy, H.: Aeolian input of bioavailable iron to the ocean, Geophys. Res. Lett., 33, L07602, https://doi.org/10.1029/2005GL024852, 2006.

Fernández, A. J., Sicard, M., Costa, M. J., Guerrero-Rascado, J. L., Gómez-Amo, J. L., Molero, F., Barragán, R., Bortoli, D., Bedoya-Velásquez, A. E., Utrillas, M. P., Salvador, P., GranadosMuñoz, M. J., Potes, M., Ortiz-Amezcua, P., Martínez-Lozano, J. A., Artíñano, B., Muñoz-Porcar, C., Salgado, R., Román, R., Rocadenbosch, F., Salgueiro, V., Benavent-Oltra, J. A., Rodríguez-Gómez, A., Alados-Arboledas, L., Comerón, A., and Pujadas, M.: February 2017 extreme Saharan dust outbreak in the Iberian Peninsula: from lidar-derived optical properties to evaluation of forecast models, Atmos. Chem. Phys. Discuss., https://doi.org/10.5194/acp-2018-370, in review, 2018.

Fiol, L. A., Fornós, J. J., Gelabert, B., and Guijarro, J. A.: Dust rains in mallorca (Western Mediterranean): Their occurrence and role in some recent geological processes, Catena, 63, 64-84, 2005.

Formenti, P., Schütz, L., Balkanski, Y., Desboeufs, K., Ebert, M., Kandler, K., Petzold, A., Scheuvens, D., Weinbruch, S., and Zhang, D.: Recent progress in understanding physical and chemical properties of African and Asian mineral dust, Atmos. Chem. Phys., 11, 8231-8256, https://doi.org/10.5194/acp11-8231-2011, 2011.

Formenti, P., Caquineau, S., Desboeufs, K., Klaver, A., Chevaillier, S., Journet, E., and Rajot, J. L.: Mapping the physicochemical properties of mineral dust in western Africa: mineralogical composition, Atmos. Chem. Phys., 14, 10663-10686, https://doi.org/10.5194/acp-14-10663-2014, 2014a.

Formenti, P., Caquineau, S., Chevaillier, S., Klaver, A., Desboeufs, K., Rajot, J. L., and Briois, V.: Dominance of goethite over hematite in iron oxides of mineral dust from Western Africa: Quantitative partitioning by X-ray absorption spectroscopy, J. Geophys. Res.-Atmos., 119, 12740-12754, 2014b.

Franzén, L.: A dustfall episode on the Swedish West Coast, October 1987, Geografiska Annaler A, Phys. Geograph., 71, 263-267, 1989.

Ganor, E., Stupp, A., and Alpert, P.: A method to determine the effect of mineral dust aerosols on air quality, Atmos. Environ., 43, 5463-5468, 2009.

Gasse, F., Stabell, B., Fourtanier, E., and van Iperen, Y.: Freshwater diatom influx in intertropical Atlantic: relationships with continental records from Africa, Quaternary Res., 32, 229-243, 1989.

Ghio, A. J., Churg, A., and Roggli, V. L.: Ferruginous bodies: implications in the mechanism of fiber and particle toxicity, Toxicol. Pathol., 32, 643-649, 2004.

Giannadaki, D., Pozzer, A., and Lelieveld, J.: Modeled global effects of airborne desert dust on air quality and premature mortality, Atmos. Chem. Phys., 14, 957-968, https://doi.org/10.5194/acp-14-957-2014, 2014.

Gieré, R. and Querol, X.: Solid particulate matter in the atmosphere, Elements, 6, 215-222, 2010

Gionis, V., Kacandes, G. H., Kastritis, I. D., and Chryssikos, G. D.: On the structure of palygorskite by mid-and near-infrared spectroscopy, Am. Mineral., 91, 1125-1133, 2006.

Glaccum, R. A. and Prospero, J. M.: Saharan aerosols over the tropical North Atlantic - Mineralogy, Mar. Geol., 37, 295-321, 1980.

Gonçalves, C., Alves, C., Nunes, T., Rocha, S., Cardoso, J., Cerqueira, M., Pio, C., Almeida, S. M., Hillamo, R., and Teinilä,
K.: Organic characterisation of PM 10 in Cape Verde under Saharan dust influxes, Atmos. Environ., 89, 425-432, 2014.

González-García, S., and Sánchez-Camazano, M.: Differentiation of kaolinite from chlorite by treatment with dimethyl sulphoxide, Clay Mineral., 7, 447-450, 1968.

Goudie, A. S.: Desert dust and human health disorders, Environ. Int., 63, 101-113, 2014.

Goudie, A. S. and Middleton, N. J.: Saharan dust storms: nature and consequences, Earth-Sci. Rev., 56, 179-204, 2001.

Griffin, D. W.: Atmospheric movement of microorganisms in clouds of desert dust and implications for human health, Clinic. Microbiol. Rev., 20, 459-477, 2007.

Guggenheim, S. and Van Groos, A. K.: Baseline studies of the clay minerals society source clays: thermal analysis, Clays Clay Mineral., 49, 433-443, 2001.

Guieu, C. and Thomas, A. J.: Saharan aerosols: From the soil to the ocean, in: The impact of desert dust across the Mediterranean, edited by: Guerzoni, S. and Chester, R., 207-216, Kluwer, Dordrecht, 1996.

Guieu, C., Loÿe-Pilot, M. D., Ridame, C., and Thomas, C.: Chemical characterization of the Saharan dust endmember: Some biogeochemical implications for the western Mediterranean Sea, J. Geophys. Res.-Atmos., 107, D154258, https://doi.org/10.1029/2001JD000582, 2002.

Guieu, C., Bonnet, S., Wagener, T., and Loÿe, M. D.; Biomass burning as a source of dissolved iron to the open ocean?, Geophys. Res. Lett., 32, L19608, https://doi.org/10.1029/2005GL022962, 2005 .

Ito, A. and Feng, Y.: Role of dust alkalinity in acid mobilization of iron, Atmos. Chem. Phys., 10, 9237-9250, https://doi.org/10.5194/acp-10-9237-2010, 2010.

Jaenicke, R. and Schütz, L.: Comprehensive study of physical and chemical properties of the surface aerosols in the Cape Verde Islands region, J. Geophys. Res.-Oceans, 83, 3585-3599, 1978.

Jambor, J. L. and Dutrizac, J. E.: Occurrence and constitution of natural and synthetic ferrihydrite, a widespread iron oxyhydroxide, Chem. Rev., 98, 2549-2586, 1998.

Jeong, G. Y. and Achterberg, E. P.: Chemistry and mineralogy of clay minerals in Asian and Saharan dusts and the implications for iron supply to the oceans, Atmos. Chem. Phys., 14, 1241512428, https://doi.org/10.5194/acp-14-12415-2014, 2014.

Jeong, G. Y., Park, M. Y., Kandler, K., Nousiainen, T., and Kemppinen, O.: Mineralogical properties and internal structures of individual fine particles of Saharan dust, Atmos. Chem. Phys., 16, 12397-12410, https://doi.org/10.5194/acp-16-12397-2016, 2016.

Jickells, T. D., An, Z. S., Andersen, K. K., Baker, A. R., Bergametti, G., Brooks, N., Cao, J. J., Boyd, P. W., Duce, R. A., Hunter, K. A., Kawahata, H., Kubilay, N., LaRoche, J., Liss, P. S., Mahowald, N., Prospero, J. M., Ridgwell, A. J., Tegen, I., and Torres, R.: Global iron connections between desert dust, ocean biogeochemistry, and climate, Science, 308, 67-71, 2005.

Johnston, J. H. and Cardile, C. M.: Iron substitution in montmorillonite, illite and glauconite by ${ }^{57} \mathrm{Fe}$ Mossbauer spectroscopy, Clays Clay Mineral., 35, 170-176, 1987.

Journet, E., Desboeufs, K. V., Caquineau, S., and Colin, J. L.: Mineralogy as a critical factor of dust iron solubility, Geophys. Res. Lett., 35, L07805, https://doi.org/10.1029/2007GL031589, 2008. 
Journet, E., Balkanski, Y., and Harrison, S. P.: A new data set of soil mineralogy for dust-cycle modeling, Atmos. Chem. Phys., 14, 3801-3816, https://doi.org/10.5194/acp-14-3801-2014, 2014.

Karanasiou, A., Moreno, N., Moreno, T., Viana, M., de Leeuw, F., and Querol, X.: Health effects from Sahara dust episodes in Europe: Lierature review and research gaps, Environ. Int., 47, 107$114,2012$.

Karickhoff, S. W. and Bailey, G. W.: Optical absorption spectra of clay minerals, Clays Clay Mineral., 21, 59-70, 1973.

Kemppinen, O., Nousiainen, T., and Jeong, G. Y.: Effects of dust particle internal structure on light scattering, Atmos. Chem. Phys., 15, 12011-12027, https://doi.org/10.5194/acp-15-120112015, 2015.

Kok, J. F.: A scaling theory for the size distribution of emitted dust aerosols suggests climate models underestimate the size of the global dust cycle, P. Natl. Acad. Sci., 108, 1016-1021, 2011.

Kok, J. F., Ridley, D. A., Zhou, Q., Miller, R. L., Zhao, C., Heald, C. L., Ward, D. S., Albani, S., and Haustein, K.: Smaller desert dust cooling effect estimated from analysis of dust size and abundance, Nat. Geosci., 10, 274-278, 2017.

Kok, J. F., Ward, D. S., Mahowald, N. M., and Evan, A. T.: Global and regional importance of the direct dust-climate feedback, Nat. Commun., 9, 241, https://doi.org/10.1038/s41467-017-02620-y, 2018.

Krueger, B. J., Grassian, V. H., Cowin, J. P., and Laskin, A.: Heterogeneous chemistry of individual mineral dust particles from different dust source regions: the importance of particle mineralogy, Atmos. Environ. 38, 6253-6261, 2004.

Lafon, S., Sokolik, I. N., Rajot, J. L., Caquineau, S., and Gaudichet, A.: Characterization of iron oxides in mineral dust aerosols: Implications for light absorption, J. Geophys. Res.-Atmos., 111, D21207, https://doi.org/10.1029/2005JD007016, 2006.

Larson, D., Powers, A., Ambrosi, J.-P., Tanji, M., Napolitano, A., Flores, E. G., Baumann, F., Pellegrini, L., Jennings, C. J., Buck, B. J., McLaurin, B. T., Merkler, D., Robinson, C., Morris, P., Dogan, M., Dogan, A. U., Pass, H. I., Pastorino, S., Carbone, M., and Yang, H.: Investigating palygorskite's role in the development of mesothelioma in southern Nevada: Insights into fiberinduced carcinogenicity, J. Toxicol. Environ. Health, 18, 213230, 2016.

Lázaro, F. J., Gutiérrez, L., Barrón, V., and Gelado, M. D.: The speciation of iron in desert dust collected in Gran Canaria (Canary Islands): Combined chemical, magnetic and optical analysis, Atmos. Environ., 42, 8987-8996, 2008.

Li, W., Xu, L., Liu, X., Zhang, J., Lin, Y., Yao, X., Gao, H., Zhang, D., Chen, J., Wang, W., Harrison, R. M., Zhang, X., Shao, L., Fu, P., Nenes, A., and Shi, Z.: Air pollution-aerosol interactions produce more bioavailable iron for ocean ecosystems, Sci. Adv., 3, e1601749, https://doi.org/10.1126/sciadv.1601749, 2017.

Lieke, K., Kandler, K., Scheuvens, D., Emmel, C., Von Glahn, C., Petzold, A., Weinzierl, B., Veira, A., Ebert, M., Weinbruch, S., and Schütz, L.: Particle chemical properties in the vertical column based on aircraft observations in the vicinity of Cape Verde Islands, Tellus B, 63, 497-511, 2011.

Loÿe-Pilot, M. D., Martin, J. M., and Morelli, J.: Influence of Saharan dust on the rain acidity and atmospheric input to the Mediterranean, Nature, 321, 427-428, 1986.
Lyamani, H., Olmo, F. J., and Alados-Arboledas, L.: Saharan dust outbreaks over southeastern Spain as detected by the sun photometer, Atmos. Environ., 39, 7226-7284, 2005.

Mahowald, N. M., Engelstaedter, S., Luo, C., Sealy, A., Artaxo, P., Benitez-Nelson, C., Bonnet, S., Chen, Y., Chuang, P. Y., Cohen, D. D., Dulac, F., Herut, B., Johansen, A. M., Kubilay, N., Losno, R., Maenhaut, W., Paytan, A., Prospero, J. M., Shank, L. M., and Siefert, R. L.: Atmospheric iron deposition: global distribution, variability, and human perturbations, Annu. Rev. Mar. Sci. 1, 245-278, 2009.

Mahowald, N., Albani, S., Kok, J. F., Engelstaeder, S., Scanza, R., Ward, D. S., and Flanner, M. G.: The size distribution of desert dust aerosols and its impact on the Earth system, Aeolian Res., 15, 53-71, 2014.

Maring, H., Savoie, D. L., Izaguirre, M. A., Custals, L., and Reid, J. S.: Mineral dust aerosol size distribution change during atmospheric transport, J. Geophys. Res.-Atmos., 108, D198592, https://doi.org/10.1029/2002JD002536, 2003.

Menéndez, I., Pérez-Chacón, E., Mangas, J., Tauler, E., Engelbrecht, J. P., Derbyshire, E., Cana, L., and Alonso, I.: Dust deposits on La Graciosa Island (Canary Islands, Spain): texture, mineralogy and a case study of recent dust plume transport, Catena, 117, 133-144, 2014.

Mestdagh, M. M., Vielvoye, L., and Herbillon, A. J.: Iron in kaolinite: II. The relationship between kaolinite crystallinity and iron content, Clay Mineral., 15, 1-13, 1980.

Middleton, H. J.: Desert dust hazards: A global review, Aeolian Res., 24, 53-63, 2017.

Molinaroli, E.: Mineralogical characterisation of Saharan dust with a view to its final destination in Mediterranean sediments, in: The impact of desert dust across the Mediterranean, edited by: Guerzoni, S. and Chester, R., 153-162, Kluwer, Dordrecht, 1996.

Moore, D. M. and Reynolds, R. C.: X-ray Diffraction and the Identification and Analysis of Clay Minerals, 378, Oxford University Press, Oxford, 1989.

Moulin, C., Lambert, C. E., Dulac, F., and Dayan, U.: Control of atmospheric export of dust from North Africa by the North Atlantic Oscillation, Nature, 387, 691-694, 1997.

Moulin, C. and Chiapello, I.: Impact of human- induced desertification on the intensification of Sahel dust emission and export over the last decade, Geophys. Res. Lett., 33, L18808, https://doi.org/10.1029/2006GL025923, 2006.

Mulitza, S., Heslop, D., Pittauerova, D., Fischer, H. W., Meyer, I., Stuut, J. -B., Zabel, M., Mollenhauer, G., Collins, J. A., Kuhnert, H., and Schulz, M.: Increase in African dust flux at the onset of commercial agriculture in the Sahel region, Nature, 466, 226228, 2010.

Nolan, R. P., Langer, A. M., and Herson, G. B.: Characterisation of palygorskite specimens from different geological locales for health hazard evaluation, British J. Indust. Mineral., 48, 463475, 1991.

Otto, S., de Reus, M., Trautmann, T., Thomas, A., Wendisch, M., and Borrmann, S.: Atmospheric radiative effects of an in situ measured Saharan dust plume and the role of large particles, Atmos. Chem. Phys., 7, 4887-4903, https://doi.org/10.5194/acp-74887-2007, 2007.

Overpeck, J., Rind, D., Lacis, A., and Healy, R.: Possible role of dust-induced regional warming in abrupt climate change during the last glacial period, Nature, 384, 447-449, 1996. 
Parkhurst, D. L. and Appelo, C. A. J.: Description of input and examples for Phreeqc version 3, A computer program for speciation, batch-reaction, one-dimensional transport, and inverse geochemical calculations, U.S. Geological Survey: Denver, available at: http://pubs.usgs.gov/tm/06/a43, 2013.

Paris, R., Desboeufs, K. V., Formenti, P., Nava, S., and Chou, C.: Chemical characterisation of iron in dust and biomass burning aerosols during AMMA-SOP0/DABEX: implication for iron solubility, Atmos. Chem. Phys., 10, 4273-4282, https://doi.org/10.5194/acp-10-4273-2010, 2010.

Paris, R. and Desboeufs, K. V.: Effect of atmospheric organic complexation on iron-bearing dust solubility, Atmos. Chem. Phys., 13, 4895-4905, https://doi.org/10.5194/acp-134895-2013, 2013.

Patey, M. D., Achterberg, E. P., Rijkenberg, M. J., and Pearce, R.: Aerosol time-series measurements over the tropical Northeast Atlantic Ocean: dust sources, elemental composition and mineralogy, Mar. Chem., 174, 103-119, 2015.

Perez, L., Tobias, A., Querol, X., Künzli, N., Pey, J., Alastuey, A., Viana, M., Valero, N., González-Cabré, M., and Sunyer, J.: Coarse particles from Saharan dust and daily mortality, Epidemiology, 19, 800-807, 2008

Pérez, C., Haustein, K., Janjic, Z., Jorba, O., Huneeus, N., Baldasano, J. M., Black, T., Basart, S., Nickovic, S., Miller, R. L., Perlwitz, J. P., Schulz, M., and Thomson, M.: Atmospheric dust modeling from meso to global scales with the online NMMB/BSC-Dust model - Part 1: Model description, annual simulations and evaluation, Atmos. Chem. Phys., 11, 1300113027, https://doi.org/10.5194/acp-11-13001-2011, 2011.

Pey, J., Querol, X., Alastuey, A., Forastiere, F., and Stafoggia, M.: African dust outbreaks over the Mediterranean Basin during 2001-2011: $\mathrm{PM}_{10}$ concentrations, phenomenology and trends, and its relation with synoptic and mesoscale meteorology, Atmos. Chem. Phys., 13, 1395-1410, https://doi.org/10.5194/acp13-1395-2013, 2013.

Pitty, A. F.: Particle size of the Saharan dust which fell in Britain in July 1968, Nature, 220, 364-365, 1968.

Plumlee, G. S., Morman, S. A., Ziegler, T. L.: The toxicological geochemistry of earth materials: an overview of processes and the interdisciplinary methods used to understand them, Rev. Mineral Geochem., 64, 5-57, 2006.

Poulton, S. W. and Raiswell, R.: Chemical and physical characteristics of iron oxides in riverine and glacial meltwater sediments, Chem. Geology, 218, 203-221, 2005.

Prodi, F. and Fea, G.: A case of transport and deposition of Saharan dust over the Italian peninsula and southern Europe, J. Geophys. Res.-Oceans, 84, 6951-6960, 1979.

Prospero, J. M.: Saharan dust transport over the North Atlantic Ocean and Mediterranean: an overview, edited by: Guerzoni, S. and Chester, R., The impact of desert dust across the Mediterranean, 133-151, Kluwer, Dordrecht, 1996.

Prospero, J. M. and Lamb, P. J.: African droughts and dust transport to the Caribbean: climate change implications, Science, 302 , 1024-1027, 2003.

Prospero, J. M., Ginoux, P., Torres, O., Nicholson, S. E., and Gill, T. E.: Environmental characterization of global sources of atmospheric soil dust identified with the Nimbus 7 Total Ozone Mapping Spectrometer (TOMS) absorbing aerosol product, Rev.
Geophys., 40, 1002, https://doi.org/10.1029/2000RG000095, 2002.

Raiswell, R.: Iron transport from the continents to the open ocean: The aging-rejuvenation cycle, Elements, 7, 101-106, 2011.

Raiswell, R. and Canfield, D. E.: The iron biogeochemical cycle: past and present, Geochem. Perspectiv., 1, 1-220, 2012.

Ramanathan, V., Crutzen, P. J., Kiehl, J. T., and Rosenfeld, D.: Aerosols, climate, and the hydrological cycle, Science, 294, 2119-2124, 2001.

Reid, J. S., Jonsson, H. H., Maring, H. B., Smirnov, A., Savoie, D. L., Cliff, S. S., Reid, E. A., Livingstone, J. M., Meier, M. M., Dubivik, O., and Tsay, S.-C.: Comparison of size and morphological measurements of coarse mode dust particles from Africa, J. Geophys. Res.-Atmos., 108, D198593, https://doi.org/10.1029/2002JD002485, 2003.

Reiff, J., Forbes, G. S., Spieksma, F. T. M., and Reynders, J. J.: African dust reaching northwestern Europe: A case study to verify trajectory calculations, J. Climat. Appl. Meteorol., 25, 15431567, 1986.

Ridley, D. A., Heald, C. L., and Prospero, J. M.: What controls the recent changes in African mineral dust aerosol across the Atlantic?, Atmos. Chem. Phys., 14, 5735-5747, https://doi.org/10.5194/acp-14-5735-2014, 2014.

Rietveld, H.: A profile refinement method for nuclear and magnetic structures, J. Appl. Cryst., 2, 65-71, 1969.

Rödelsperger, K., Brükel, B., Manke, J., Woitowitz, H.-J., and Pott, F.: Potential health risks from the use of fibrous mineral absorption granulates, British J. Indust. Med. 44, 337-343, 1987.

Rodriguez, S., Querol, X., Alastuey, A., Kallos, G., and Kakaliagou, O.: Saharan dust contributions to $\mathrm{PM}_{10}$ and TSP levels in Southern and Eastern Spain, Atmos. Environ., 35, 2433-2447, 2001.

Rodriguez-Navarro, C., Ruiz-Agudo, E., Luque, A., RodriguezNavarro, A. B., and Ortega-Huertas, M.: Thermal decomposition of calcite: Mechanisms of formation and textural evolution of CaO nanocrystals, Am. Mineral, 94, 578-593, 2009.

Rodriguez-Navarro, C., Kudlacz, K., and Ruiz-Agudo, E.: The mechanism of thermal decomposition of dolomite: New insights from 2D-XRD and TEM analyses, Am. Mineral, 97, 38-51, 2012.

Russell, J. D.: Infrared spectroscopy of ferrihydrite: evidence for the presence of structural hydroxyl groups, Clay Mineral, 14, 109114, 1979.

Ryder, C. L., Highwood, E. J., Lai, T. M., Sodemann, H., and Marsham, J. H.: Impact of atmospheric transport on the evolution of microphysical and optical properties of Saharan dust, Geophys. Res. Lett., 40, 2433-2438, 2013.

Sala, J. Q., Cantos, J. O., and Chiva, E. M.: Red dust rain within the Spanish Mediterranean area, Clim. Change, 32, 215-228, 1996.

Scheinost, A. C., Chavernas, A., Barrón, V., and Torrent, J.: Use and limitations of second-derivative diffuse reflectance spectroscopy in the visible to near-infrared range to identify and quantity fe oxide minerals in soils, Clays Clay Mineral, 46, 528-536, 1998.

Scheuvens, D., Schütz, L., Kandler, K., Ebert, M., and Weinbruch, S.: Bulk composition of northern African dust and its source sediments - A compilation, Earth-Sci. Rev., 116, 170-194, 2013.

Schroth, A. W., Crusius, J., Sholkovitz, E. R., and Bostick, B. C.: Iron solubility driven by speciation in dust sources to the ocean, Nat. Geosci., 2, 337-340, 2009. 
Schwertmann, U., Cambier, P., and Murad, E.: Properties of goethites of varying crystallinity, Clays Clay Mineral, 33, 369378, 1985.

Sherman, D. M. and Waite, T. D.: Electronic spectra of $\mathrm{Fe}^{3+}$ oxides and oxide hydroxides in the near IR to near UV, Am. Mineral, 70, 1262-1269, 1985.

Shi, Z. B., Krom, M. D., Bonneville, S., Baker, A. R., Jickells, T. D., and Benning, L. G.: Formation of iron nanoparticles and increase in iron reactivity in mineral dust during simulated cloud processing, Environ. Sci. Technol., 43, 6592-6596, 2009.

Shi, Z. B., Woodhouse, M. T., Carslaw, K. S., Krom, M. D., Mann, G. W., Baker, A. R., Savov, I., Fones, G. R., Brooks, B., Drake, N., Jickells, T. D., and Benning, L. G.: Minor effect of physical size sorting on iron solubility of transported mineral dust, Atmos. Chem. Phys., 11, 8459-8469, https://doi.org/10.5194/acp11-8459-2011, 2011a.

Shi, Z. B., Krom, M. D., Bonneville, S., Baker, A. R., Bristow, C., Drake, N., Mann, G., Carslaw, K., McQuaid, J. B., Jickells, T., and Benning, L. G.: Influence of chemical weathering and aging of iron oxides on the potential iron solubility of Saharan dust during simulated atmospheric processing, Global Biogeochem. Cy., 25, GB2010, https://doi.org/10.1029/2010GB003837, 2011 b.

Shi, Z. B., Krom, M. D., Jickells, T. D., Bonneville, S., Carslaw, K. S., Mihalopoulos, N., Baker, A. R., and Benning, L. G.: Impacts on iron solubility in the mineral dust by processes in the source region and the atmosphere: A review, Aeolian Res., 5, 21-42, 2012.

Sing, K. S., Everett, D. H., Haul, P. A. W., Moscou, L., Pierotti, R. A., Rouquerol, J., and Siemieniewska, T.: Reporting physisorption data for gas/solid systems with special reference to the determination of surface area and porosity (Recommendations 1984), Pure Appl. Chem., 57, 603-619, 1985.

Singer, A. and Galan, E. (Eds.): Palygorskite-sepiolite: occurrences, genesis and uses, Elsevier, Amsterdam, 1984.

Skonieczny, C., Bory, A., Bout-Roumazeilles, V., Abouchami, W., Galer, S. J. G., Crosta, X., Stuut, J.-B., Meyer, I., Podvin, T., Chatenet, B., Diallo, A., and Ndiaye, T.: The 7-13 March 2006 major Saharan outbreak: Multiproxy characterization of mineral dust deposited on the West African Margin, J. Geophys. Res.Atmos., 116, D18210, https://doi.org/10.1029/2011JD016173, 2011.

Sholkovitz, E. R., Sedwick, P. N., and Church, T. M.: Influence of anthropogenic combustion emissions on the deposition of soluble aerosol iron to the ocean: Empirical estimates for island sites in the North Atlantic, Geochim. Cosmochim. Acta, 73, 3981-4003, 2009.

Sholkovitz, E. R., Sedwick, P. N., Church, T. M., Baker, A. R., and Powell, C. F.: Fractional solubility of aerosol iron: Synthesis of a global-scale data set, Geochim. Cosmochim. Acta, 89, 173-189, 2012.

Sokolik, I. N. and Toon, O. B.: Incorporation of mineralogical composition into models of the radiative properties of mineral aerosol from UV to IR wavelengths, J. Geophys. Res.-Atmos., 104, 9423-9444, 1999.

Stein, A. F., Draxler, R. R., Rolph, G. D., Stunder, B. J., Cohen, M. D., and Ngan, F.: NOAA's HYSPLIT Atmospheric Transport and Dispersion Modeling System, B. Am. Meteor. Soc., 96, 20592077, 2015.
Stumm, W. and Morgan, J. J.: Aquatic chemistry: chemical equilibria and rates in natural waters, Wiley, New York, 1996.

Taylor, S. R. and McLennan, S. M.: The continental crust: Its composition and evolution, Blackwell Scientific, New York, 1985.

Tegen, I.: Modeling the mineral dust aerosol cycle in the climate system, Quatern. Sci. Rev., 22, 1821-1834, 2003.

Tegen, I. and Lacis, A. A.: Modeling of particle size distribution and its influence on the radiative properties of mineral dust aerosol, J. Geophys. Res.-Atmos., 101, 19237-19244, 1996.

Titos, G., Ealo, M., Pandolfi, M., Pérez, N., Sola, Y., Sicard, M., Comerón, A., Querol, X., and Alastuey, A.: Spatiotemporal evolution of a severe winter dust event in the western Mediterranean: Aerosol optical and physical properties, J. Geophys. Res.-Atmos., 122, 4052-4069, 2017.

Usher, C. R., Michel, A. E., and Grassian, V. H.: Reactions on mineral dust, Chem. Rev. 103, 4883-4939, 2003.

Vincent, J., Laurent, B., Losno, R., Bon Nguyen, E., Roullet, P., Sauvage, S., Chevaillier, S., Coddeville, P., Ouboulmane, N., di Sarra, A. G., Tovar-Sánchez, A., Sferlazzo, D., Massanet, A., Triquet, S., Morales Baquero, R., Fornier, M., Coursier, C., Desboeufs, K., Dulac, F., and Bergametti, G.: Variability of mineral dust deposition in the western Mediterranean basin and south-east of France, Atmos. Chem. Phys., 16, 8749-8766, https://doi.org/10.5194/acp-16-8749-2016, 2016.

Vrede, T. and Tranvik, L. J.: Iron constraints on planktonic primary production in oligotrophic lakes, Ecosystems, 9, 1094 1105, 2006.

Wagner, R., Ajtai, T., Kandler, K., Lieke, K., Linke, C., Müller, T., Schnaiter, M., and Vragel, M.: Complex refractive indices of Saharan dust samples at visible and near UV wavelengths: a laboratory study, Atmos. Chem. Phys., 12, 2491-2512, https://doi.org/10.5194/acp-12-2491-2012, 2012.

Wanas, H. A.: Pseudospherulitic fibrous calcite from the Quaternary shallow lacustrine carbonates of the Farafra Oasis, Western Desert, Egypt: A primary precipitate with possible bacterial influence, J. African Earth Sci., 65, 105-114, 2012.

Weaver, C. E. and Pollard, L. D.: The chemistry of clay minerals, Elsevier, New York, 1973.

Weinzierl, B., Petzold, A., Esselborn, M., Wirth, M., Rasp, K., Kandler, K., Schütz, L., Koepke, P., and Fiebig, M.: Airborne measurements of dust layer properties, particle size distribution and mixing state of Saharan dust during SAMUM 2006, Tellus B, 61, 96-117, 2009.

White, J. R., Cerveny, R. S., and Balling Jr, R. C.: Seasonality in European red dust/"blood" rain events, B. Am. Meteorol. Soc., 93, 471-476, 2012.

Zhang, X. L., Wu, G. J., Zhang, C. L., Xu, T. L., and Zhou, Q. Q.: What is the real role of iron oxides in the optical properties of dust aerosols?, Atmos. Chem. Phys., 15, 12159-12177, https://doi.org/10.5194/acp-15-12159-2015, 2015.

Zhang, X., Zhao, L., Tong, D. Q., Wu, G., Dan, M., and Teng, B.: A systematic review of global desert dust and associated human health effects, Atmosphere, 7, 158, https://doi.org/10.3390/atmos7120158, 2016.

Zhu, X. R., Prospero, J. M., and Millero, F. J.: Diel variability of soluble Fe (II) and soluble total Fe in North African dust in the trade winds at Barbados, J. Geophys. Res.-Atmos., 102, 2129721305, 1997. 